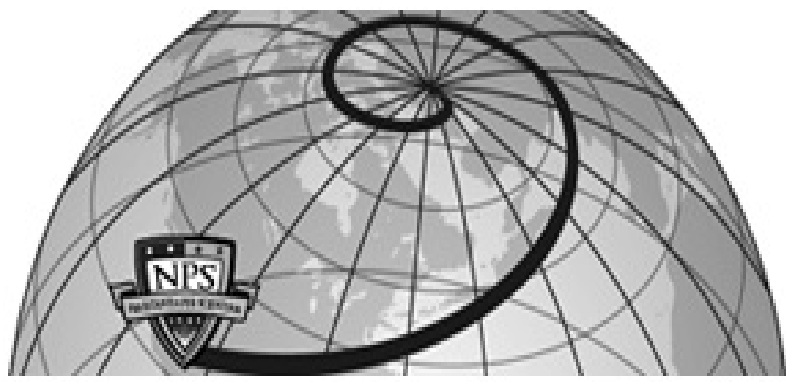

Calhoun: The NPS Institutional Archive DSpace Repository

\title{
Building collaborative capacity for homeland security
}

Hocevar, Susan Page; Jansen, Erik; Thomas, Gail Fann Monterey, California. Naval Postgraduate School

https://hdl.handle.net/10945/571

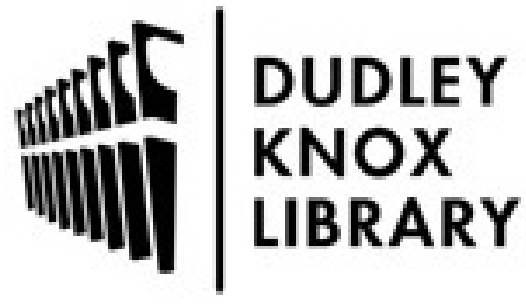

http://www.nps.edu/library
Calhoun is the Naval Postgraduate School's public access digital repository for research materials and institutional publications created by the NPS community. Calhoun is named for Professor of Mathematics Guy K. Calhoun, NPS's first appointed -- and published -- scholarly author.

Dudley Knox Library / Naval Postgraduate School 411 Dyer Road / 1 University Circle Monterey, California USA 93943 

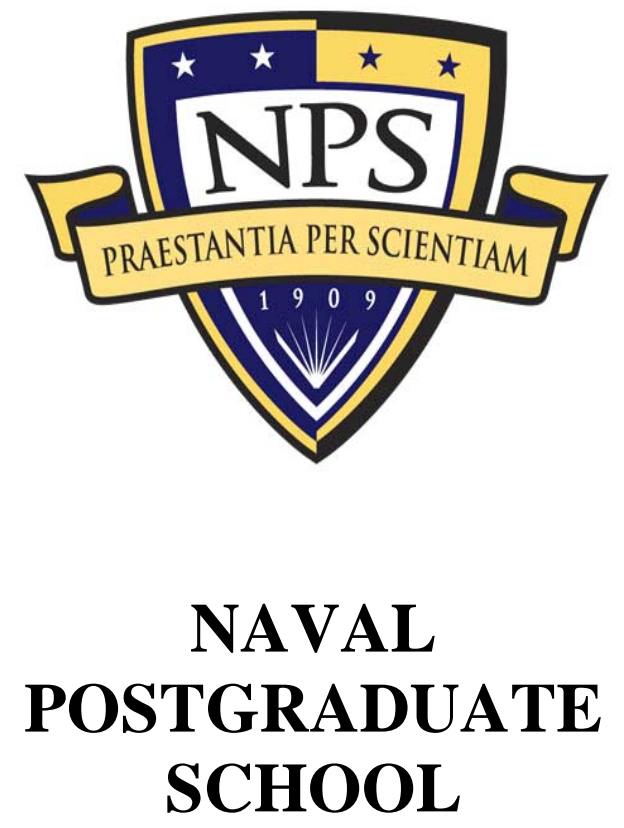

MONTEREY, CALIFORNIA

\section{Building Collaborative Capacity for Homeland Security}

by

Susan Hocevar, $\mathrm{PhD}$

Erik Jansen, $\mathrm{PhD}$

Gail Fann Thomas, EdD

01 November 2004

Approved for public release; distribution is unlimited

Prepared for: Office of Domestic Preparedness

801 7th NW, Washington, D.C. 93907 


\title{
Naval Postgraduate School \\ Monterey, California 93943-5000
}

\author{
RDML Patrick W. Dunne, USN Richard Elster \\ President Provost
}

This report was funded by the Office of Domestic Preparedness

$8017^{\text {th }}$ St., NW, Washington, D.C.

Reproduction of all or part of this report is authorized.

This report was prepared by:

Susan Hocevar

Associate Professor

Graduate School of Business and

Public Policy

Gail Fann Thomas

Associate Professor

Graduate School of Business and

Public Policy

Reviewed by:

Douglas A. Brook

Dean

Graduate School of Business and Public Policy
Erik Jansen

Senior Lecturer

Information Sciences

Released by:

Leonard A. Ferrari, Ph.D.

Associate Provost and

Dean of Research 
Public reporting burden for this collection of information is estimated to average 1 hour per response, including the time for reviewing instruction, searching existing data sources, gathering and maintaining the data needed, and completing and reviewing the collection of information. Send comments regarding this burden estimate or any other aspect of this collection of information, including suggestions for reducing this burden, to Washington headquarters Services, Directorate for Information Operations and Reports, 1215 Jefferson Davis Highway, Suite 1204, Arlington, VA 22202-4302, and to the Office of Management and Budget, Paperwork Reduction Project (0704-0188) Washington DC 20503.

\begin{tabular}{|c|c|c|c|}
\hline 1. AGENCY USE ONLY (Leave blank) & $\begin{array}{l}\text { 2. REPORT DATE } \\
1 \text { November } 2004\end{array}$ & \multicolumn{2}{|c|}{$\begin{array}{l}\text { 3. REPORT TYPE AND DATES COVERED } \\
\text { Technical Report Jan } 04 \text {-Nov } 04\end{array}$} \\
\hline \multicolumn{3}{|c|}{$\begin{array}{l}\text { 4. TITLE AND SUBTITLE: } \\
\text { Building Collaborative Capacity for Homeland Security }\end{array}$} & \multirow[t]{2}{*}{$\begin{array}{l}\text { 5. FUNDING NUMBERS } \\
\text { 2002-6T-R-057 }\end{array}$} \\
\hline \multicolumn{3}{|c|}{ 6. AUTHOR(S) Susan Hocevar, Erik Jansen and Gail Fann Thomas } & \\
\hline \multicolumn{3}{|c|}{$\begin{array}{l}\text { 7. PERFORMING ORGANIZATION NAME(S) AND ADDRESS(ES) } \\
\text { Naval Postgraduate School } \\
\text { Monterey, CA 93943-5000 }\end{array}$} & $\begin{array}{l}\text { 8. PERFORMING } \\
\text { ORGANIZATION REPORT } \\
\text { NUMBER NPS-GSBPP-04-008 }\end{array}$ \\
\hline \multicolumn{3}{|c|}{$\begin{array}{l}\text { 9. SPONSORING /MONITORING AGENCY NAME(S) AND ADDRESS(ES) } \\
\text { Office of Domestic Preparedness } \\
8017^{\text {th }} \text { St., N.W., Washington D.C. }\end{array}$} & $\begin{array}{l}\text { 10. SPONSORING/MONITORING } \\
\text { AGENCY REPORT NUMBER }\end{array}$ \\
\hline
\end{tabular}

11. SUPPLEMENTARY NOTES The views expressed in this thesis are those of the author and do not reflect the official policy or position of the Department of Defense or the U.S. Government.

\begin{tabular}{l|l} 
12a. DISTRIBUTION / AVAILABILITY STATEMENT & 12b. DISTRIBUTION CODE
\end{tabular}

Approved for public release; distribution unlimited

13. ABSTRACT (maximum 200 words)

The purpose of this project was to build a foundation of relevant knowledge about interorganizational collaboration that would assist local, state and federal officials in their management of activities related to Homeland Security. Academics and practitioners stress the criticality of coordinating the efforts of federal, state, local and private sectors. Some barriers to interorganizational collaboration include: missions that are at odds with one another, unclear roles and responsibilities lack of accountability. Managers of homeland security will need to find ways to overcome these barriers and work together more effectively. This project is meant to discover the factors that contribute to and inhibit collaboration. The first phase of the research focused on the development of a conceptual model of interagency collaboration. Phase II was an action-based workshop to gather data from a group of 30 senior homeland security managers. Nine major topics that were central to interagency collaboration were identified in Phase III. We anticipate that these deliverables will be used for future workshops, seminars, short class modules or longer graduate-level courses. Future plans include developing a diagnostic survey. This diagnostic tool could be used by HLS organizations to evaluate their current collaborative capacity and, based on this assessment, establish action plans to improve their collaborative capacity.

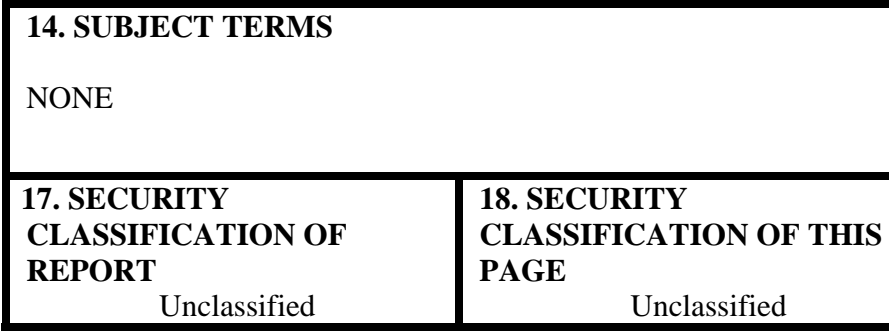

NSN 7540-01-280-5500

19. SECURITY
CLASSIFICATION OF
ABSTRACT

Unclassified
15. NUMBER OF

PAGES

173

16. PRICE CODE

20. LIMITATION

OF ABSTRACT

SAR

Standard Form 298 (Rev. 2-89)

Prescribed by ANSI Std. 239-18 


\title{
Developing Collaborative Capacity for Homeland Security Executive Summary
}

\author{
Dr. Susan Hocevar, Graduate School of Business and Public Policy \\ Dr. Erik Jansen, Department of Information Sciences \\ Dr. Gail Fann Thomas, Graduate School of Business and Public Policy
}

\section{Purpose}

The aim of this project was to build a foundation of relevant knowledge about interorganizational collaboration that would assist local, state and federal officials in their management of activities related to Homeland Security.

Homeland security includes several phases including detection, prevention, response, recovery and incident management. Coordination and collaboration are critical in all these phases. While agencies seem to be capable of working together in response to a crises, they are less able to work together effectively in the earlier stages of planning and prevention. It is in these early stages that we have focused our research.

\section{Importance of Building Collaborative Capacity}

Academics and practitioners stress the criticality of coordinating the efforts of federal, state, local and private sectors. It is clear that current efforts must be improved significantly to enhance our national security. Documented barriers to interorganizational collaboration include:

- missions that are at odds with one another,

- unclear roles and responsibilities,

- agencies' need to protect their jurisdiction and control their resources

- incompatible procedures, processes, data and information systems,

- disparate organizational cultures,

- lack of accountability,

- mistrust and skepticism, and

- lack of knowledge of others' capabilities.

Managers of homeland security will need to find ways to overcome these barriers and work together more effectively. This project is meant to discover the factors that contribute to successful collaboration and the factors that inhibit collaboration. 


\section{Overview of Project}

Phase I The first phase of our research focused on the development of a conceptual model of interagency collaboration. Drawing on relevant literature and other experts in the field, we deductively developed a framework to map the conditions for effective interagency collaboration.

Phase II Following that, we designed an action-based workshop to gather data from a group of 30 senior homeland security managers. These data were used to develop, inductively a systems-based model describing both successful and unsuccessful interagency collaborative efforts.

Phase III Using the literature on interagency collaboration and the results from the workshop, we identified 9 major topics that were central to interagency collaboration. Slides were developed for each of these topical areas. The topical areas include:

- Building Collaborative Capacity: Context and Problems

- Absorptive Capacity

- Organizational Interdependence

- Coordination and Collaboration

- Transorganizational Development

- Boundary Spanners

- Culture and Knowledge Management

- Social Networks

- Systems Model

Finally, our project includes a bibliography with key references related to interagency collaboration.

\section{Potential Uses for Deliverables}

We anticipate that these deliverables will be used for future workshops, seminars, short class modules, or longer graduate-level courses. Individual topical modules could be presented independently or embedded in related courses. These materials could be used in the field with practicing homeland security managers or in an academic setting. Students completing theses related to homeland security could also make use of these materials.

\section{Future Plans}

Our goal is to ultimately use these data, along with the conceptual material from the literature (illustrated in the "Topical Material” section of this report) to develop a diagnostic survey. This diagnostic tool could be used by HLS organizations to evaluate their current collaborative capacity and, based on this assessment, establish action plans to improve their collaborative capacity. 


\section{DEVELOPING COLLABORATIVE CAPACITY \\ FOR HOMELAND SECURITY}

TABLE OF CONTENTS

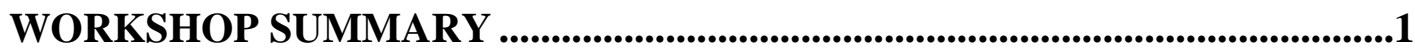

WORKSHOP DATA ANALYSIS .................................................................13

BIBLIOGRAPHY - ORGANIZATION \& COLLABORATION ....................18

BIBLIOGRAPHY - INTERORGANIZATIONAL_............................................22

POWERPOINT FILES

SYSTEMS MODEL ON WORKSHOP RESULTS ..........................................29

TOPICAL MODULE - CONTEXT \& PROBLEM ..........................................57

TOPICAL MODULE - ABSORPTIVE CAPACITY .........................................74

TOPICAL MODULE - ORGANIZATIONAL INTERDEPENDENCE ..........96

TOPICAL MODULE - COORDINATION \& COLLABORATION .............105

TOPICAL MODULE - TRANSORGANIZATIONAL DEVELOPMENT ....125

TOPICAL MODULE - BOUNDARY SPANNERS .......................................140

TOPICAL MODULE - CULTURE \& KNOWLEDGE MANAGEMENT ....148

TOPICAL MODULE - SOCIAL NETWORKS .......................................159

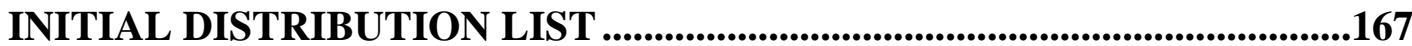




\section{Developing Collaborative Capacity for Homeland Security Part I: Summary of Workshop on Collaborative Capacity 1/6/04 Susan Hocevar \\ Erik Jansen \\ Gail Thomas}

This document provides a brief summary of two main elements of our work on collaborative capacity for Homeland Security. First described is a workshop provided to Dr. Chris Bellavita's classes on 1/6/04. The second part of this document presents the results of data gathered during the conduct of these workshops. The analyses of these data, along with the topical materials provided in this report, form the foundation for a diagnostic survey for assessing Collaborative Capacity which is the second phase of our project effort.

\section{Workshop Background}

This workshop was prepared and delivered by the three NPS faculty named above and Stu Winby, an outside expert in the area of strategic analysis, organizational change and coordination. The purpose of the workshop was to increase awareness and understanding of collaboration for better coordination and to set the stage for future work in designing organizations with enhanced collaborative capabilities. Specific objectives included:

1. Provide information and demonstrate methods for analyzing collaborative capacity and taking steps to improve that capability.

2. Demonstrate collaboration through the pedagogy of the workshop.

3. Gather preliminary data from class participants about factors that facilitate or constrain interagency collaboration in the context of homeland security planning.

4. Use the data above, inductively, to begin to develop a model for collaborative capacity.

Several assumptions framed the design of this workshop:

1. Interagency collaboration is critical to the success of homeland security.

2. There is some evidence of successful interagency collaboration when faced with responding to a critical event. There is less evidence of such collaboration in preparation, planning, and prevention. Thus, the focus of our work is on the latter.

3. Collaboration occurs within organizations. However, in the context of homeland security, our focus is on developing capability for collaboration across organizations.

4. Current systems for collaboration in the context of Homeland Security are underdesigned. The recommendations of the recently published report of the 9/11 Commission offer recommendations to provide/refine the design of organizational systems at the highest levels. This workshop provides techniques for planning and coordination "by design" rather than "by default" at the local/operational level. 
The workshop was presented to both sections of HLS students at NPS. Powerpoint slides used in the conduct of the workshop are attached.

\section{Workshop Conduct Part 1 - Identifying Facilitators and Barriers to Collaboration in HLS}

The workshop began with brief introductions of the workshop facilitators, followed by a presentation of the agenda and discussion of the focus.

The centerpiece of the workshop was an exercise in which class participants were asked the following: "Think back to a specific HLS or other effort that included at least two other agencies or organizations that you consider to have been a successful collaboration in the preparation phase (not response phase) of HLS. Identify three key factors that contributed to this success."

Participants where asked to rank order the "success factors" and record each on a separate green post-it note. Each post-it note was to include the following information:

Participant Name Factor Ranking

1a. Briefly describe the factor that contributed to coordination/collaboration success (1-2 sentences).

1b. Key word or phrase that captures this factor:

1c. Names of primary organizations involved in collaboration:

At the end of this activity, each participant had 3 green post-it notes identifying their rank-ordered success characteristics for a specific collaborative experience related to HLS.

The next phase of the exercise was to ask the class participants to think about an interagency collaboration related to homeland security that was NOT successful. They were asked to identify and rank order three barriers to collaboration that inhibited success in this situation. These were recorded following a format similar to that above only using pink post-it notes. 
Workshop Conduct Part 2 - Consolidating Themes from Individual Participants

The above activity was conducted individually. Upon its completion, the participants were asked to share with the group as a whole the thematic words/phrases they had identified as facilitators of success. These were recorded on chart paper at the front of the class. If there were questions as to the meaning of a word or phrase, the class member elaborated and clarified. Participants did not repeat themes that had already been identified, but discussion continued until all key terms/phrases had been captured. A similar process was used to identify the list of barriers to collaboration that represented the input of all participants.

This activity generated a lengthy list of both facilitators and barriers to collaboration. It was anticipated that this discussion of both positive and negative factors would lead participants to clarify/refine their evaluation of the key contributors to the specific situations they had identified. We also wanted to determine which factors were most frequently identified by the group as a whole. To accomplish this we asked participants to attach their post-it notes to the chart paper lists that were mounted on the walls around the room. During a break, the most frequent factors were identified for use in the next activity - Force Field Analysis.

\section{Workshop Conduct Part 3 - Force Field Analysis}

There was a notable variety in the number of barriers identified. The implication is that a single approach to improving collaboration is not likely to be successful. It is necessary to specifically assess a given inter-agency situation to identify both the facilitating and impeding factors and use this analysis to construct an action plan for improving collaboration. This was illustrated with some of the data from the previous group activity.

Attachment 1 presents a sample of the most frequently identified facilitators and barriers to collaboration in the experience of the HLS professionals in this class. Using the technique of Force Field Analysis, these factors are categorized as either "driving” forces for collaboration capability or "restraining" forces. This analysis technique was explained and illustrated using only a small subset of the data generated in Parts 1-2 of the exercise. A blank template for Force Field Analysis is included as part of the Tool Kit at the end of this document.

The Force Field Analysis technique is just a first step toward action planning for improved collaboration. Once the driving and restraining forces are identified, they form the foundation for developing strategies to build coordination capability (the desired end state) as indicated in Attachment 1. 


\section{Workshop Conduct Part 4 - Strategies to Build Collaboration Capability}

Following the explanation and illustration of the Force Field Analysis technique, the facilitators led a discussion among class participants to begin to identify strategies that would address the factors in the previous analysis and move toward the desired end state of improved collaborative capacity.

This activity uses the data from the Force Field Analysis to identify current of potential coordination risks or problems. Once these are identified, the desired end state situation should be defined. Finally, action steps are designed to address the identified risk/problem to accomplish the desired end state.

Attachment 2 presents an illustration that emerged from the workshop as it was conducted on 1/6/04. The specific "risk/problems" that were identified were: territorial orientation and lack or insufficient felt need for collaboration. Specific examples of "evidence" were elicited and added to the problem definition as clarification. The second step was to have the group define the desired end state that would reflect a successful solution to these risks/problems. These are illustrated in the second column of Attachment 2. Finally, the participants described specific action steps that could be taken to accomplish the desired end state. Because of time limitations, these were not intended to be comprehensive or exhaustive, but illustrative of the technique. Examples of action steps are presented in column 3 of Attachment 2. A blank version of this template is included in the "Tool Kit" at the end of this document.

\section{Workshop Tool Kit}

The workshop described in this document included an electronic "Tool Kit" that was shared with all of the participants. This Tool Kit included a number of items that are now in elaborated form in the "Topical Materials" section of this project deliverable.

Provided in the "Took Kit" section of this part of the document are the templates for the analysis techniques that were presented and used during the workshop as well as materials for one additional analytic technique that was referred to but not used due to time limitations of the workshop. This is the RACI analysis.

RACI is an acronym for four aspects of role clarification: Responsible, Approves, Consulted, Informed. The value of the RACI analysis technique is evident by the data presented in Attachment 2 that identifies a significant problem for collaboration in statements like: “That's NOT my responsibility” or “That IS MY responsibility.” Such role conflict issues can be a significant barrier to collaboration. An explicit discussion of RACI can add value to any decision-making problem-solving situation; but it is particularly important in an inter-agency or network organization context when roles and authorities are ill-defined as the issues span organizational boundaries. 
Attachments 3-4 present the RACI technique. Attachment 3 shows a RACI Role/Responsibility Decision Matrix and defines the 4 role categories. Attachment 4 presents a sample illustrating how the RACI technique might be used regarding decisions about home remodeling. While you might disagree with the roles attributed to each stakeholder in this case, the important aspect of this technique is that all key stakeholders are involved and must negotiate and agree to the determinations made. It is in this process, as much as in the resulting chart, that benefits are gained.

\section{Workshop Conclusions}

The concluding slides in the PowerPoint presentation used for this workshop outline key questions that need to be addressed as we work to continue to improve collaborative capability for Homeland Security. 
FORCE FIELD ANALYSIS

\section{Building Collaboration Capability}

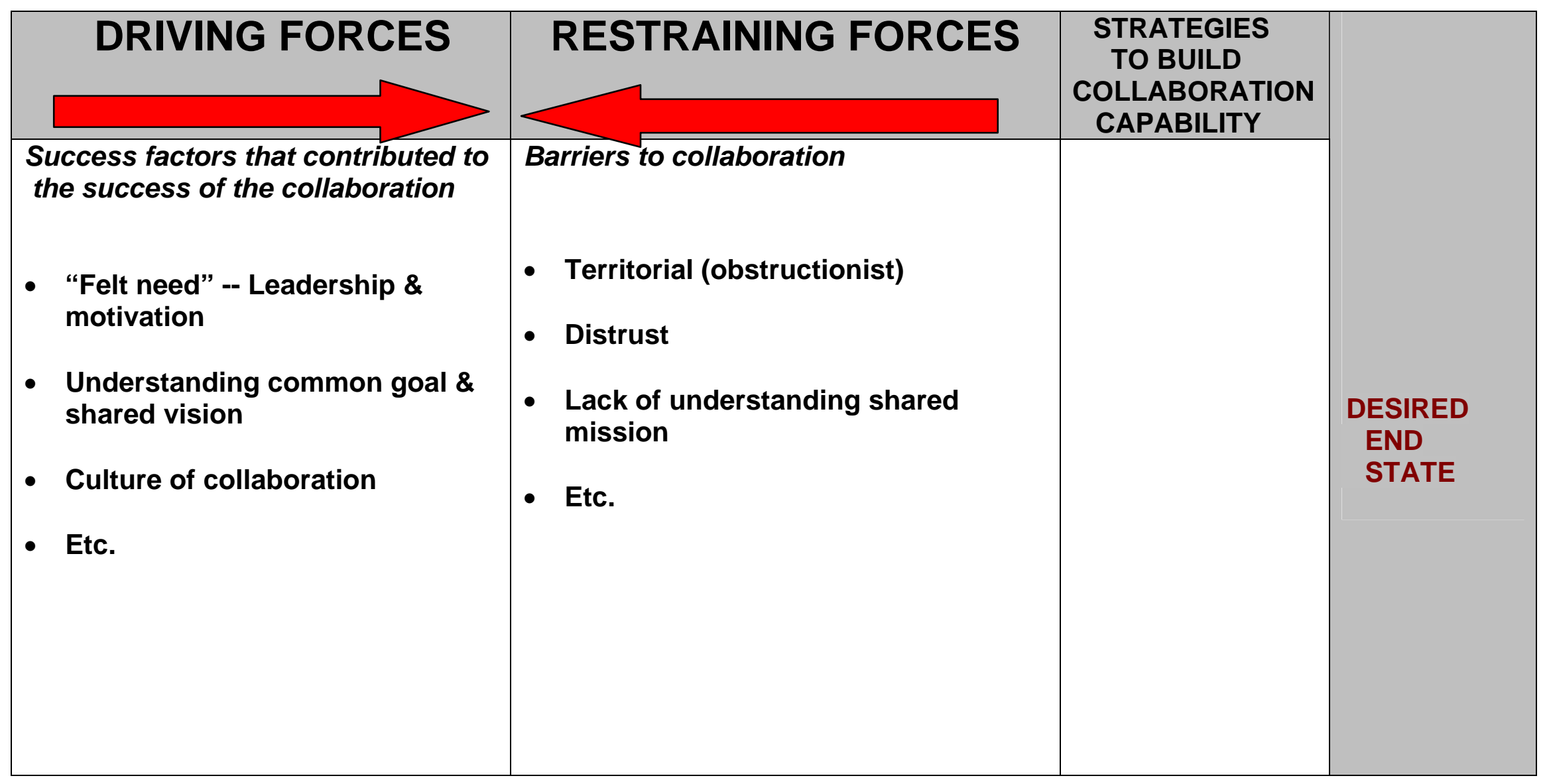


Attachment 2

\section{HOMELAND SECURITY}

\section{Strategies to Build Collaboration Capability - Preparation Phase}

Instructions: Use the data from the force field analysis to identify a perceived and potential coordination risk or problem. Work through the template to identify the steps needed to build the capability and prevent the problem from occurring.

\begin{tabular}{|c|c|c|}
\hline $\begin{array}{l}\text { Define a perceived coordination } \\
\text { risk / problem }\end{array}$ & $\begin{array}{l}\text { Define the desired situation / end state } \\
\text { solution }\end{array}$ & $\begin{array}{l}\text { List the steps in building the } \\
\text { capability? }\end{array}$ \\
\hline $\begin{array}{l}\text { Territorial orientation and } \\
\text { behaviors } \\
\text { What are some quotes you hear? } \\
\text { "turfism" "rice bowls" } \\
\text { "That's My responsibility" } \\
\text { "That's NOT my responsibility" } \\
\text { What do people feel? } \\
\text { Fear; job preservation; sense of } \\
\text { organizational loyalty; protective }\end{array}$ & $\begin{array}{l}\text { - See HLS as one organization. } \\
\text { - } \quad \text { Realize "value" of coordination to } \\
\text { balance the "costs". } \\
\text { - Everybody would have a common } \\
\text { shared vision of the End State \& } \\
\text { Mission \& how to accomplish this. } \\
\text { - In "my" interests; personal ownership } \\
\text { \& organizational risk mitigation. } \\
\text { - Sense if joint responsibility and } \\
\text { accountability. } \\
\text { - Clear metrics for success; evidence of } \\
\text { accomplishment; tangible output. }\end{array}$ & $\begin{array}{l}\text { 1. Get stakeholders (sponsors) } \\
\text { together to plan a meeting, agenda, } \\
\text { "integrated mission", \& a champion } \\
\text { (not figurehead) and develop their } \\
\text { relationships. Find targets of } \\
\text { opportunity and early success. } \\
\text { (Option: table top exercise } \rightarrow \text { shared } \\
\text { knowledge; sense of shared risk)) } \\
\text { 2. Meeting with all critical actors \& } \\
\text { champion \& sponsors who can } \\
\text { contribute and come up with an } \\
\text { "integrated mission" and develop the } \\
\text { felt need for their people \& develop } \\
\text { structural mechanisms (\& their own } \\
\text { relationships) }\end{array}$ \\
\hline
\end{tabular}




\section{TOOL KIT}

The following materials are included in the Tool Kit of this section of the report. Additional concepts and teaching materials can be found in the section entitled "Topical Materials."

- RACI Role/Responsibility Decision Matrix

- RACI Role/Responsibility Decision Matrix: Sample Case

- Force Field Analysis Template

- Template for Strategies to Build Collaborative Capability 
RACI: Role/Responsibility Decision Matrix

\begin{tabular}{|l|l|l|l|l|l|}
\hline & \multicolumn{4}{|c|}{ Stakeholders/ Roles } \\
\hline $\begin{array}{l}\text { Key decisions or } \\
\text { tasks }\end{array}$ & & & & & \\
\hline & & & & & \\
\hline & & & & & \\
\hline & & & & & \\
\hline
\end{tabular}

$\mathrm{R}=$ Responsible: Has duty and obligation to do the work; must exercise independent judgment to raise appropriate issues.

$\mathrm{C}=$ Consulted (before decision): Stakeholder with expertise, experience and interests who must be given opportunity to influence plans and decisions.

A = Approves: Accountable for decision; has authority to decide and is recipient of any consequences.

I = Informed (after decision): Important for this stakeholder to know decision to collaborate well in related areas.

Blank $=$ No involvement in this decision 
RACI: Role/Responsibility Decision Matrix:

Sample Case

\begin{tabular}{|l|l|l|l|l|l|}
\hline & \multicolumn{5}{|c|}{ Stakeholders/ Roles } \\
\hline $\begin{array}{l}\text { Key } \\
\text { decisions or } \\
\text { tasks }\end{array}$ & $\begin{array}{l}\text { Home } \\
\text { buyer }\end{array}$ & Architect & Contractor & Electrician & Family \\
\hline $\begin{array}{l}\text { Home size \& } \\
\text { style }\end{array}$ & R & C & & A & A \\
\hline $\begin{array}{l}\text { Door, window } \\
\text { placement }\end{array}$ & A & R & I & I & C \\
\hline $\begin{array}{l}\text { Bldg permits \& } \\
\text { schedule }\end{array}$ & A & I & R & C & \\
\hline $\begin{array}{l}\text { Outlet } \\
\text { placement }\end{array}$ & A & C & C & R & C \\
\hline
\end{tabular}

$\mathrm{R}=$ Responsible: Has duty and obligation to do the work; must exercise independent judgment to raise appropriate issues.

$\mathrm{C}=$ Consulted (before decision): Stakeholder with expertise, experience and interests who must be given opportunity to influence plans and decisions.

A = Approves: Accountable for decision; has authority to decide and is recipient of any consequences.

I = Informed (after decision): Important for this stakeholder to know decision in order to collaborate well in related areas.

Blank $=$ No involvement in this decision 
FORCE FIELD ANALYSIS

\section{Building Collaboration Capability}

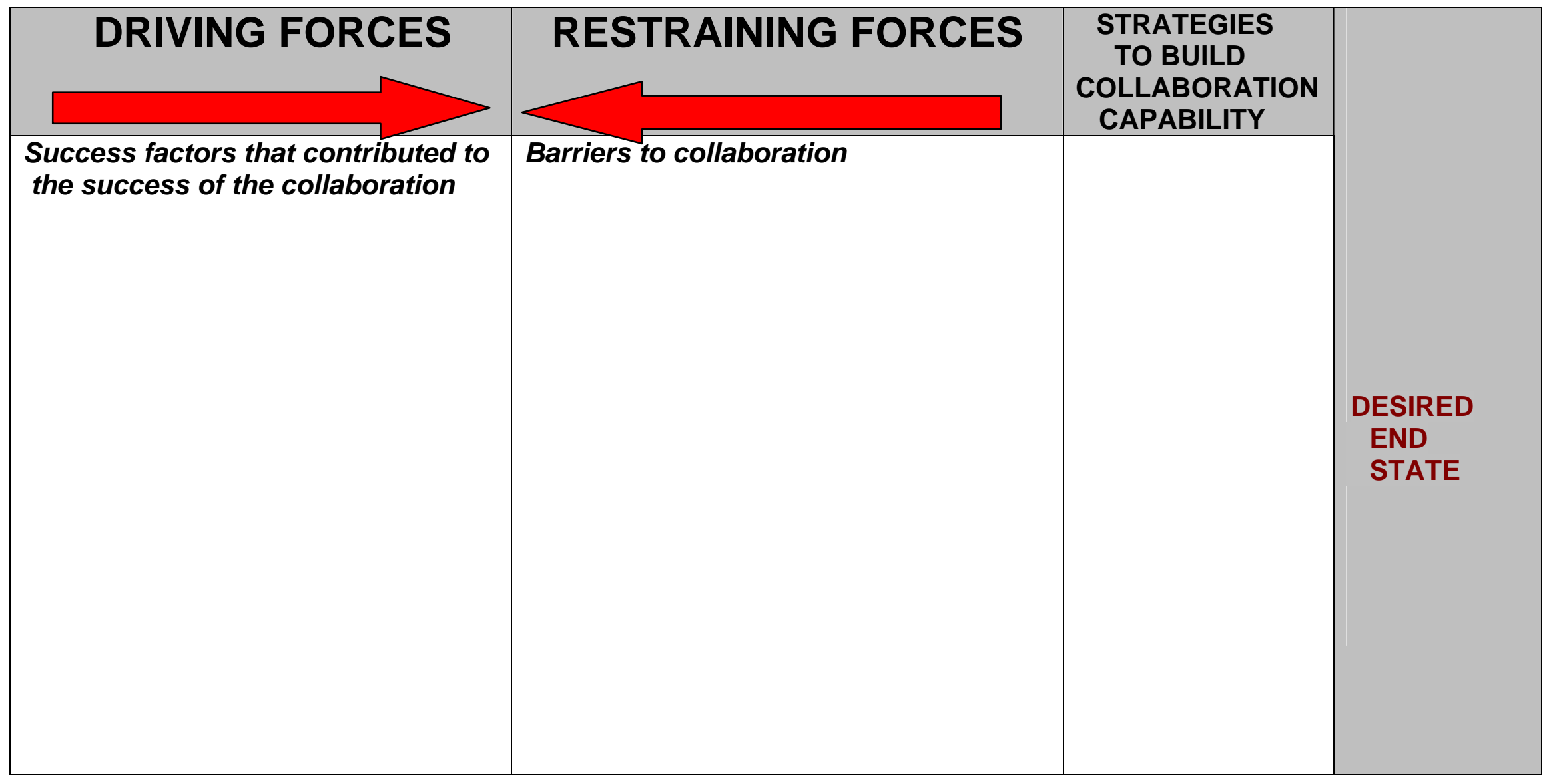




\section{HOMELAND SECURITY}

\section{Strategies to Build Collaboration Capability - Preparation Phase}

Instructions: Use the data from the force field analysis to identify a perceived and potential coordination risk or problem. Work through the template to identify the steps needed to build the capability and prevent the problem from occurring.

\begin{tabular}{|l|l|l|}
\hline $\begin{array}{l}\text { Define a perceived coordination } \\
\text { risk / problem }\end{array}$ & $\begin{array}{l}\text { Define the desired situation / end state } \\
\text { solution }\end{array}$ & $\begin{array}{l}\text { List the steps in building the } \\
\text { capability }\end{array}$ \\
\hline & & \\
& & \\
& & \\
\end{tabular}




\section{Developing Collaborative Capacity for Homeland Security Part II: Workshop Data and Analysis \\ Susan Hocevar \\ Erik Jansen \\ Gail Thomas}

This document provides a summary of the analysis and findings to date based on the data that were gathered as part of the Workshop described in Part I. Our goal is to ultimately use these data, along with the conceptual material from the literature (illustrated in the "Topical Material" section of this report) to develop a diagnostic survey. This diagnostic tool could be used by HLS organizations to evaluate their current collaborative capacity and, based on this assessment, establish an action plan to improve that collaborative capacity.

The first sections below describe the method used to collect the data. Following this, the analysis approach is presented. The results of our analysis are briefly described with reference to detailed documentation of these results in Excel tables. A conceptual model is presented in a PowerPoint attachment that integrates our findings with an open systems model of organizations. The concluding section presents our planned "next steps" to involve NPS HLS students in further refining this conceptual model, developing instrumentation, and testing the diagnostic instrument for collaborative capacity.

\section{Participants}

The workshop was conducted for both the morning and afternoon sections of Dr. Chris Bellavita's course. A total of 24 students participated. Their organizational affiliations are included in a file included with this document (filename: HLS workshop participants 040106.xls). Overall, this group represented civilian, government and military organizations from around the U.S. with HLS responsibilities. Illustrative organizations include: USNORTHCOM, US Coast Guard, Center for Disease Control Special Operations Unit of Kansas City Police Department, NYC Office of Emergency Management, Austin Fire Dept, Office of Emergency Services and Counter Terrorism for San Francisco. In addition to the class members, the instructor, Dr. Chris Bellavita, was a full participant in the exercise and contributed to the data.

\section{Procedure for Gathering Data}

The centerpiece of the workshop, as described in Part I of this document, was an exercise in which class participants were asked the following: "Think back to a specific HLS or other effort that included at least two other agencies or organizations that you consider to have been a successful collaboration in the preparation phase (not response phase) of HLS. Identify three key factors that contributed to this success.”

Participants where asked to rank order the "success factors" and record each on a separate green post-it note. Each post-it note was to include the following information: 
Participant Name

Factor Ranking

1a. Briefly describe the factor that contributed to coordination/collaboration success (1-2 sentences).

1b. Key word or phrase that captures this factor:

1c. Names of primary organizations involved in collaboration:

At the end of this activity, each participant had 3 green post-it notes identifying their rank-ordered success characteristics for a specific collaborative experience related to HLS.

The next phase of the exercise was to ask the class participants to think about an interagency collaboration related to homeland security that was NOT successful. They were asked to identify and rank order three barriers to collaboration that inhibited success in this situation. These were recorded following a format similar to that above only using pink post-it notes.

Following the individually-based activities described above, the participants were asked to share with the group the thematic words/phrases they had identified as facilitators of success. These were recorded on chart paper eliciting any necessary elaboration or clarification of the meaning of these themes. Discussion continued until all key terms/phrases had been captured. A similar process was used to identify the list of barriers to collaboration that represented the input of all participants.

This activity generated a lengthy list of both facilitators and barriers to collaboration. It was anticipated that this discussion of both positive and negative factors would lead participants to clarify/refine their evaluation of the key contributors to the specific situations they had identified in the initial activity. We also wanted to determine which factors were most frequently identified by the group as a whole. To accomplish this we asked participants to attach their post-it notes to the chart paper lists of themes that were mounted on the walls around the room. This formed the basis of the data that the research team analyzed to derive a preliminary model for collaborative capacity. 


\section{Analysis of Workshop Data}

The first step in preparing the data for analysis was to create a database. As described above, participants had assigned their "post-it note" entries to a specific theme that had been identified in the open discussion. The initial database represented a transcription of individual "post-it" entries grouped by theme to which it had been assigned. Thus, the entries in the database included the following (all but the first derived from the individual data generated on the "post-it" notes):

- Theme (as generated by group discussion)

- Elaborated text of factor contributing to successful or unsuccessful collaboration

- Name of participant

- Summary phrase capturing facilitating or inhibiting factor

- Rank order of this factor $\left(1^{\text {st }}, 2^{\text {nd }}\right.$, or $3^{\text {rd }}$ most important $)$

- Names of other organizations involved

This database had a broad range of, often overlapping themes. The researchers reviewed these data and generated a set of "revised themes" that both consolidated related factors and integrated language and concepts from the research literature on organizational collaboration. At the same time, the researchers noted that the factors often had different points of reference. In other words, in some cases the description reflected an organization-level factor; in others the narrative focused on group or individual level factors. Seeing this as important "data," the researchers also "tagged" each entry with a "level" variable where level could be any or all of three types - individual, group, or organizational. The database representing these analyses is included in this report (filename: HLS workshop data_V2.xls).

Further analysis was conducted to identify the most frequently cited barriers and facilitating factors for collaboration. Figure 1 presents these findings.

Figure 1

\begin{tabular}{|l|l|}
\hline \multicolumn{2}{|c|}{ Most Frequently Cited Factors } \\
\hline \multicolumn{1}{|c|}{ Success Factors } & \multicolumn{1}{c|}{ Barriers } \\
\hline "Felt need" to collaborate (10) & Lack of trust (13) \\
Common goal (9) & Inhibiting attitudes (12) \\
Motivation (7) & Lack of familiarity (10) \\
Communication (7) & Poor leadership (7) \\
Absence of competitive rivalries (7) & Competition (7) \\
Social capital (5) & Motivation (5) \\
Trust (4) & Lack of information sharing (5) \\
Familiarity (3) & Impeding rules or policies (4) \\
Interoperability (3) & Inhibiting behaviors (3) \\
Leadership motivation (3) & Resource scarcity (3) \\
Coordination of resources (3) & Lack of flexibility (3) \\
Appreciation of other's perspective (3) & Lack of competency (3) \\
Authority to act/decide (3) & Lack of accountability (3) \\
\hline
\end{tabular}


Included in this figure are only the items for which there were at least three confirming entries from the workshop participants. The number in parentheses represents how many participants identified this factor in their data entry. For a complete list of the factors, see the database identified in the paragraph above.

\section{Emergent Conceptual Model}

As is evident from this report, we have a dual objective to our work. We are interested in developing a conceptual model for collaborative capacity; and we intend to apply this conceptual model both in the classroom as well as toward the development of a diagnostic instrument for evaluating organizational collaborative capacity and planning interventions to improve that capability. As we brought together both the inductive model-building described in the analysis above and our growing familiarity with literature relevant to collaboration, a conceptual model emerged. This model is presented in detail in a PowerPoint presentation included in this report.

This model is based on an open-systems perspective on organizations. The organizational systems components are presented, and the data derived from the analyses above are attributed to the appropriate component. In its current format, this presentation can be used for teaching. But a related goal is to use this as the basis for the next step of designing a diagnostic survey instrument.

\section{Next Steps}

As noted above, we have dual objectives. We hope to continue to engage with HLS students in presenting what we've learned to date about collaboration in the HLS context; and, as part of this engagement, we plan to continue the development of the collaborative capacity diagnostic instrument. Outlined below are some activities that would address both of these objectives.

1. In class presentations of the open systems model that compiles the data gathered on factors (barriers and facilitators) that effect collaborative capacity. Given whatever timeframe is available, this can be elaborated from the "Topical Materials" slides that accompany this report. Our goal would be two-fold: 1) to present the model and data; 2) to elicit from HLS professionals within the class additional validation and elaboration of the current inductively derived model:

a. What needs to be added to the model? Are there critical factors missing?

b. Do their experiences confirm this model? Can they give specific case examples that provide validation and clarification?

c. Refine the "most frequent" factors presented in Figure 1 above, by conducting an exercise in which class members would rate the importance of these factors. If data can be compiled during class time, discuss the implication of the findings to action planning for improving collaborative capacity. 
2. Focus Groups would be conducted with students who volunteered to spend an additional couple of hours on this topic. This effort might lay the groundwork for a couple of students to pursue this topic as their thesis research. The goal of the focus groups would be to elaborate further on the activities described in (1) above. The value of small groups is that specific case examples can be explored in more detail which in turn refines and elaborates the model of collaborative capacity:

a. What needs to be added to the model?

b. Which factors suggest the most important leverage for action?

c. Individual focus group members will be asked to consider a specific situation requiring collaboration that they have experienced and address the following questions:

i. Before the event, could you have predicted the aspects and sources of success?

ii. The barriers and problems faced in this situation?

iii. What is the basis of this prediction (behaviors, attitudes, policies, etc.)?

iv. In what ways does the model assist in ability to predict?

d. We're particularly interested in understanding the differences between collaboration in a consequence situation and in a planning situation.

i. Is collaboration different in these two contexts?

ii. How/Why?

iii. How can we capitalize on what we hypothesize are the greater success factors in collaboration in consequence situations to improve collaboration in planning and prevention?

3. Interviews would be conducted in a one-on-one session with students who were willing to volunteer their time to share details about a specific case example. The range of case data we would elicit in the interview would include:

a. Context/situation

b. Participants (who and how they became involved)

c. Timeframe

d. Goals/problem of focus

e. Incentives

f. Barriers

g. Role of trust

h. Structural factors

i. Attitudinal/Behavioral factors

4. Use data above to refine model and develop diagnostic instrument for pilot testing. Based on both the data above and the literature we have been reviewing and will continue to review, we will prepare a diagnostic survey instrument. It will include multiple items for each of the elements of the organization system model as illustrated in the PowerPoint "Systems Model on Workshop Results" which is included in this material. Our plan is to use the HLS students (and their network to a broader pool of HLS professionals) as a source of pilot data to evaluate the measurement characteristics of the survey (reliability, validity). 


\section{BIBLIOGRAPHY}

\section{Organization \& Collaboration}

Ahuja, G. (2000). Collaboration networks, structural holes, and innovation: A longitudinal study. Administrative Science Quarterly, 45(3), 425-455.

Arino, A., \& de la Torre, J. (1998). Learning from failure: Towards an evolutionary model of collaborative ventures. Organization Science, 9(3), 306-325.

Austin, D. E. (2003). Community-based collaborative team ethnography: A community-university-agency partnership. Human Organization, 62(2), 143-152.

Boddy, D., Macbeth, D., \& Wagner, B. (2000). Implementing collaboration between organizations: An empirical study of supply chain partnering. Journal of Management Studies, 37(7), 1003-1017.

Carson, S. J., Madhok, A., Varman, R., \& John, G. (2003). Information processing moderators of the effectiveness of trust-based governance in interfirm R\&D collaboration. Organization Science, 14(1), 45-56.

Coleman, G., \& Rippin, A. (2000). Putting feminist theory to work: Collaboration as a means towards organizational change. Organization, 7(4), 573-587.

Cramton, C. D. (2001). The mutual knowledge problem and its consequences for dispersed collaboration. Organization Science, 12(3), 346-371.

Dam, K. W. (1996). Inter-organizational collaboration: Biotechnology and computers compared - Comment. Journal of Institutional and Theoretical Economics-Zeitschrift Fur Die Gesamte Staatswissenschaft, 152(1), 216219.

Derr, C. B. (1978). Managing Organizational Conflict - Collaboration, Bargaining, and Power Approaches. California Management Review, 21(2), 76-83.

Ephross, P. H. (1993). The Community Collaboration Manual - the National Assembly of National Voluntary Health and Social-Welfare Organizations. Social Work with Groups, 16(4), 145-147.

Faerman, S. R., McCaffrey, D. P., \& Van Slyke, D. M. (2001). Understanding interorganizational cooperation: Public-private collaboration in regulating financial market innovation. Organization Science, 12(3), 372-388. 
Glass, J. M. (1999). Two models of political organization - Collaboration versus resistance. American Behavioral Scientist, 43(2), 278-300.

Grubbs, J. W. (2000). Can agencies work together? Collaboration in public and nonprofit organizations. Public Administration Review, 60(3), 275.

Hameri, A. P., Puittinen, M., \& Syrjalahti, M. (2002). Organizational emergence in networked collaboration. International Journal of Communication Systems, 15(7), 607-619.

Hardy, C., \& Phillips, N. (1998). Strategies of engagement: Lessons from the critical examination of collaboration and conflict in an interorganizational domain. Organization Science, 9(2), 217-230.

Hardy, C., Phillips, N., \& Lawrence, T. B. (2003). Resources, knowledge and influence: The organizational effects of interorganizational collaboration. Journal of Management Studies, 40(2), 321-347.

Harris, A., \& Dombrowski, P. (2002). Military collaboration with humanitarian organizations in complex emergencies. Global Governance, 8(2), 155178.

Hinds, P., \& Kiesler, S. (1995). Communication across Boundaries - Work, Structure, and Use of Communication Technologies in a Large Organization. Organization Science, 6(4), 373-393.

Hord, S. M. (1986). A Synthesis of Research on Organizational Collaboration. Educational Leadership, 43(5), 22-26.

Huxham, C., \& Vangen, S. (2000). Leadership in the shaping and implementation of collaboration agendas: How things happen in a (not quite) joined-up world. Academy of Management Journal, 43(6), 1159.

Inkpen, A. C., \& Dinur, A. (1998). Knowledge management processes and international joint ventures. Organization Science, 9(4), 454-468.

Intriligator, B. A. (1982). Inter-Organizational Collaboration - a Strategy for Faculty-Development and Organization Renewal. Journal of Teacher Education, 33(5), 14-17.

Khan, P. (2003). An analysis of conflict experienced between agencies involved with asylum seekers. Journal of Social Work Practice, 17(1), 115-126.

Kraus, W. (1981). Collaboration in Organizations. Personnel Journal, 60(1), 6060.

Kreiner, K., \& Schultz, M. (1993). Informal Collaboration in Research-andDevelopment - the Formation of Networks across Organizations. Organization Studies, 14(2), 189-209.

Kumar, K., \& vanDissel, H. G. (1996). Sustainable collaboration: Managing conflict and cooperation in interorganizational systems. Mis Quarterly, 20(3), 279-300. 
Kumar, R., \& Nti, K. O. (1998). Differential learning and interaction in alliance dynamics: A process and outcome discrepancy model. Organization Science, 9(3), 356-367.

Larsson, R., Bengtsson, L., Henriksson, K., \& Sparks, J. (1998). The interorganizational learning dilemma: Collective knowledge development in strategic alliances. Organization Science, 9(3), 285-305.

Lawrence, T. B., Hardy, C., \& Phillips, N. (2002). Institutional effects of interorganizational collaboration: The emergence of proto-institutions. Academy of Management Journal, 45(1), 281-290.

Lewin, A. Y., Long, C. P., \& Carroll, T. N. (1999). The coevolution of new organizational forms. Organization Science, 10(5), 535-550.

Madhok, A., \& Tallman, S. B. (1998). Resources, transactions and rents: Managing value through interfirm collaborative relationships. Organization Science, 9(3), 326-339.

Massarik, F. (1982). Collaboration in Organizations - Alternatives to Hierarchy Kraus,Wa. Contemporary Psychology, 27(5), 367-367.

McServey, P. M. (1995). Fostering Collaboration in a Boundaryless Organization. N\&Hc-Perspectives on Community, 16(4), 234-236.

Munkvold, B. E. (1999). Challenges of IT implementation for supporting collaboration in distributed organizations. European Journal of Information Systems, 8(4), 260-272.

Pfeffer, J., \& Langton, N. (1993). The Effect of Wage Dispersion on Satisfaction, Productivity, and Working Collaboratively - Evidence from College and University-Faculty. Administrative Science Quarterly, 38(3), 382-407.

Phillips, N., Lawrence, T. B., \& Hardy, C. (2000). Inter-organizational collaboration and the dynamics of institutional fields. Journal of Management Studies, 37(1), 23-43.

Powell, W. W. (1996). Inter-organizational collaboration in the biotechnology industry. Journal of Institutional and Theoretical Economics-Zeitschrift Fur Die Gesamte Staatswissenschaft, 152(1), 197-215.

Powell, W. W., Koput, K. W., \& SmithDoerr, L. (1996). Interorganizational collaboration and the locus of innovation: Networks of learning in biotechnology. Administrative Science Quarterly, 41(1), 116-145.

Robinson, D. F., Savage, G. T., \& Campbell, K. S. (2003). Organizational learning, diffusion of innovation, and international collaboration in telemedicine. Health Care Management Review, 28(1), 68-78.

Rondinelli, D. A., \& London, T. (2003). How corporations and environmental groups cooperate: Assessing cross-sector alliances and collaborations. Academy of Management Executive, 17(1), 61-76. 
Rosenkopf, L., Metiu, A., \& George, V. P. (2001). From the bottom up? Technical committee activity and alliance formation. Administrative Science Quarterly, 46(4), 748-772.

Simonin, B. L. (1997). The importance of collaborative know-how: An empirical test of the learning organization. Academy of Management Journal, 40(5), 1150-1174.

Smith, A. D., \& Zeithaml, C. (1996). Garbage cans and advancing hypercompetition: The creation and exploitation of new capabilities and strategic flexibility in two regional bell operating companies. Organization Science, 7(4), 388-399.

Smith, K. (1989). Non-Governmental Organizations in the Health Field Collaboration, Integration and Contrasting Aims. Social Science \& Medicine, 29(3), 395-402.

Sundaramurthy, C., \& Lewis, M. (2003). Control and collaboration: Paradoxes of governance. Academy of Management Review, 28(3), 397-415.

Tjosvold, D., \& Tsao, Y. (1989). Productive Organizational Collaboration - the Role of Values and Cooperation. Journal of Organizational Behavior, 10(2), 189-195.

Walker, G., Kogut, B., \& Shan, W. J. (1997). Social capital, structural holes and the formation of an industry network. Organization Science, 8(2), 109-125.

Waugh, W. L., \& Sylves, R. T. (2002). Organizing the war on terrorism. Public Administration Review, 62, 145.

Westenholz, A. (1983). Collaboration in Organizations - Alternatives to Hierarchy - Kraus,Wa. Organization Studies, 4(3), 282-283.

Westley, F., \& Vredenburg, H. (1997). Interorganizational collaboration and the preservation of global biodiversity. Organization Science, 8(4), 381-403.

Zanglis, I., Furlong, M. J., \& Casas, J. M. (2000). Case study of a community mental health collaborative: Impact on identification of youths with emotional or behavioral disorders. Behavioral Disorders, 25(4), 359-371.

Zollo, M., Reuer, J. J., \& Singh, H. (2002). Interorganizational routines and performance in strategic alliances. Organization Science, 13(6), 701-713. 


\section{BIBLIOGRAPHY}

Interorganizational

Ackroyd, S. (1998). How organizations act together: Interorganizational coordination in theory and practice. Administrative Science Quarterly, 43(1), 217-220.

Alter, C. (1990). An Exploratory-Study of Conflict and Coordination in Interorganizational Service Delivery Systems. Academy of Management Journal, 33(3), 478-502.

Beckman, C. M., \& Haunschild, P. R. (2002). Network learning: The effects of partners' heterogeneity of experience on corporate acquisitions. Administrative Science Quarterly, 47(1), 92-124.

Begun, J. W. (1984). Interorganization Coordination - Theory, Research, and Implementation - Rogers,DI, Whetten,Da. Administrative Science Quarterly, 29(3), 470-472.

Benson, J. K. (1975). Interorganizational Network as a Political-Economy. Administrative Science Quarterly, 20(2), 229-249.

Burns, L. R., \& Wholey, D. R. (1993). Adoption and Abandonment of Matrix Management Programs - Effects of Organizational Characteristics and Interorganizational Networks. Academy of Management Journal, 36(1), 106-138.

Cummings, T. G. (1984). Transorganizational Development. Research in Organizational Behavior, 6, 367-422.

Czepiel, J. A. (1975). Patterns of Interorganizational Communications and Diffusion of a Major Technological Innovation in a Competitive Industrial Community. Academy of Management Journal, 18(1), 6-24.

Daveni, R. A. (1996). A multiple-constituency, status-based approach to interorganizational mobility of faculty and input-output competition among top business schools. Organization Science, 7(2), 166-189.

Daveni, R. A., \& Kesner, I. F. (1993). Top Managerial Prestige, Power and Tender Offer Response - a Study of Elite Social Networks and Target Firm Cooperation During Takeovers. Organization Science, 4(2), 123-151.

Davis, G. F. (1991). Agents without Principles - the Spread of the Poison Pill through the Intercorporate Network. Administrative Science Quarterly, 36(4), 583-613.

Dyer, J. H., \& Singh, H. (1998). The relational view: Cooperative strategy and sources of interorganizational competitive advantage. Academy of Management Review, 23(4), 660-679. 
Faerman, S. R., McCaffrey, D. P., \& Van Slyke, D. M. (2001). Understanding interorganizational cooperation: Public-private collaboration in regulating financial market innovation. Organization Science, 12(3), 372-388.

Galaskiewicz, J., \& Burt, R. S. (1991). Interorganization Contagion in Corporate Philanthropy. Administrative Science Quarterly, 36(1), 88-105.

Galaskiewicz, J., \& Wasserman, S. (1989). Mimetic Processes within an Interorganizational Field - an Empirical-Test. Administrative Science Quarterly, 34(3), 454-479.

Ghoshal, S., \& Bartlett, C. A. (1990). The Multinational-Corporation as an Interorganizational Network. Academy of Management Review, 15(4), 603-625.

Goes, J. B., \& Park, S. H. (1997). Interorganizational links and innovation: The case of hospital services. Academy of Management Journal, 40(3), 673696.

Hall, R. H., Clark, J. P., Giordano, P. C., Johnson, P. V., \& Vanroekel, M. (1977). Patterns of Interorganizational Relationships. Administrative Science Quarterly, 22(3), 457-474.

Harrigan, K. R., \& Newman, W. H. (1990). Bases of Interorganization Cooperation - Propensity, Power, Persistence. Journal of Management Studies, 27(4), 417-434.

Hart, P., \& Saunders, C. (1997). Power and trust: Critical factors in the adoption and use of electronic data interchange. Organization Science, 8(1), 23-42.

Haunschild, P. R. (1993). Interorganizational Imitation - the Impact of Interlocks on Corporate Acquisition Activity. Administrative Science Quarterly, 38(4), 564-592.

Haunschild, P. R. (1994). How Much Is That Company Worth Interorganizational Relationships, Uncertainty, and Acquisition Premiums. Administrative Science Quarterly, 39(3), 391-411.

Haunschild, P. R., \& Miner, A. S. (1997). Modes of interorganizational imitation: The effects of outcome salience and uncertainty. Administrative Science Quarterly, 42(3), 472-500.

Heimer, C. A. (1985). Allocating Information Costs in a Negotiated Information Order - Interorganizational Constraints on Decision-Making in Norwegian Oil Insurance. Administrative Science Quarterly, 30(3), 395-417.

Herbert, T. T. (1984). Strategy and Multinational Organization Structure - an Interorganizational Relationships Perspective. Academy of Management Review, 9(2), 259-271.

Holland, C. P., \& Lockett, A. G. (1997). Mixed mode network structures: The strategic use of electronic communication by organizations. Organization Science, 8(5), 475-488. 
Kenis, P., \& Knoke, D. (2002). How organizational field networks shape interorganizational tie-formation rates. Academy of Management Review, 27(2), 275-293.

Klonglan, G. E., Warren, R. D., Winkelpleck, J. M., \& Paulson, S. K. (1976). Interorganizational Measurement in Social-Services Sector - Differences by Hierarchical Level. Administrative Science Quarterly, 21(4), 675-687.

Kochan, T. A. (1975). Determinants of Power of Boundary Units in an Interorganizational Bargaining Relation. Administrative Science Quarterly, 20(3), 434-452.

Koza, M. P., \& Lewin, A. Y. (1998). The co-evolution of strategic alliances. Organization Science, 9(3), 255-264.

Kraatz, M. S. (1998). Learning by association? Interorganizational networks and adaptation to environmental change. Academy of Management Journal, 41(6), 621-643.

Kumar, N., Stern, L. W., \& Anderson, J. C. (1993). Conducting Interorganizational Research Using Key Informants. Academy of Management Journal, 36(6), 1633-1651.

Lammers, C. J. (1988). The Interorganizational Control of an Occupied Country. Administrative Science Quarterly, 33(3), 438-457.

Lane, P. J., \& Lubatkin, M. (1998). Relative absorptive capacity and interorganizational learning. Strategic Management Journal, 19(5), 461.

Lawrence, T. B., Hardy, C., \& Phillips, N. (2002). Institutional effects of interorganizational collaboration: The emergence of proto-institutions. Academy of Management Journal, 45(1), 281-290.

Leblebici, H., \& Salancik, G. R. (1982). Stability in Interorganizational Exchanges - Rulemaking Processes of the Chicago-Board-of-Trade. Administrative Science Quarterly, 27(2), 227-242.

Leblebici, H., Salancik, G. R., Copay, A., \& King, T. (1991). Institutional Change and the Transformation of Interorganizational Fields - an Organizational History of the United-States Radio Broadcasting Industry. Administrative Science Quarterly, 36(3), 333-363.

Levinthal, D. A., \& Fichman, M. (1988). Dynamics of Interorganizational Attachments - Auditor-Client Relationships. Administrative Science Quarterly, 33(3), 345-369.

Li, S. X., \& Rowley, T. J. (2002). Inertia and evaluation mechanisms in interorganizational partner selection: Syndicate formation among US investment banks. Academy of Management Journal, 45(6), 1104-1119.

Lind, M. R., \& Zmud, R. W. (1995). Improving Interorganizational Effectiveness through Voice Mail Facilitation of Peer-to-Peer Relationships. Organization Science, 6(4), 445-461. 
Luke, R. D., Begun, J. W., \& Pointer, D. D. (1989). Quasi Firms - Strategic Interorganizational Forms in the Health-Care Industry. Academy of Management Review, 14(1), 9-19.

Martin, X., Swaminathan, A., \& Mitchell, W. (1998). Organizational evolution in the interorganizational environment: Incentives and constraints on international expansion strategy. Administrative Science Quarterly, 43(3), 566-601.

Meindl, J. R., Stubbart, C., \& Porac, J. F. (1994). Cognition within and between Organizations - 5 Key Questions. Organization Science, 5(3), 289-293.

Mindlin, S. E., \& Aldrich, H. (1975). Interorganizational Dependence - Review of Concept and a Re-Examination of Findings of Aston Group. Administrative Science Quarterly, 20(3), 382-392.

Miner, A. S., Amburgey, T. L., \& Stearns, T. M. (1990). Interorganizational Linkages and Population-Dynamics - Buffering and Transformational Shields. Administrative Science Quarterly, 35(4), 689-713.

Mol, M. J. (2001). Creating wealth through working with others: Interorganizational relationships. Academy of Management Executive, 15(1), 150-152.

Molnar, J. J., \& Rogers, D. L. (1979). Comparative Model of Interorganizational Conflict. Administrative Science Quarterly, 24(3), 405-425.

Monge, P. R., Fulk, J., Kalman, M. E., Flanagin, A. J., Parnassa, C., \& Rumsey, S. (1998). Production of collective action in alliance-based interorganizational communication and information systems. Organization Science, 9(3), 411-433.

Newmann, W. W. (2002). Reorganizing for national security and homeland security. Public Administration Review, 62, 126.

Nooteboom, B., Berger, H., \& Noorderhaven, N. G. (1997). Effects of trust and governance on relational risk. Academy of Management Journal, 40(2), 308-338.

Oliver, C. (1990). Determinants of Interorganizational Relationships - Integration and Future-Directions. Academy of Management Review, 15(2), 241-265.

Osborn, R. N., \& Baughn, C. C. (1990). Forms of Interorganizational Governance for Multinational Alliances. Academy of Management Journal, 33(3), 503519.

Osborn, R. N., \& Hagedoorn, J. (1997). The institutionalization and evolutionary dynamics of interorganizational alliances and networks. Academy of Management Journal, 40(2), 261-278.

Park, S. H., \& Ungson, G. R. (2001). Interfirm rivalry and managerial complexity: A conceptual framework of alliance failure. Organization Science, 12(1), 37-53. 
Parkhe, A. (1993). Strategic Alliance Structuring - a Game-Theoretic and Transaction Cost Examination of Interfirm Cooperation. Academy of Management Journal, 36(4), 794-829.

Pfeffer, J., \& Nowak, P. (1976). Joint Ventures and Interorganizational Interdependence. Administrative Science Quarterly, 21(3), 398-418.

Pickering, J. M., \& King, J. L. (1995). Hardwiring Weak Ties - Interorganizational Computer-Mediated Communication, Occupational Communities, and Organizational-Change. Organization Science, 6(4), 479-486.

Post, J. E. (1987). United-States Coal Goes Abroad - a Social-Action Perspective on Interorganizational Networks - Rogers, Ks. Academy of Management Review, 12(1), 175-177.

Provan, K. G. (1982). Interorganizational Linkages and Influence over DecisionMaking. Academy of Management Journal, 25(2), 443-451.

Provan, K. G. (1983). The Federation as an Interorganizational Linkage Network. Academy of Management Review, 8(1), 79-89.

Provan, K. G. (1984). Interorganizational Cooperation and Decision-Making Autonomy in a Consortium Multihospital System. Academy of Management Review, 9(3), 494-504.

Provan, K. G. (1984). Technology and Interorganizational Activity as Predictors of Client Referrals. Academy of Management Journal, 27(4), 811-829.

Provan, K. G., \& Milward, H. B. (1995). A Preliminary Theory of Interorganizational Network Effectiveness - a Comparative-Study of 4 Community Mental-Health Systems. Administrative Science Quarterly, 40(1), 1-33.

Provan, K. G., \& Skinner, S. J. (1989). Interorganizational Dependence and Control as Predictors of Opportunism in Dealer-Supplier Relations. Academy of Management Journal, 32(1), 202-212.

Ring, P. S., \& Vandeven, A. H. (1994). Developmental Processes of Cooperative Interorganizational Relationships. Academy of Management Review, 19(1), 90-118.

Ritti, R. R., \& Silver, J. H. (1986). Early Processes of Institutionalization - the Dramaturgy of Exchange in Interorganizational Relations. Administrative Science Quarterly, 31(1), 25-42.

Scheer, L. K., Kumar, N., \& Steenkamp, J. (2003). Reactions to perceived inequity in US and Dutch interorganizational relationships. Academy of Management Journal, 46(3), 303-316.

Schermerhorn, J. R. (1975). Determinants of Interorganizational Cooperation. Academy of Management Journal, 18(4), 846-856. 
Schermerhorn, J. R. (1976). Openness to Interorganizational Cooperation Study of Hospital Administrators. Academy of Management Journal, 19(2), 225-236.

Schermerhorn, J. R. (1977). Information Sharing as an Interorganizational Activity. Academy of Management Journal, 20(1), 148-153.

Schmidt, S. M., \& Kochan, T. A. (1977). Interorganizational Relationships Patterns and Motivations. Administrative Science Quarterly, 22(2), 220234.

Schopler, J. H. (1987). Interorganizational Groups - Origins, Structure, and Outcomes. Academy of Management Review, 12(4), 702-713.

Seabright, M. A., Levinthal, D. A., \& Fichman, M. (1992). Role of Individual Attachments in the Dissolution of Interorganizational Relationships. Academy of Management Journal, 35(1), 122-160.

Sebring, R. H. (1977). 5-Million Dollar Misunderstanding - Perspective on State Government-University Interorganizational Conflicts. Administrative Science Quarterly, 22(3), 505-523.

Smith, K. G., Carroll, S. J., \& Ashford, S. J. (1995). Intraorganizational and Interorganizational Cooperation - toward a Research Agenda. Academy of Management Journal, 38(1), 7-23.

Stearns, L. B., \& Mizruchi, M. S. (1986). Broken-Tie Reconstitution and the Functions of Interorganizational Interlocks - a Reexamination. Administrative Science Quarterly, 31(4), 522-538.

Stearns, T. M., Hoffman, A. N., \& Heide, J. B. (1987). Performance of Commercial Television Stations as an Outcome of Interorganizational Linkages and Environmental-Conditions. Academy of Management Journal, 30(1), 71-90.

Stern, R. N. (1979). Development of an Interorganizational Control Network Case of Intercollegiate Athletics. Administrative Science Quarterly, 24(2), 242-266.

Stern, R. N. (1981). Competitive Influences on the Interorganizational Regulation of College Athletics. Administrative Science Quarterly, 26(1), 15-32.

Stuart, T. E., Hoang, H., \& Hybels, R. C. (1999). Interorganizational endorsements and the performance of entrepreneurial ventures. Administrative Science Quarterly, 44(2), 315-349.

Subramani, M. R., \& Venkatraman, N. (2003). Safeguarding investments in asymmetric interorganizational relationships: Theory and evidence. Academy of Management Journal, 46(1), 46-62.

Tucker, D. (2000). The RMA and the interagency: Knowledge and speed vs. ignorance and sloth? Parameters, 30(3), 66. 
Turner, B. A. (1976). Organizational and Interorganizational Development of Disasters. Administrative Science Quarterly, 21(3), 378-397.

Vandeven, A. H., \& Walker, G. (1984). The Dynamics of Interorganizational Coordination. Administrative Science Quarterly, 29(4), 598-621.

Weiss, A. M., \& Kurland, N. (1997). Holding distribution channel relationships together: The role of transaction-specific assets and length of prior relationship. Organization Science, 8(6), 612-623.

Weiss, S. E. (1993). Analysis of Complex Negotiations in International-Business the Rbc Perspective. Organization Science, 4(2), 269-300.

Westphal, J. D., Seidel, M. D. L., \& Stewart, K. J. (2001). Second-order imitation: Uncovering latent effects of board network ties. Administrative Science Quarterly, 46(4), 717-747.

Wholey, D. R., \& Huonker, J. W. (1993). Effects of Generalism and Niche Overlap on Network Linkages among Youth Service Agencies. Academy of Management Journal, 36(2), 349-371.

Wiewel, W., \& Hunter, A. (1986). The Interorganizational Network as a Resource - a Comparative Case-Study on Organizational Genesis. Administrative Science Quarterly, 30(4), 482-496.

Williamson, I. O., \& Cable, D. M. (2003). Organizational hiring patterns, interfirm network ties, and interorganizational imitation. Academy of Management Journal, 46(3), 349-358.

Young-Ybarra, C., \& Wiersema, M. (1999). Strategic flexibility in information technology alliances: The influence of transaction cost economics and social exchange theory. Organization Science, 10(4), 439-459.

Zaheer, A., McEvily, B., \& Perrone, V. (1998). Does trust matter? Exploring the effects of interorganizational and interpersonal trust on performance. Organization Science, 9(2), 141-159.

Zajac, E. J. (1988). Interlocking Directorates as an Interorganizational Strategy a Test of Critical Assumptions. Academy of Management Journal, 31(2), 428-438.

Zajac, E. J., \& Westphal, J. D. (1996). Director reputation, CEO-board power, and the dynamics of board interlocks. Administrative Science Quarterly, 41(3), 507-529.

Zeitz, G. (1980). Interorganizational Dialectics. Administrative Science Quarterly, 25(1), 72-88. 
Slide 1

Building Collaborative Capacity for
Homeland Security:
$\begin{aligned} & \text { A Systems Model Perspective on Workshop } \\ & \text { Results }\end{aligned}$
$\begin{aligned} & \text { Susan Hocevar, Ph.D. } \\ & \text { Erik Jansen, Ph.D. } \\ & \text { Gail Fann Thomas, Ed.D. }\end{aligned}$
view in notes mode to see commentary


Slide 2

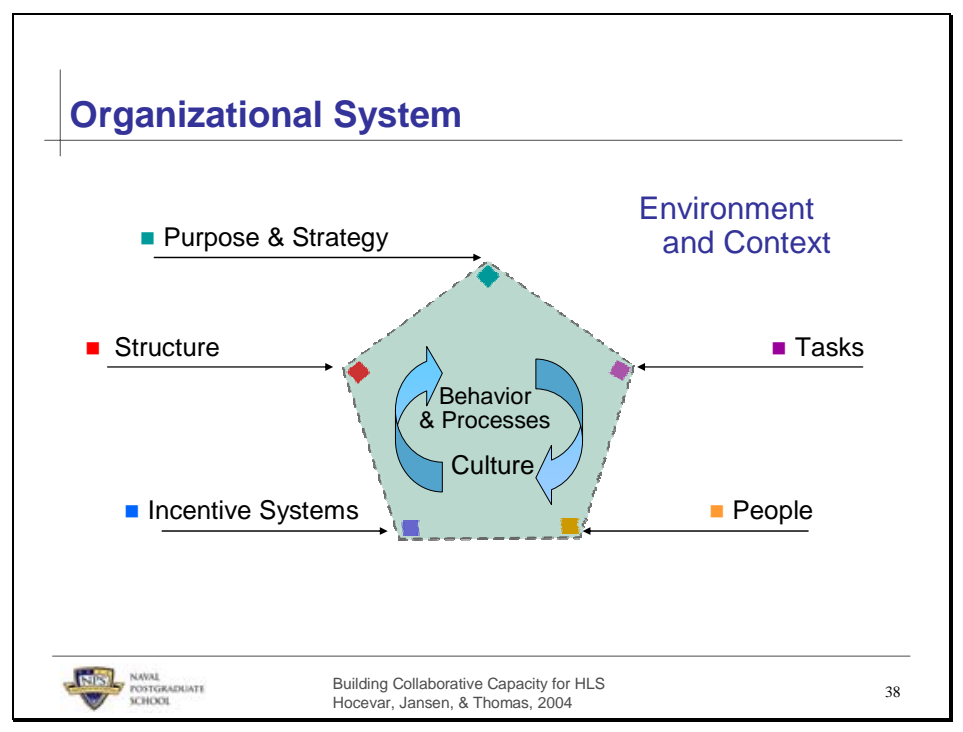

This figure presents an open systems model of the organization. The pentagon represents the organization, which is embedded in a specific environment and "problem” context. The organization is comprised of interacting elements:

Purpose and strategy

Structure

Tasks and Workflow

People

Incentive systems

Culture that is reflected in behavior and processes

In the following slides, this model is used to display the data that was generated by the two classes that participated in the workshop in which barriers and facilitators of collaboration were identified. Attributing the data elements to this system model is another step toward the development of a diagnostic instrument for collaborative capacity. The model allows for the identification of domains of collaborative capacity that will better enable both diagnosis and action taking to improve collaboration for homeland security. 
Slide 3

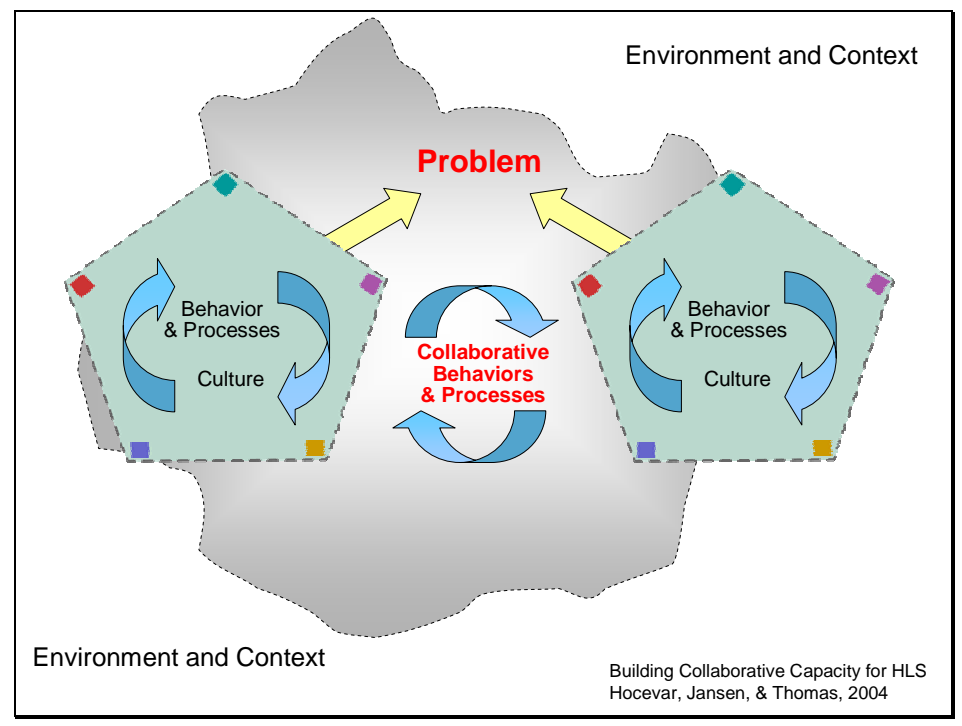

This slide represents two organizations in a given problem context. It is the simplest representation of inter-organizational collaboration for homeland security. Each organization has a functional contribution to make toward a homeland security "problem." In addition to their unique efforts toward addressing the "problem," these organizations have some degree of requirements for collaborative behaviors and processes in order to effectively address the HLS issue.

The following slides outline some of the specific examples of organizational factors that contribute to collaborative capacity for effective homeland security. These examples are derived from data gathered from professionals representing multiple organizations from around the U.S. who are involved in HLS. 
Slide 4

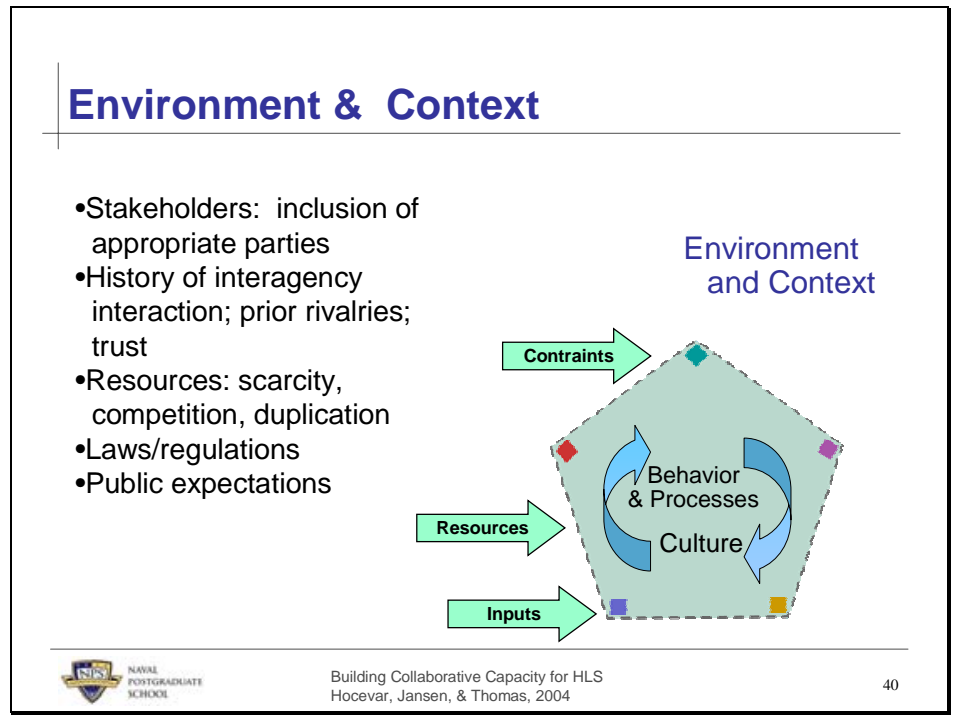


Slide 5

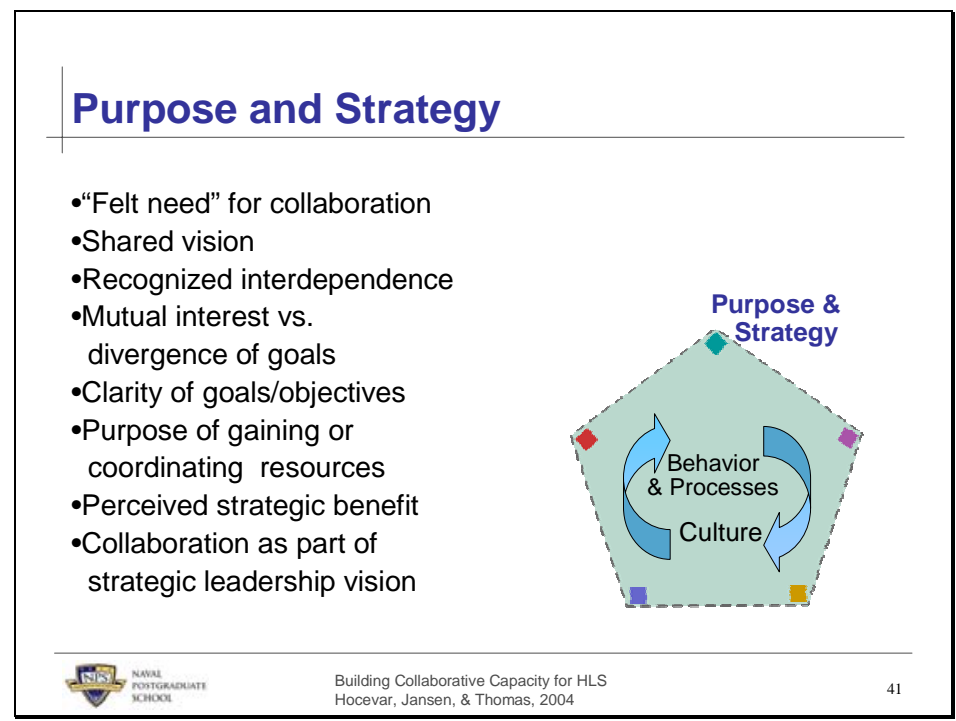


Slide 6

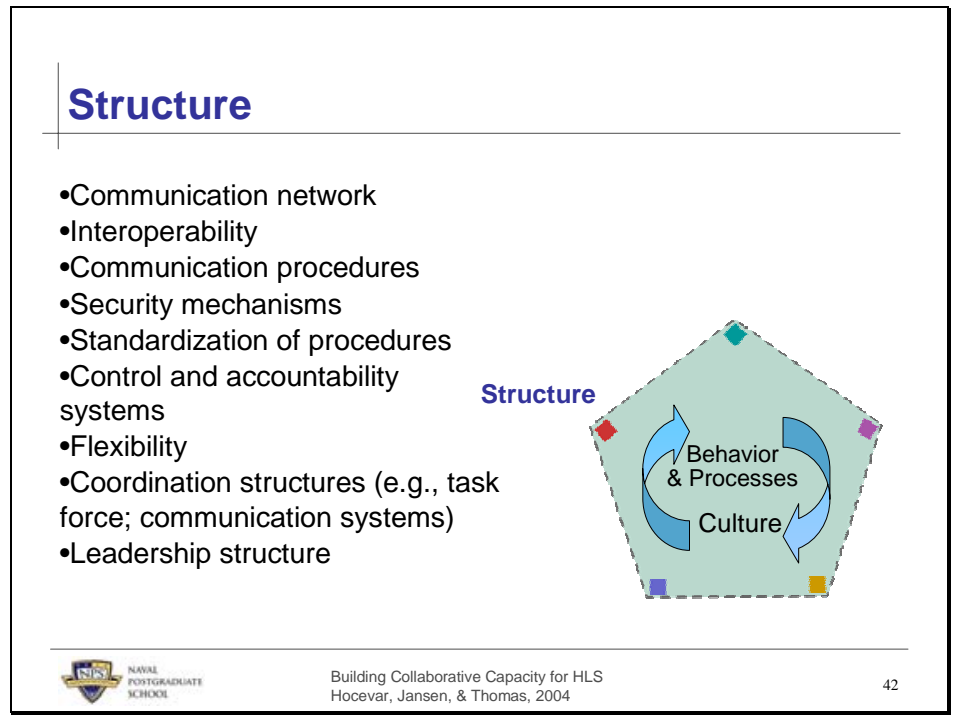


Slide 7

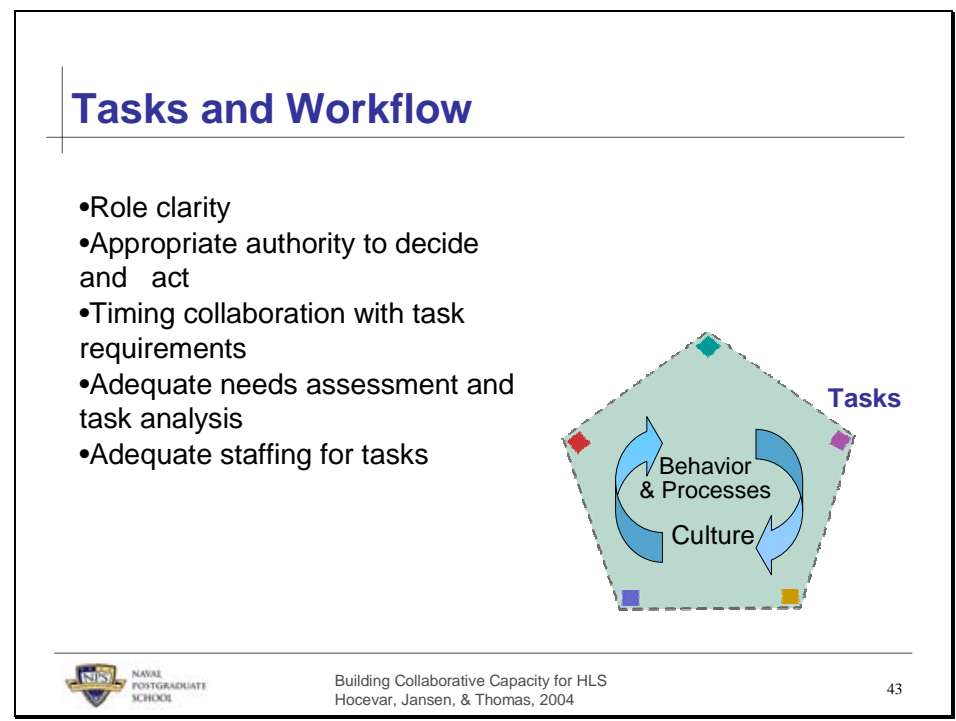


Slide 8

\section{People: Attitudes}

-Commitment to collaboration

- Tolerance for consensus process

- Openness

- Relational orientation

- Tolerance for conflict

-Respect for other parties

-Willingness to listen

-Willingness to negotiate vs.

-Arrogance

-Lack of respect

-Animosity

-Apathy

-Denial

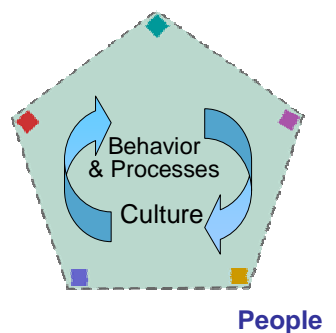

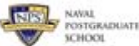


Slide 9

\section{People: Capabilities}

-Functional expertise

-Social capital within other and own organization

-Familiarity with other organizations

-Appreciation of value of other

organizations

-Empowered with needed authority

-Diversity

-Interpersonal skills

- Rehearsal in coordination

requirements

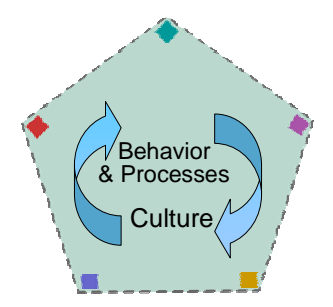

People

\begin{tabular}{ll}
\hline Bustilding Collaborative Capacity for HLS \\
Hocevar, Jansen, \& Thomas, 2004
\end{tabular}


Slide 10

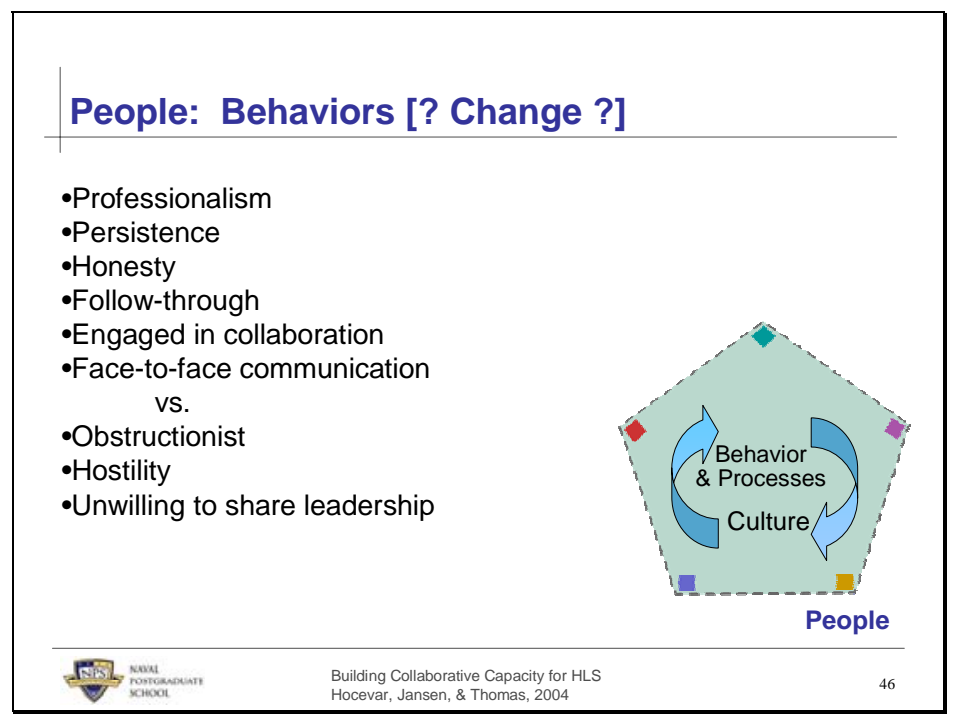


Slide 11

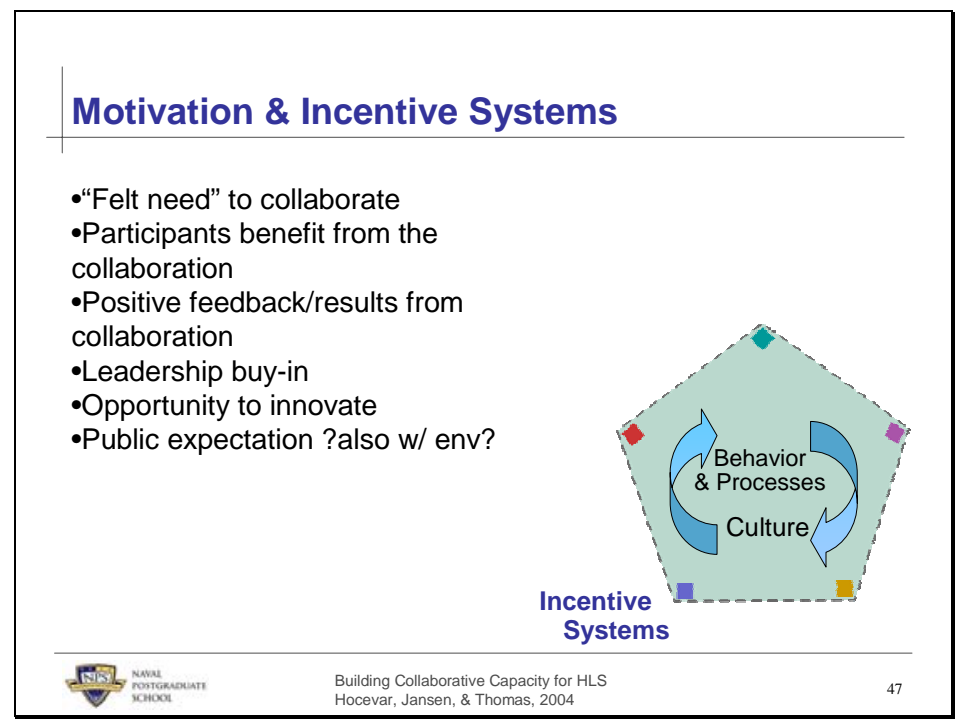


Slide 12

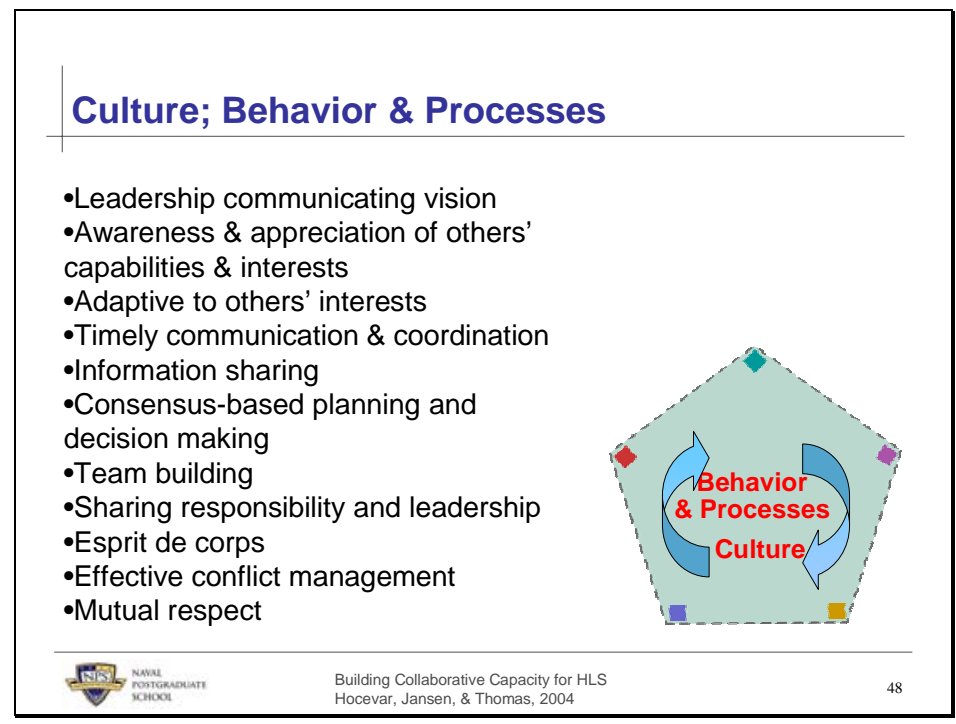


Slide 13

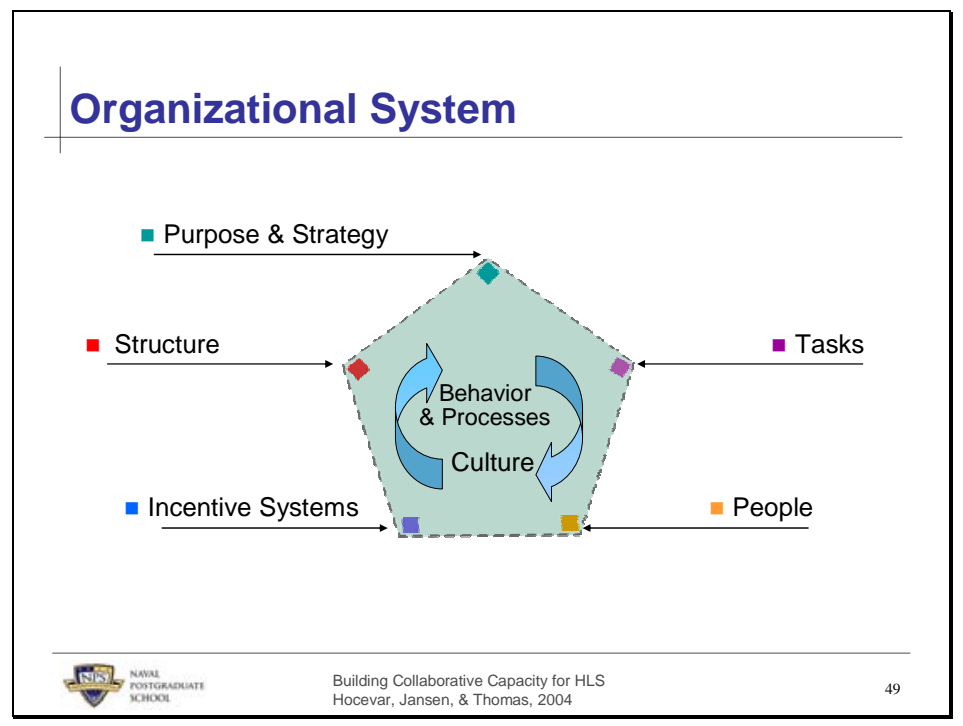

This figure presents an open systems model of the organization. The pentagon represents the organization, which is embedded in a specific environment and "problem" context. The organization is comprised of interacting elements:

Purpose and strategy

Structure

Tasks and workflow

People

Incentive systems

Culture that is reflected in behavior and processes. 
Slide 14

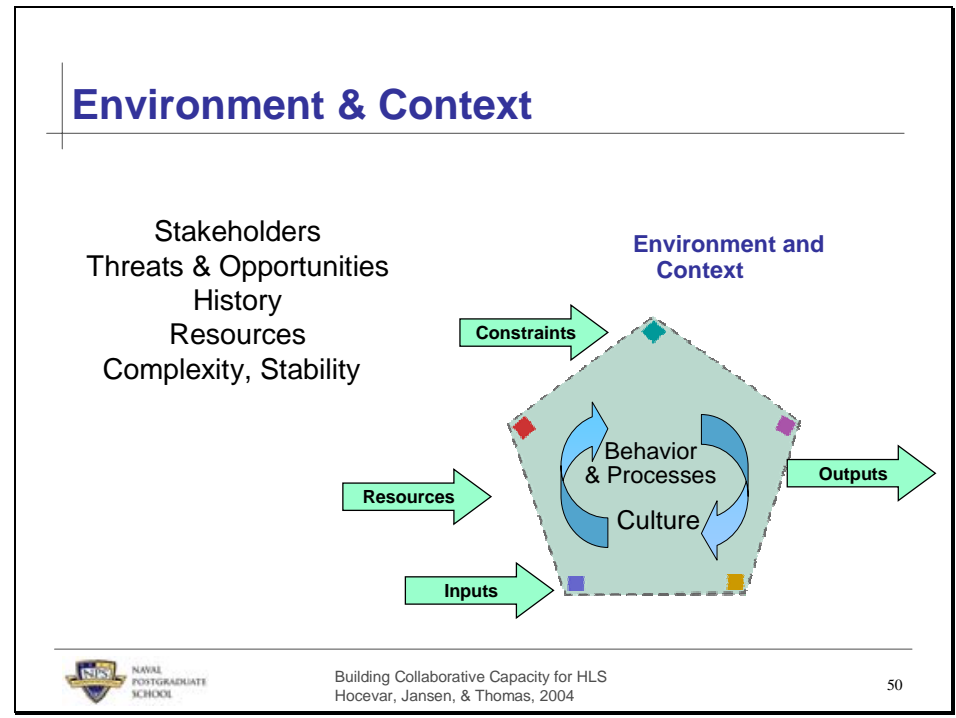


Slide 15

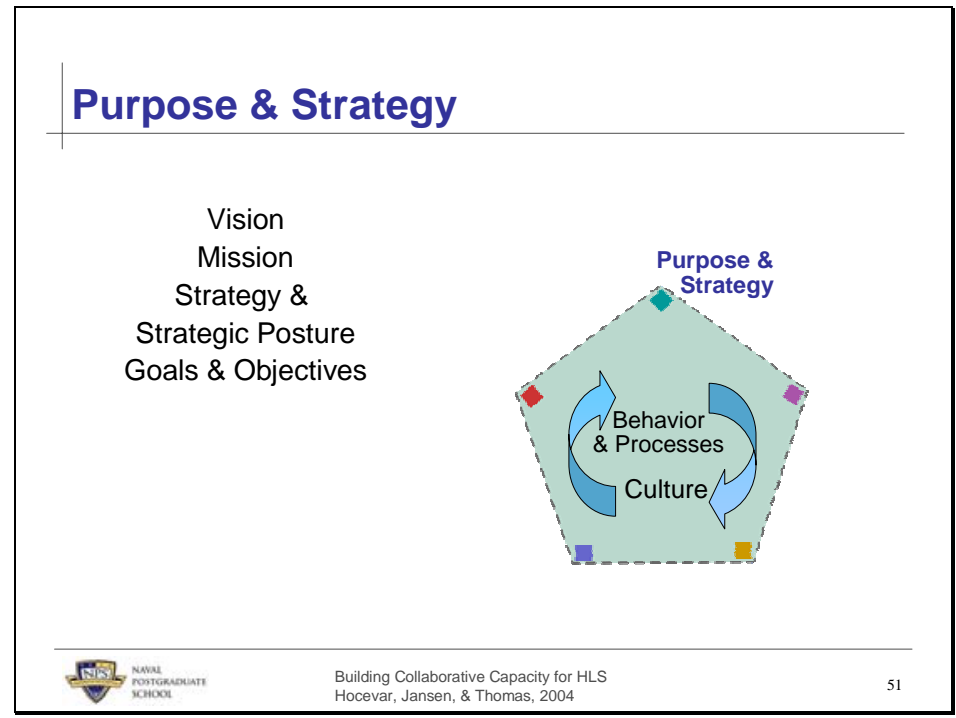


Slide 16

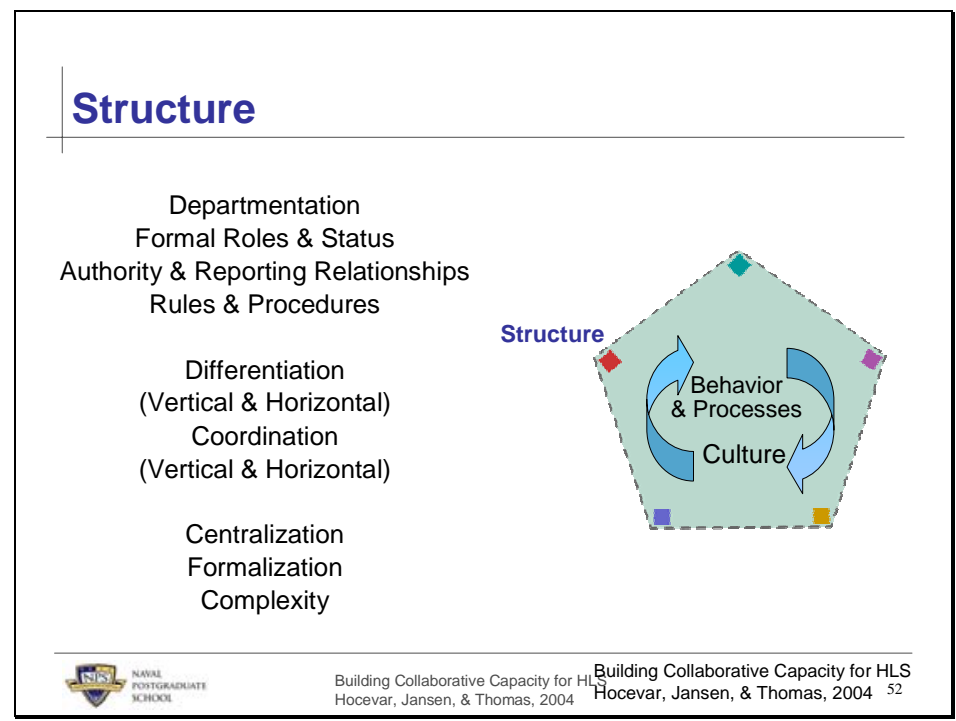


Slide 17

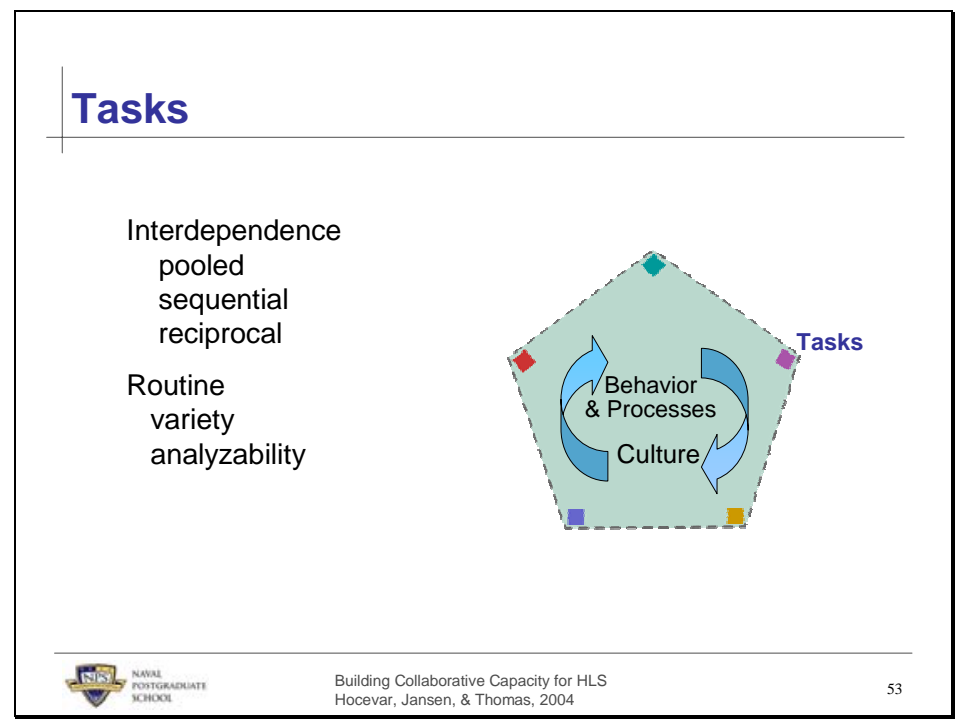


Slide 18

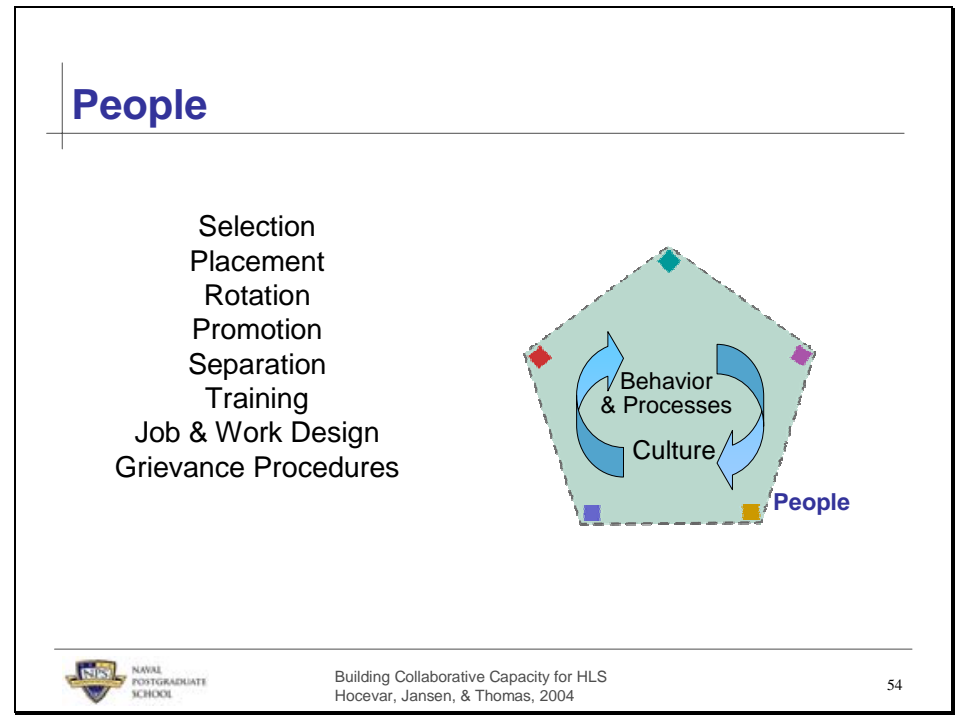


Slide 19

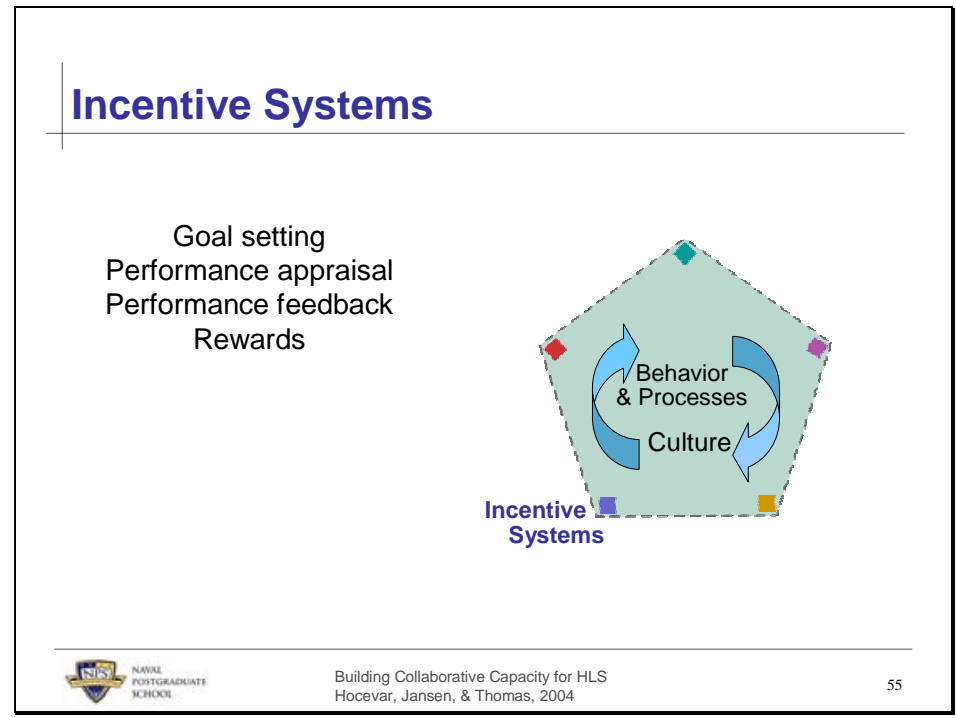


Slide 20

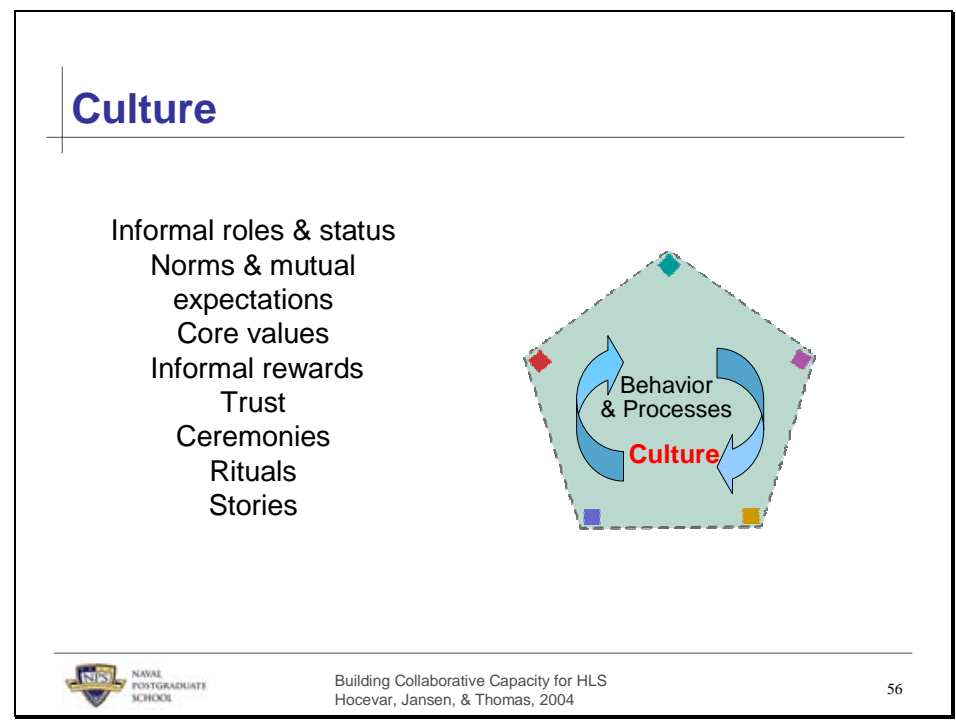


Slide 21

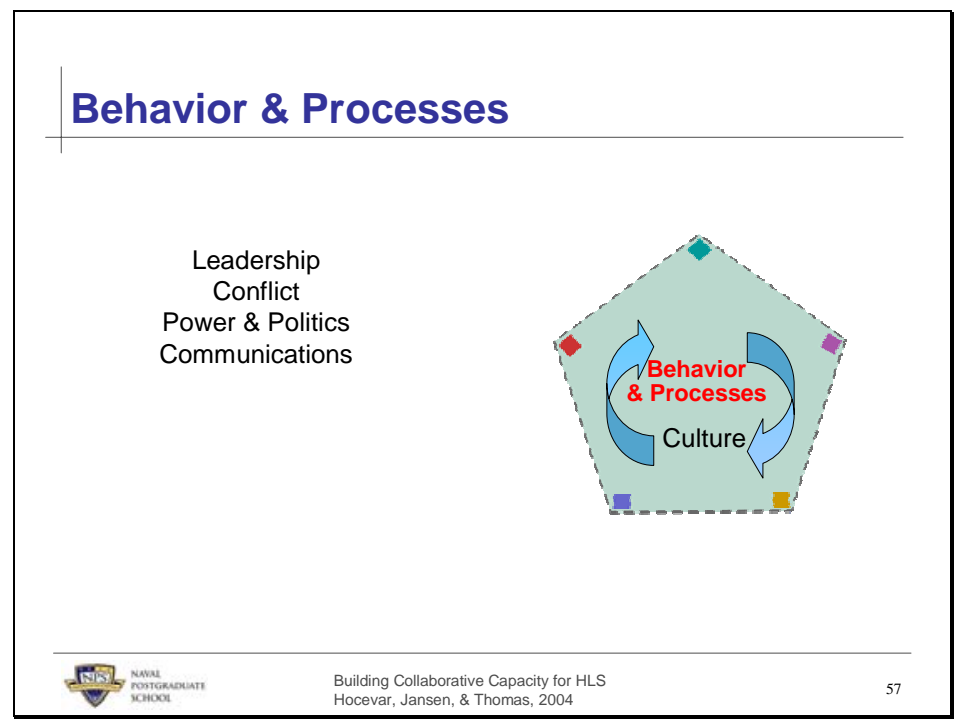


Slide 22

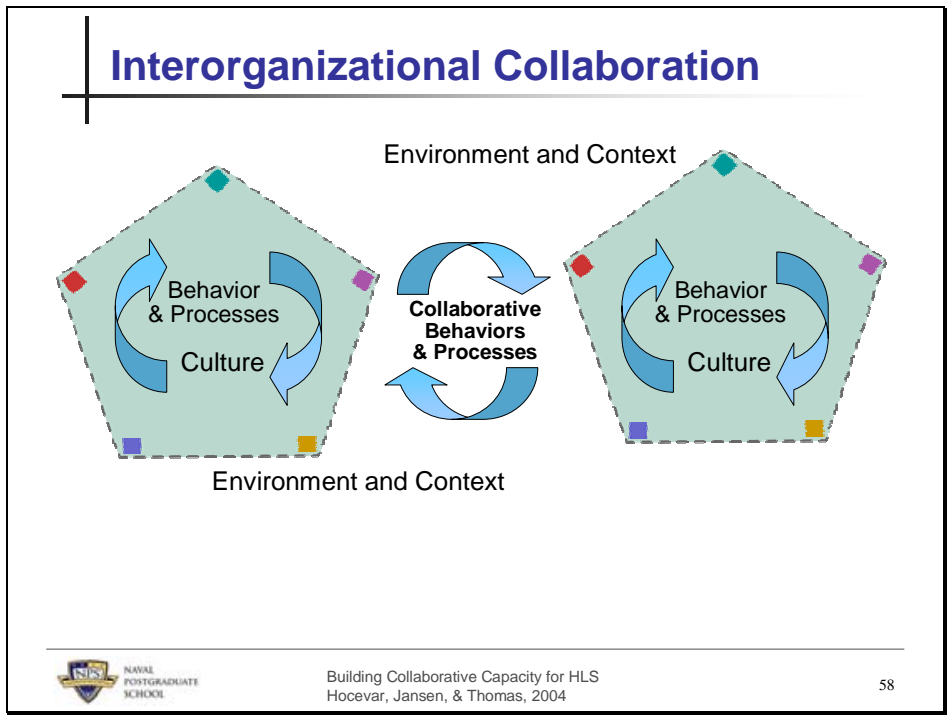


Slide 23

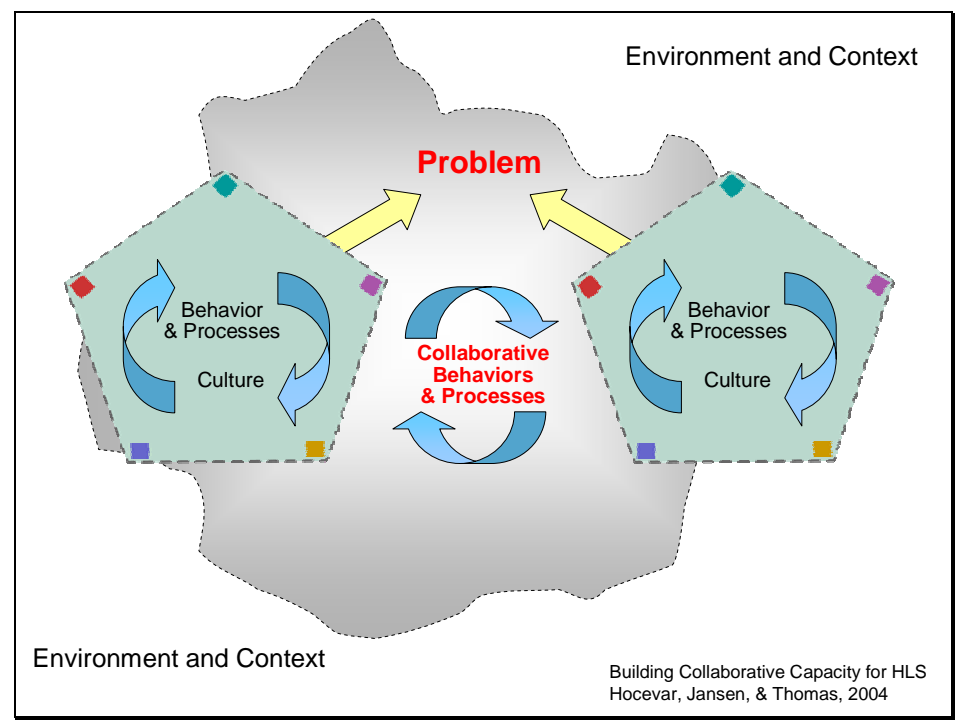

This slide represents two organizations in a given problem context. It is the simplest representation of inter-organizational collaboration for homeland security. Each organization has a functional contribution to make toward a homeland security "problem.” In addition to their unique efforts toward addressing the "problem,” these organizations have some degree of requirements for collaborative behaviors and processes to effectively address the HLS issue. 
Slide 24

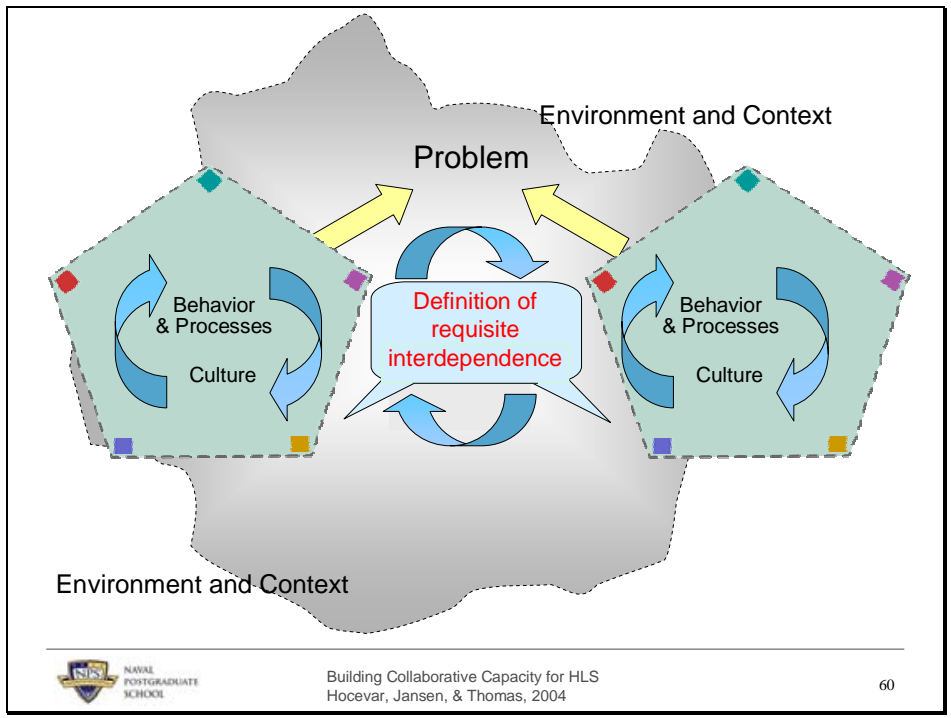


Slide 25

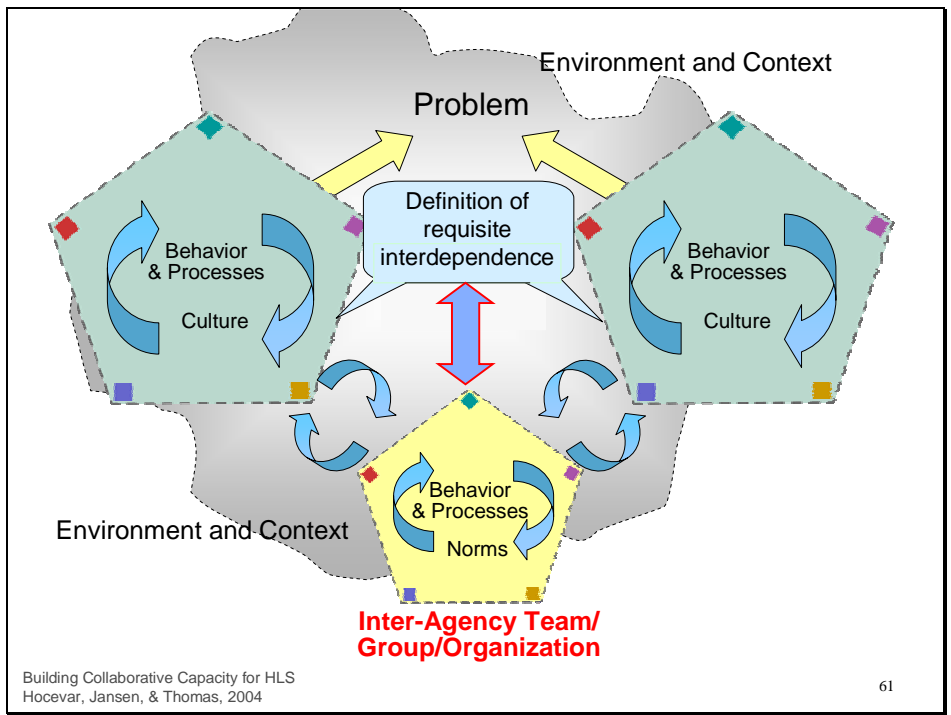


Slide 26

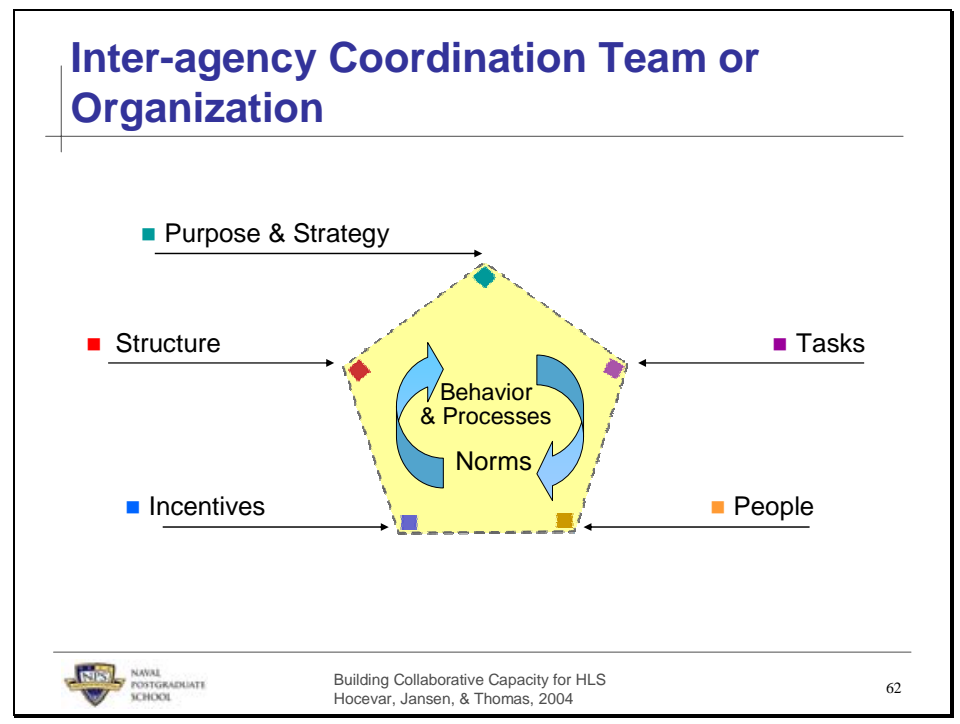


Slide 27

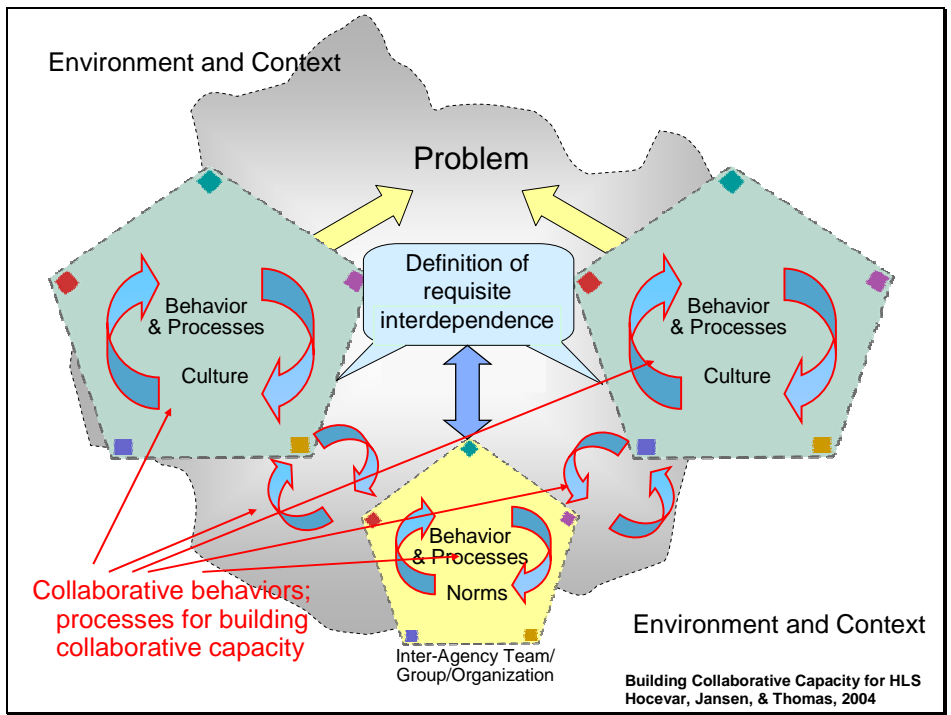


Slide 28

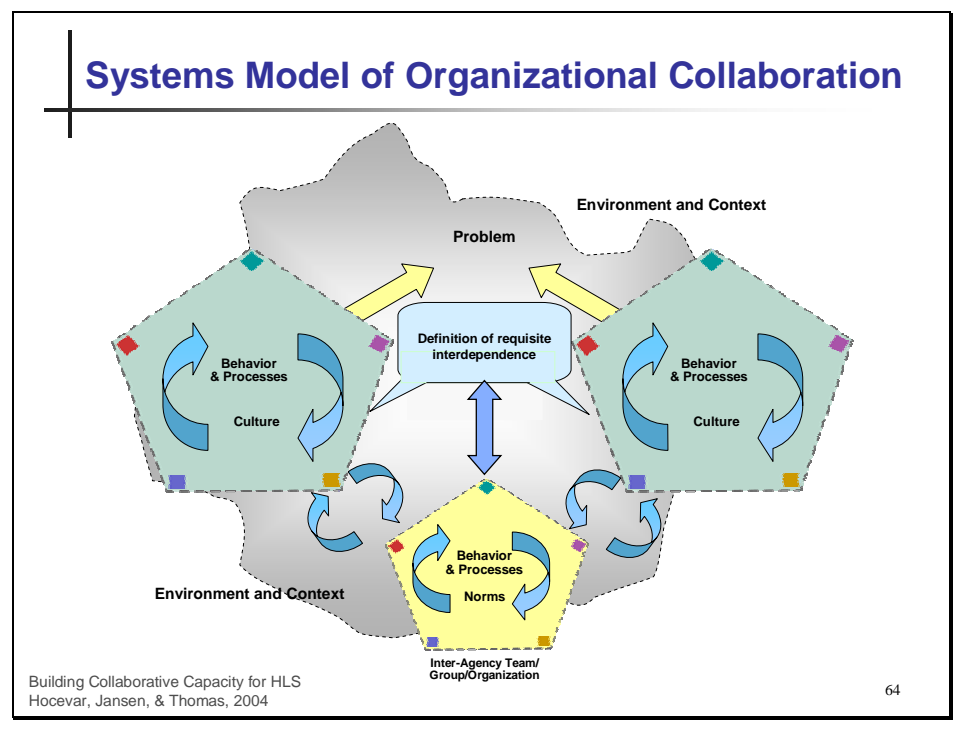


Slide 29

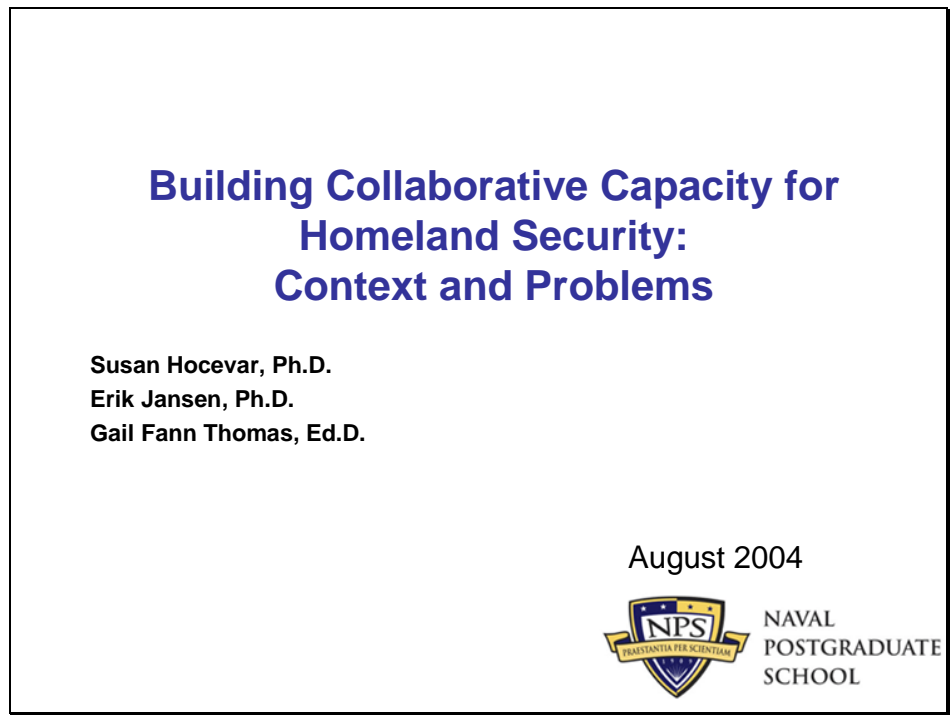


Slide 30

\section{Homeland Security}

-The National Strategy for Homeland Security is designed to mobilize and organize our nation to secure the homeland from terrorist attacks.

-This is a complex mission requiring coordinated and focused efforts among national, state and local agencies, and the private sector. 
Slide 31

\section{HLS, Turbulent Environments and Collaboration}

- The Department of Homeland Security was formed in response to turbulent, uncertain, and complex conditions.

- Such environments cannot be managed by a single organization because disruptions and their causes cannot be anticipated or averted with unilateral action. Multiple agencies are required to plan for and manage the problem domain.

- Under turbulent and complex conditions, organizations become highly interdependent in unexpected but consequential ways.

- Research shows that collaboration within and among these organizations is a logical and necessary response to turbulent and complex conditions. 
Slide 32

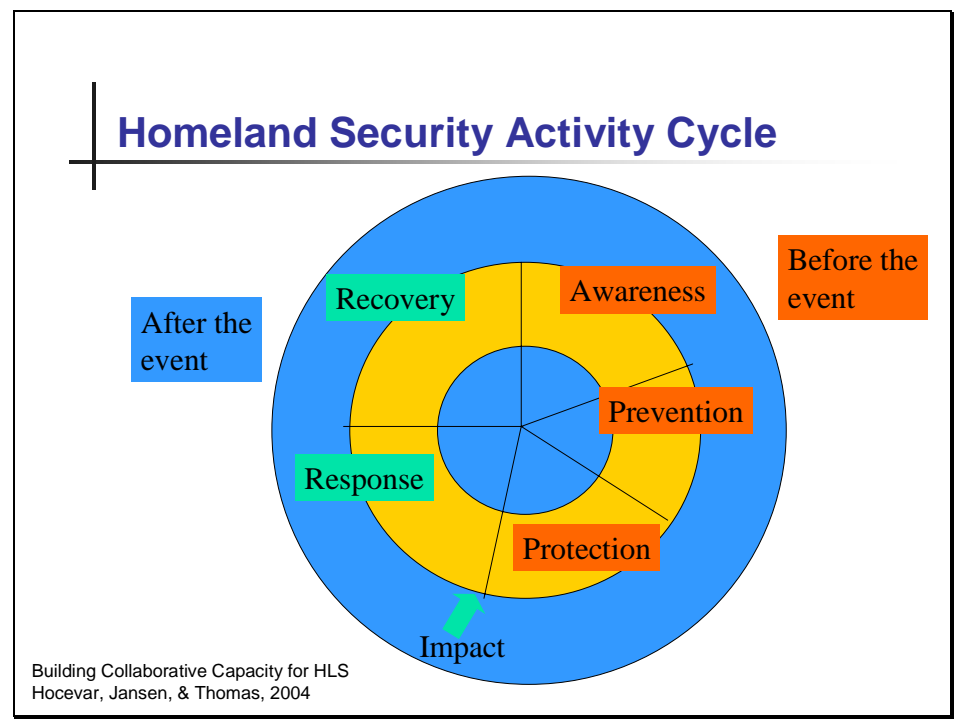

The Department of Homeland Security has identified activities that encompass their mission. These activities include: Awareness, Prevention, Protection, Response, and Recovery. In particular, this project focuses on the first three phases that would precede a terrorist attack: Awareness, Prevention, and Protection. 
Slide 33

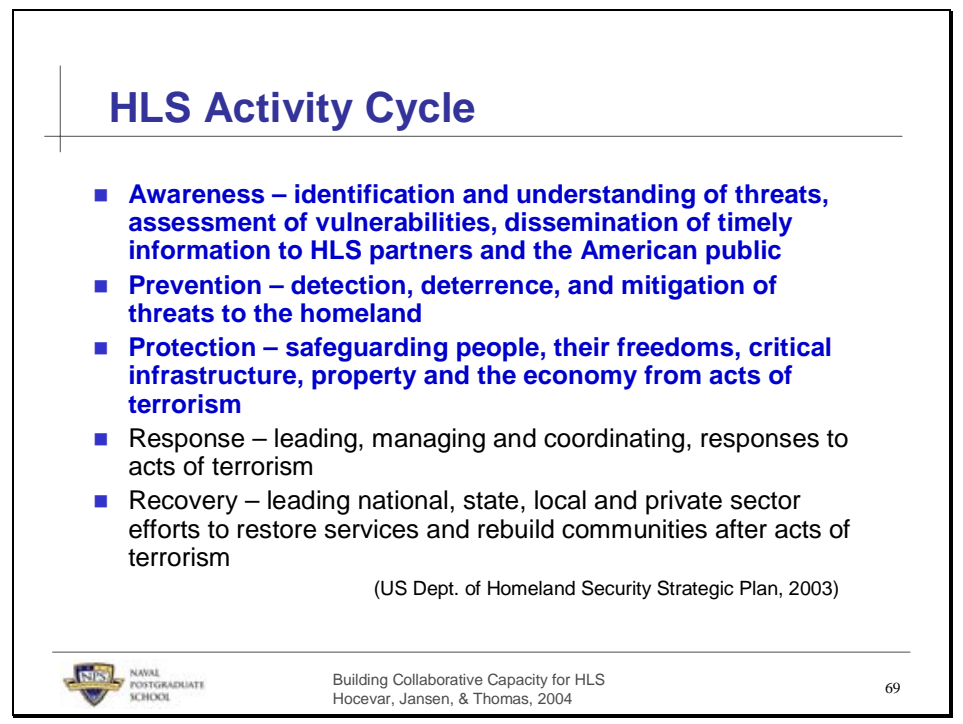

Much of the work related to disaster management has focused on the activities related to response. Fewer studies have addressed the earlier phases which, if done well, could prevent an attack or better prepare agencies to handle an attack, if it were to occur. 
Slide 34

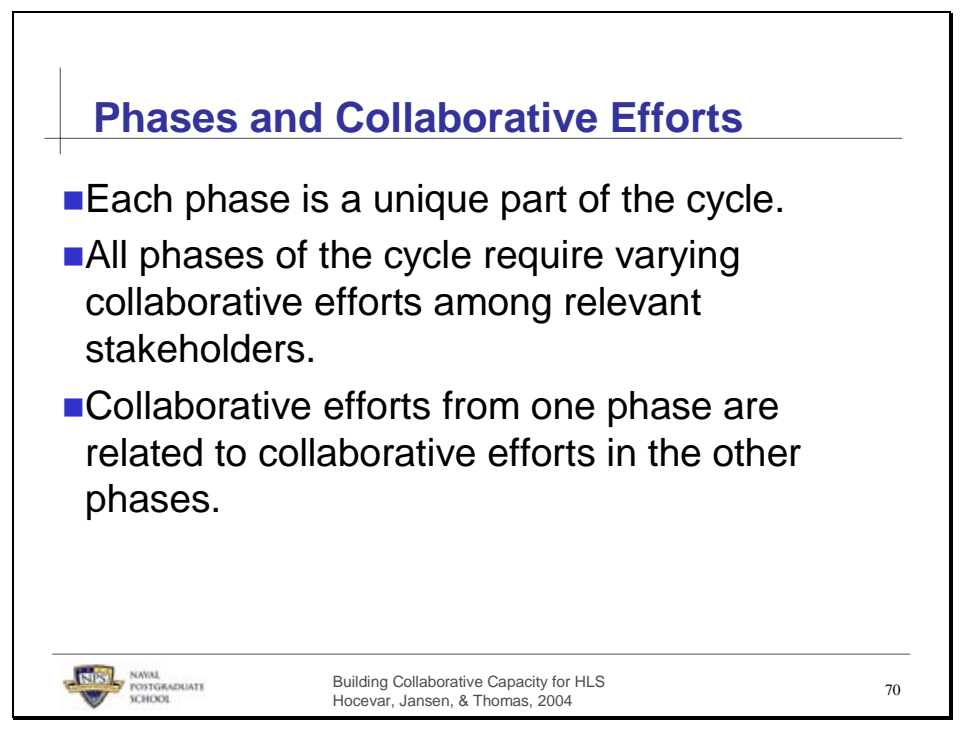

Much like emergency disaster planning, HLS has activity phases. Each phase requires involvement of a subset of stakeholders. Planners should be aware of the need to link stakeholders from one phase to another. 
Slide 35

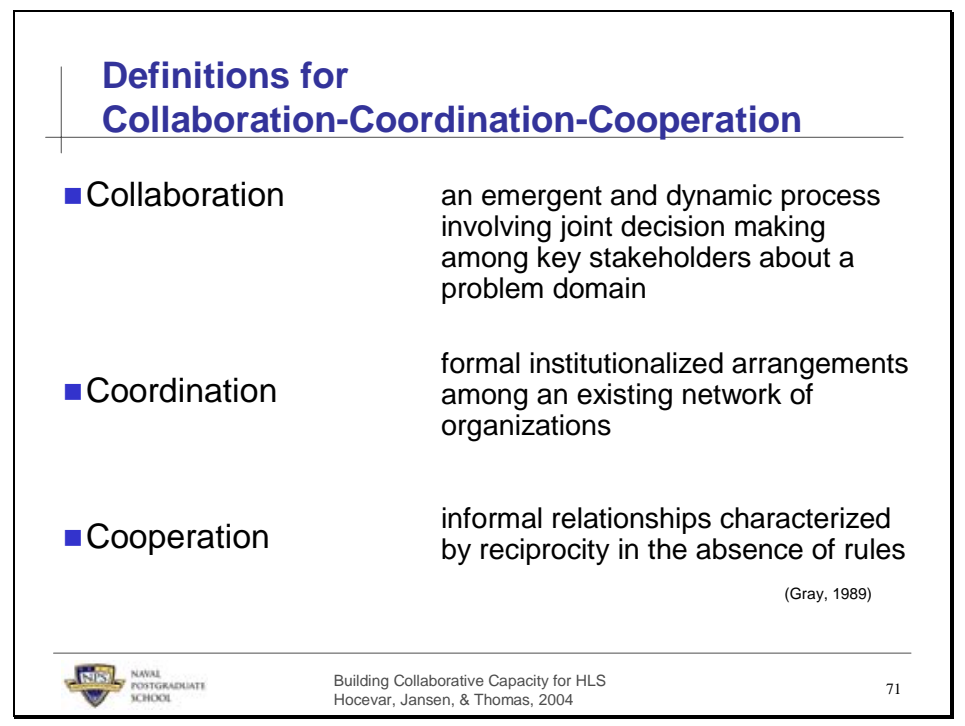

Collaboration is a dynamic process. Both cooperation and coordination can occur as part of the process of collaboration.

Coordination refers to more formal arrangements.

Cooperation refers to more informal relationships. 
Slide 36

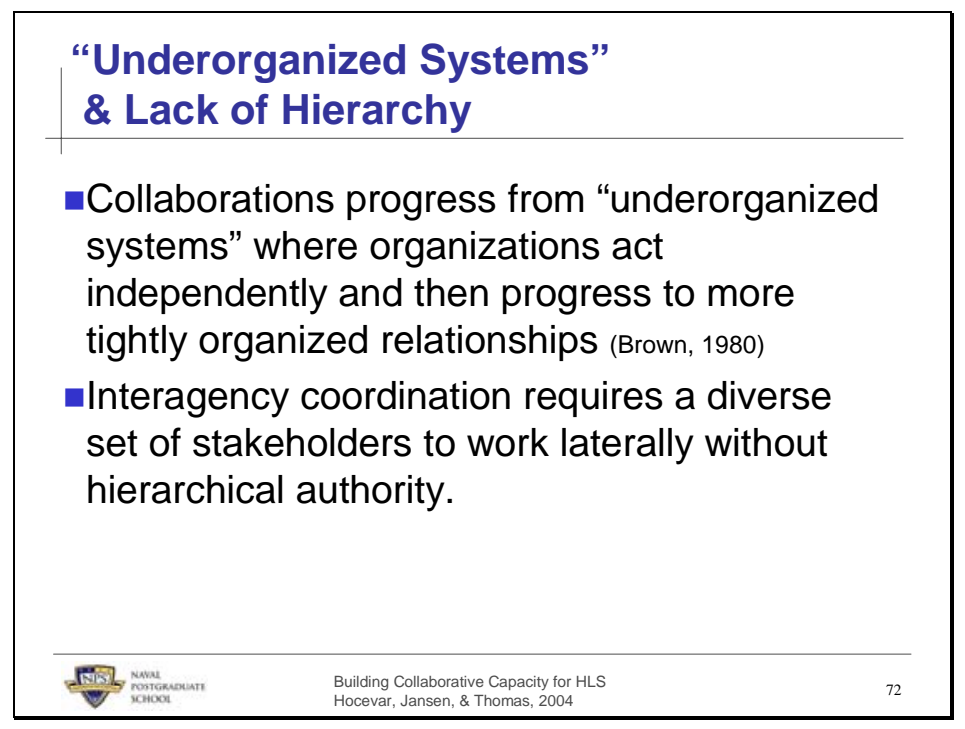

Stakeholders in "underorganized" or less structured interorganizational systems are often focused on self-interests and tend to act independently in spite of the need to coordinate their efforts in service of a superordinate goal.

In the case of Homeland Security, the various agencies are not arranged in a hierarchical structure, yet must coordinate their work to promote efficiency and effectiveness. 
Slide 37

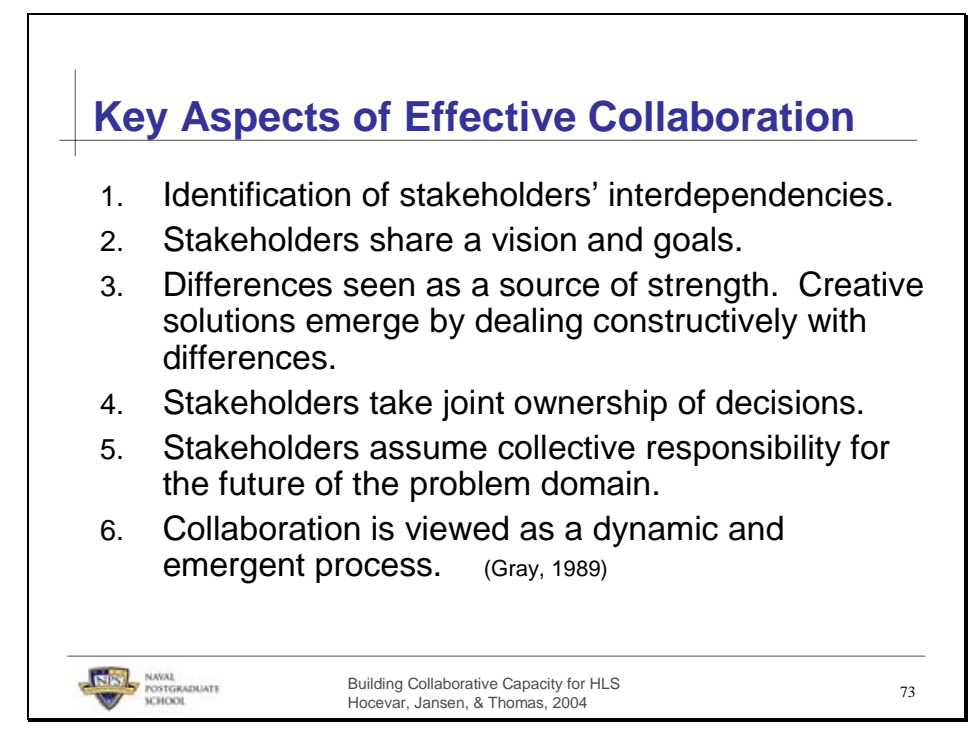

Agencies should determine when and how they might coordinate their efforts.

Here is a list of key aspects that one would find in an effective collaborative effort: Interdependencies among stakeholders are not always self evident. The initial phase of a collaboration should seek to determine the interdependencies among the stakeholders. Stakeholders share a common vision and work toward common goals. It is often difficult to appreciate differences, yet the differences are a source of creative potential. Getting past stereotypes and legitimizing each other's point of view are important steps toward successful collaboration. This diversity can lead to innovative solutions that are key to dealing with novel situations such as terrorism.

Joint ownership means that the participants in a collaboration are directly responsible for reaching agreement on a solution.

One outcome of collaboration is a set of agreements governing future interactions of the stakeholders.

Collaboration is an emergent process not a prescribed state. Collaboration creates a temporary forum within which consensus about a problem can be sought, mutual agreeable solutions can be invented, and collective action to solutions can be taken.

(Gray, 1989) 
Slide 38

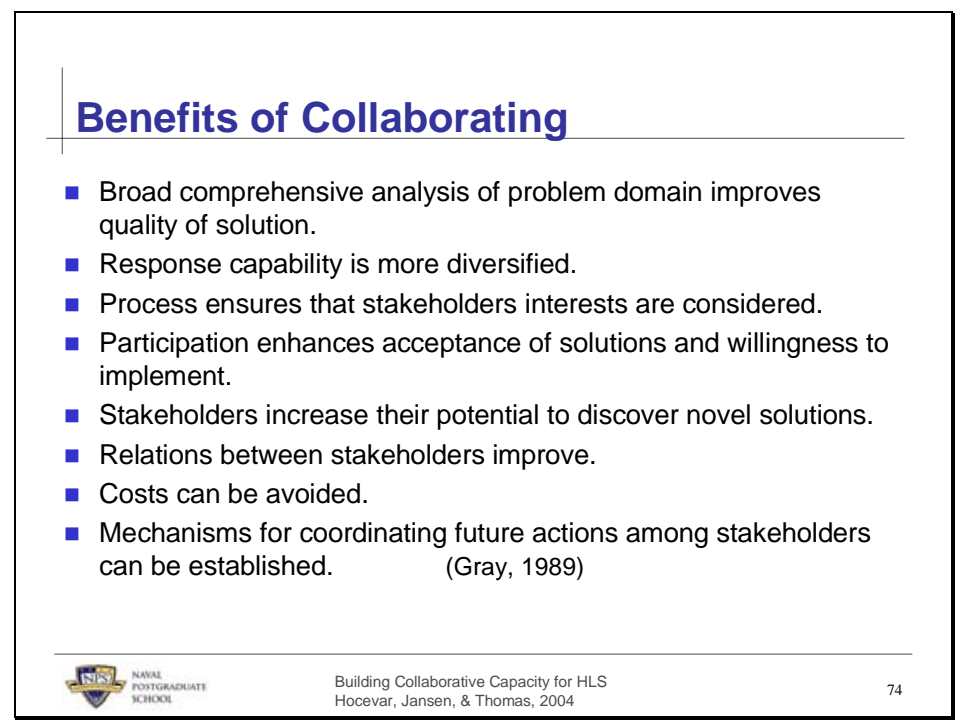

While collaboration is not a panacea, research shows that collaboration can contribute to a more effective outcome. 
Slide 39

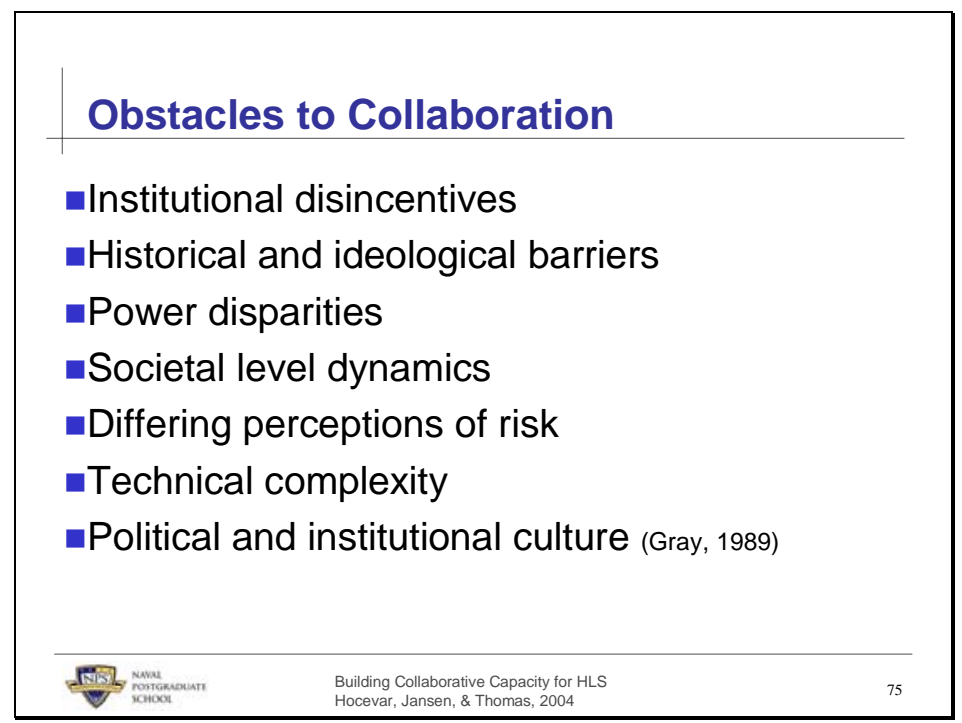

Collaborative efforts often fail despite best efforts. Numerous obstacles get in the way of a successful collaboration. These obstacles include:

Institutional disincentives. Institutions often create disincentives for collaboration. Strong advocacy often precludes stakeholders from working toward consensus or finding common ground. Participation in collaborative efforts may be seen as a drain on time and valuable resources.

Long-standing bitter relationships among stakeholders often make it difficult, if not impossible, for members to collaborate.

If members perceive power disparities, it may to difficult to encourage collaboration. Some parties may believe that they have more to gain by not collaborating. Societal cultural norms may work against collaboration. US's individualistic culture can be a barrier to collaboration.

Depending on how one views risks, very different problem definitions and solutions emerge. Differing views of risks may make it difficult to collaborate. Parties may question the accuracy of technical reports or other experts. Cultures within organizations can oppose collaboration. An organization must see collaboration as a feasible and even desirable route for formulating problem domains and 
solving problems. Organizations may dispute the management of the interagency task force.

(Gray, 1989) 
Slide 40

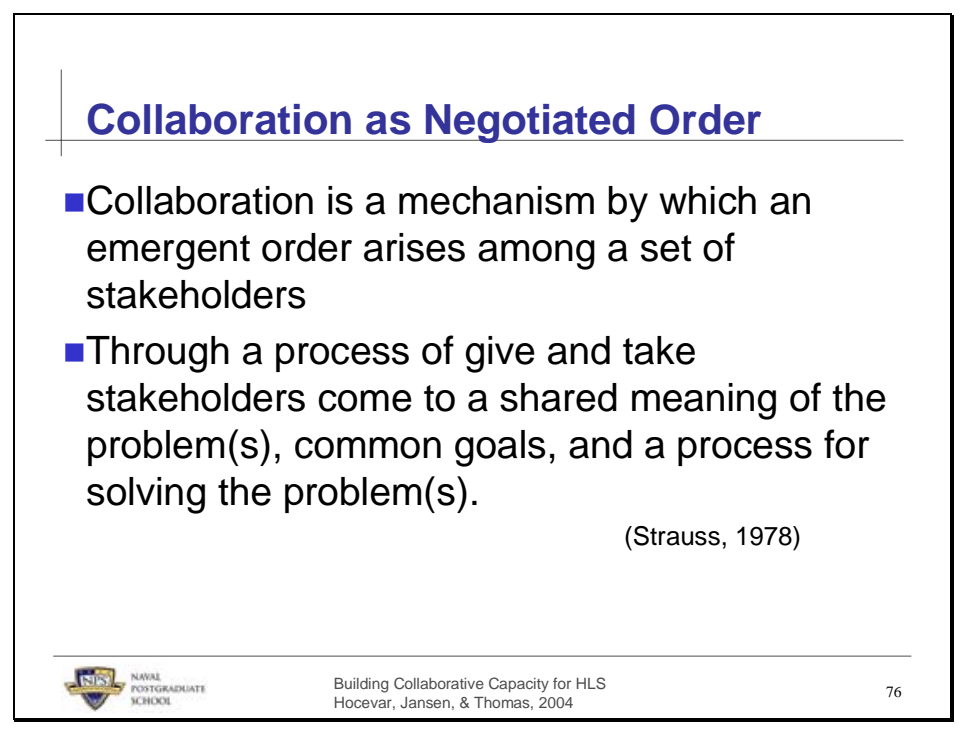

Negotiated order downplays the notion of rigid systems and instead emphasizes fluid, emerging relationships among various stakeholders. 
Slide 41

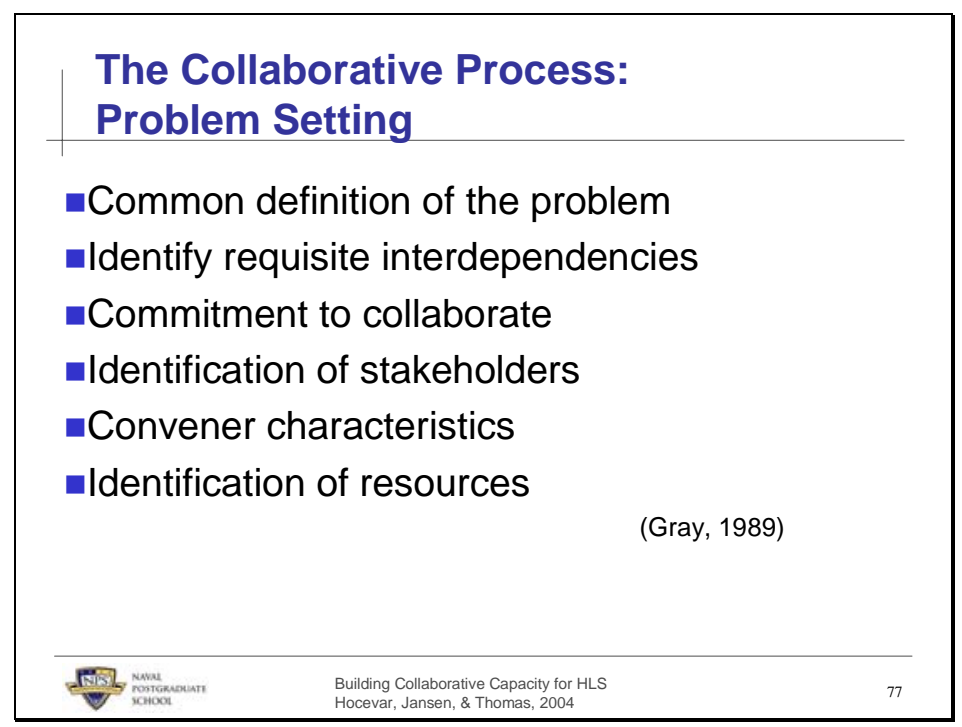

Prior to defining the problem, stakeholders should be identified, issues should be mutually determined, and a commitment should be made to address these issues. The primary objective of problem-setting is to give the situation an explicit form or identity that allows stakeholders to communicate about it and eventually act upon it. Common problem definitions are rooted in the stakeholders' interdependencies. Stakeholders need to see that their desired outcomes are inextricably linked.

Stakeholders must identify the requisite interdependencies to determine when and how the agencies can best coordinate their efforts.

Stakeholders must see a need to collaborate. A strong need to collaborate will strengthen the organization's commitment to collaborate.

A comprehensive view of the issues will help identify the full range of relevant stakeholders.

The convener of the collaborative effort must be seen as legitimate by all of the stakeholders. The convener must be seen as having the power to convene the group. Credibility is key.

Generally resources will be required for the interagency task group. Resources should be earmarked for the collaboration to proceed successfully. 
Slide 42

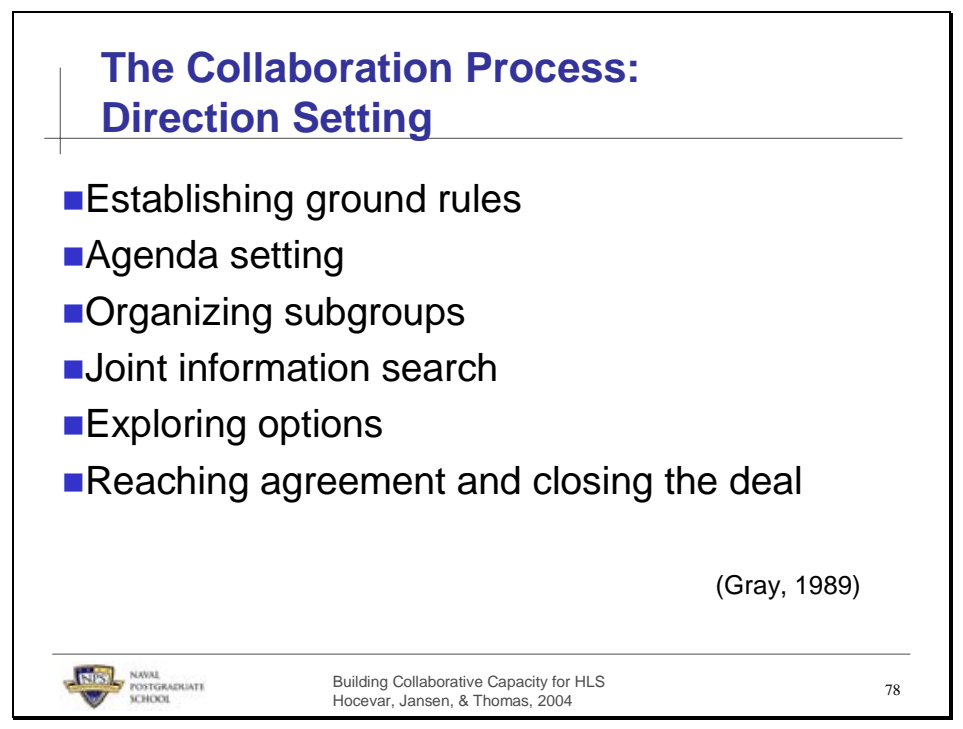

After the problem has been defined, the stakeholders can focus on setting a direction for their collaboration.

Stakeholders can establish ground rules to clarify acceptable and unacceptable behaviors. This can help reduce uncertainties and lessen misunderstandings.

An agenda can be a sensitive issue. It determines what gets included or omitted from the discussions.

Generally 12-15 member groups can be effective. Beyond that number, subgroups may be more effective for tackling issues. Stakeholders should determine when to use homogeneous caucuses and when to convene heterogeneous task forces. Purpose of the group should be considered.

Stakeholders may need to take on joint information searches to establish legitimacy in the information that is brought to the table.

Stakeholders will need to come to an agreement about the options they face. 
Slide 43

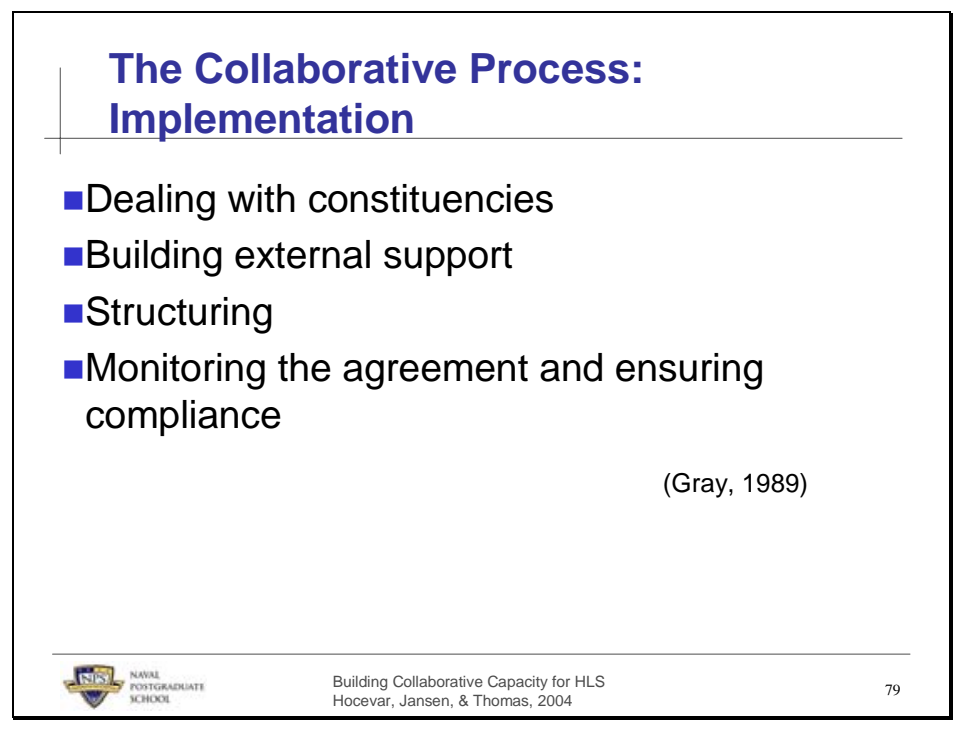

Even though the interagency task force has reached a consensus, plans can fall apart if this final stage is not considered.

Representatives have to go back to their home institutions and persuade their constituencies that the agreements are supportable.

All those who will be involved in the implementation will need to be onboard with the agreements.

Agreements may require organizations to change and/or commit resources.

Procedures should be put into place to monitor agreements and track compliance. 
Slide 44

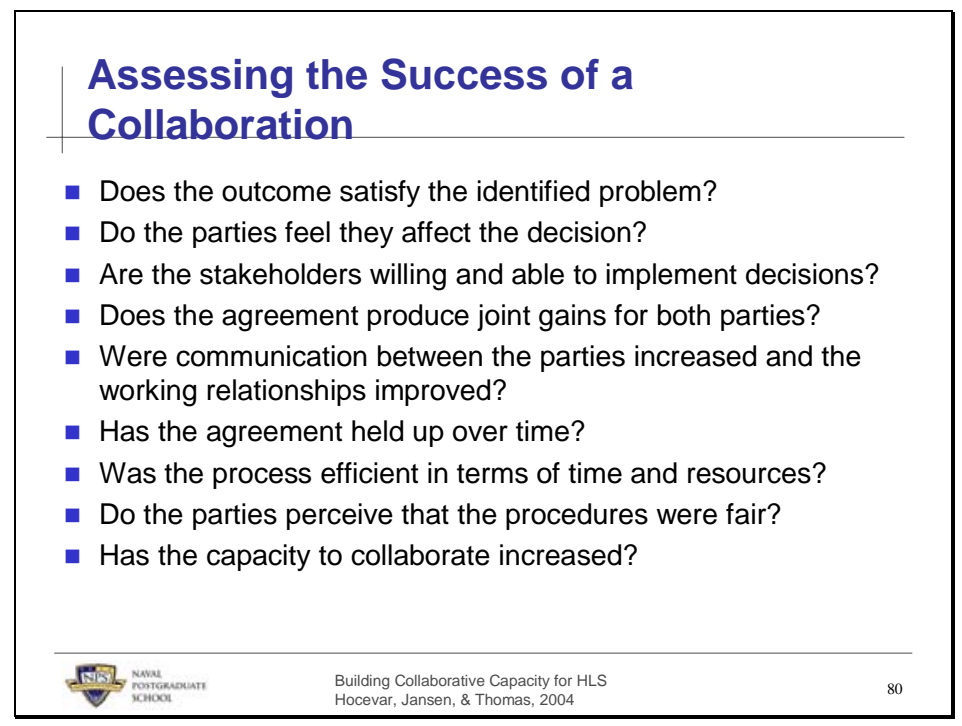

Constituents should periodically assess the outcomes of the collaboration. Here are some questions that might be useful in assessing the success of a collaboration. 
Slide 45

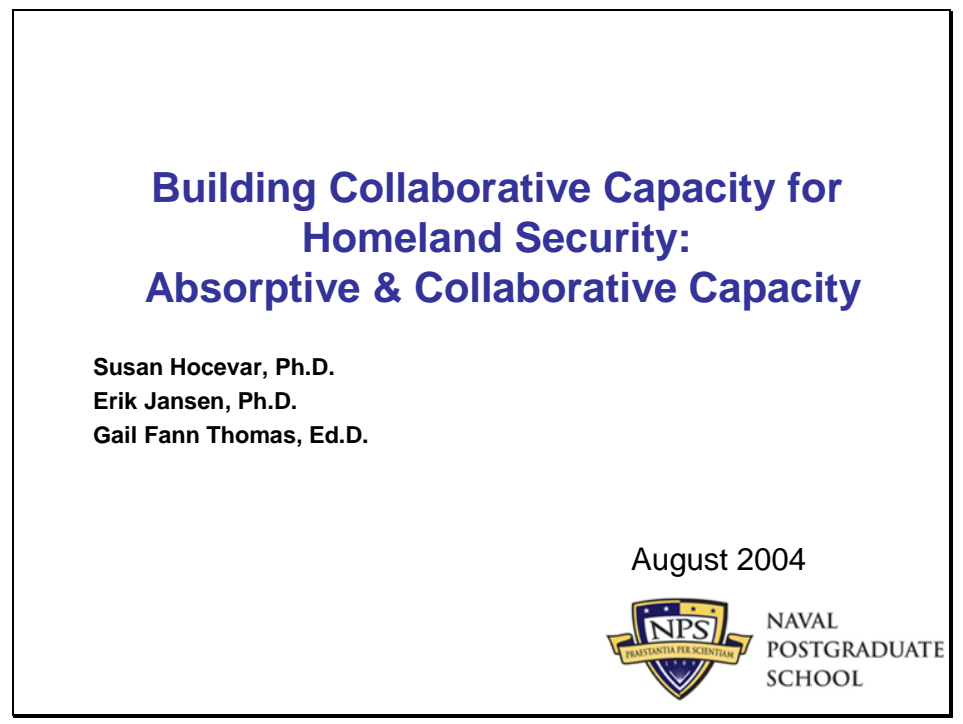


Slide 46

\section{The Capacity Concept}

The capacity concept can be applied to:

- Single organizations or agencies.

- For example, the collaborative capacity or absorptive capacity of the City's police department.

- Multiple organizations and interagency systems.

- For example, the collaborative capacity or absorptive capacity of the network of County and City law enforcement, fire protection, and public health agencies.

- As the capacity of groups depends on the capacity of its individuals, so does the capacity of interagency partnerships depend on the capacity of individual organizations.

\begin{tabular}{ll}
\hline Building Collaborative Capacity for HLS \\
Hocevar, Jansen, \& Thomas, 2004
\end{tabular}

Viewing interagency collaboration involves seeing the agency system has "conventional agency systems inside it—an operating system, an overhead and control system, a decisionmaking system” (Bardach, p. 21) 
Slide 47

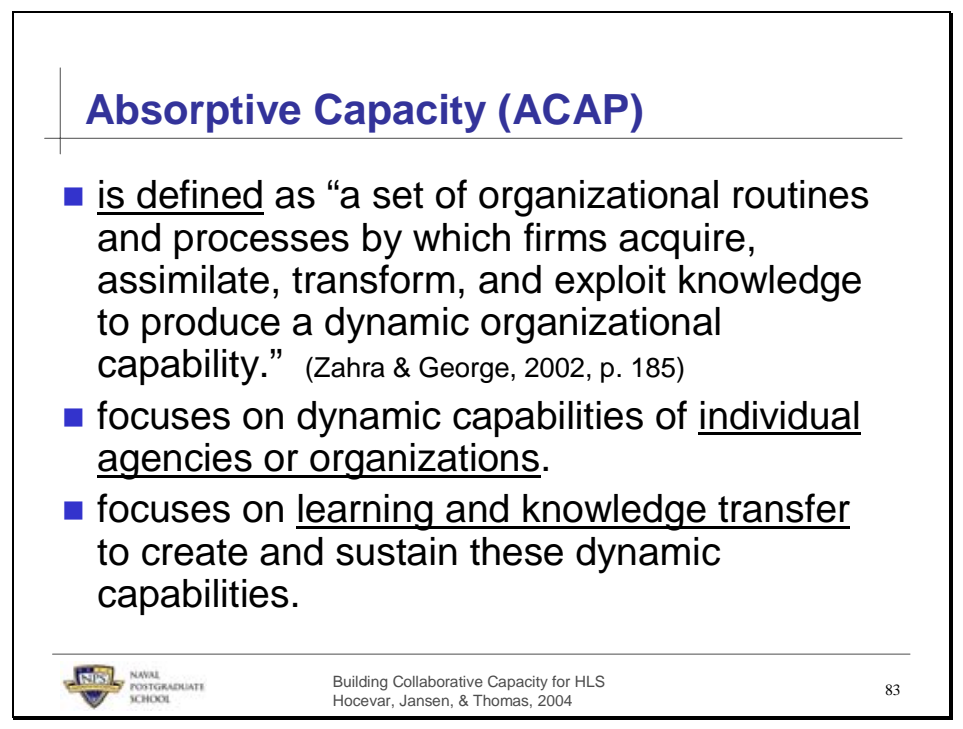

This is not simply information transfer, but knowledge transfer. Knowledge unfortunately sometimes suggests “objects” of knowledge, which ARE important. Such "know-what" is part of what is being discussed here. Equally important are "know-how": understanding how to take particular actions and generate particular results. Also important, in many cases, is "know-why": understanding the "logics" and reasons behind certain actions and their importance. 
Slide 48

\section{Absorptive Capacity (ACAP)}

\section{ACAP includes}

- Technical, functional, and operational knowledge \& skills,

- Situational awareness of where useful expertise and knowledge is outside the agency in other organizations, groups and individuals, and

- Self awareness of where useful expertise and knowledge is within the organization itself

ACAP is driven by and includes:

- The collaborative processes and capabilities that underlie the discovery and generation of such knowledge and awareness. 
Slide 49

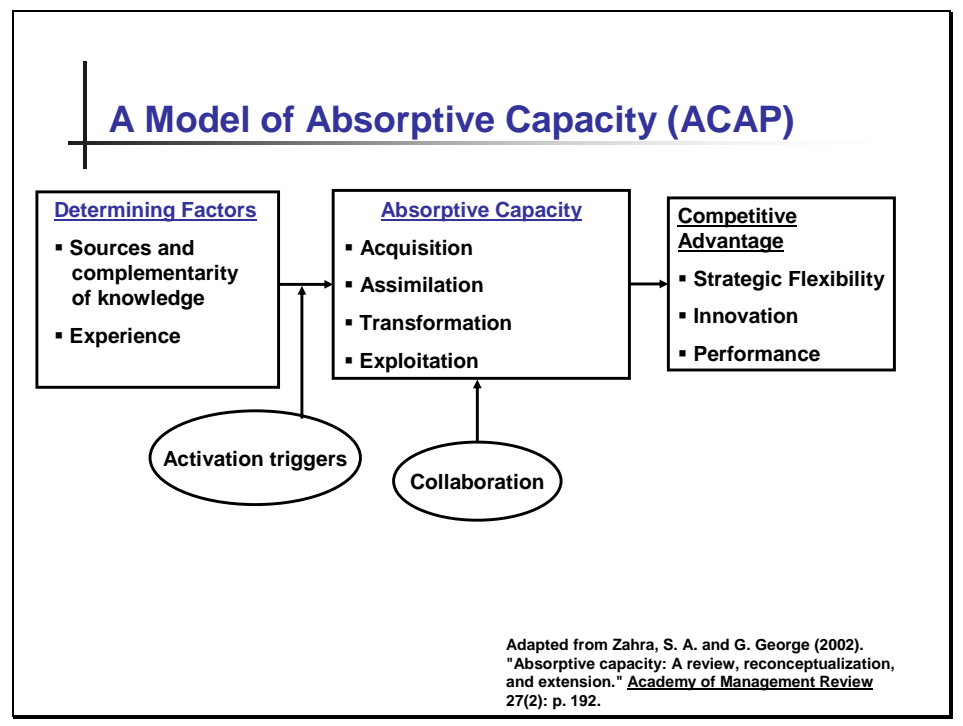

The following slides each describe the elements of this model, beginning with the outcomes of "Competitive Advantage" and working backwards through the four Absorptive Capacity Processes and then the initial Determining Factors. Subsequently both Action Triggers and Collaboration factors are discussed. 
Slide 50

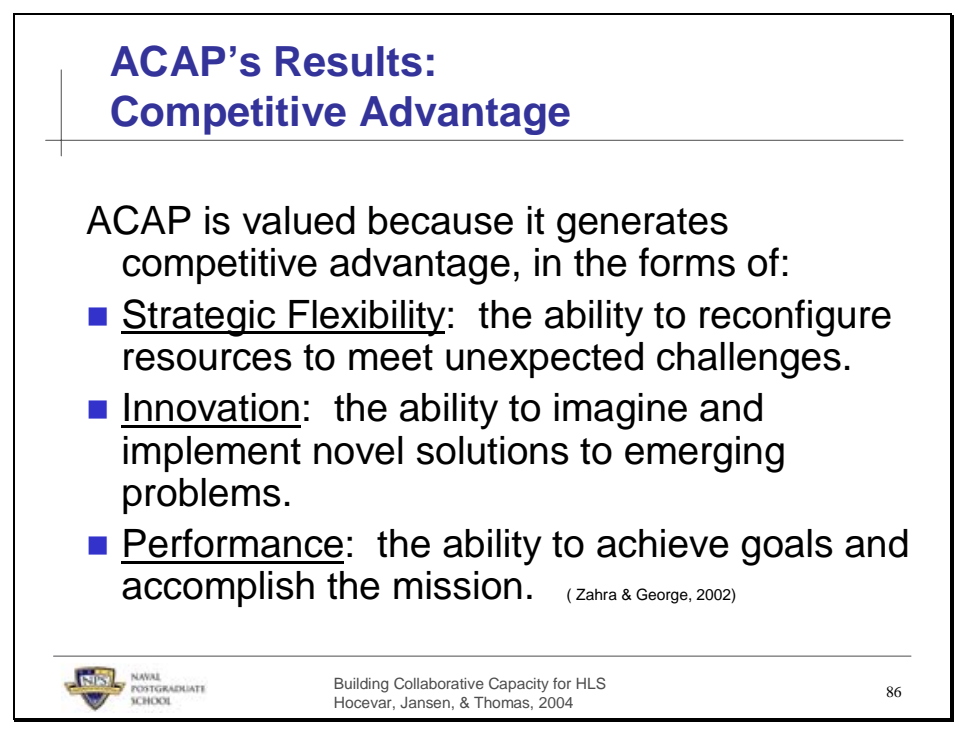

Note that "flexibility" is modified by the term strategic, thus referring to outputs.

Flexibility can also characterize internal organizational processes and contribute to the likelihood that knowledge, once acquired, will be assimilated into the organization and transformed into actionable knowledge. 
Slide 51

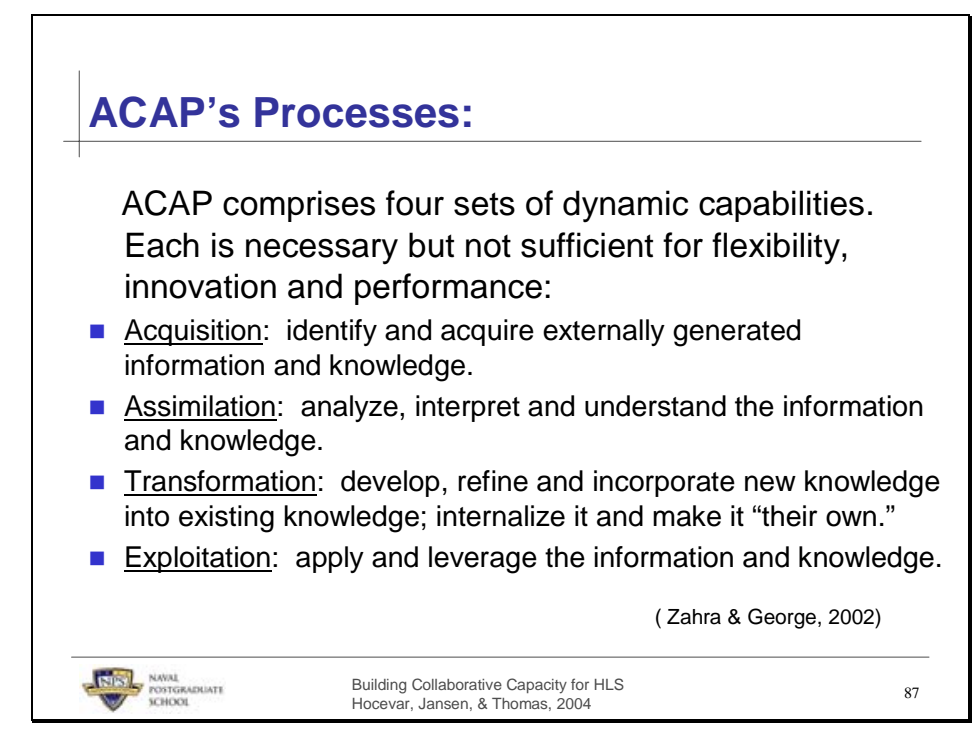

Assimilation and Acquisition are - ideally - related processes. Assimilation can provide feedback to redirect the acquisition process.

Similarly, there is feedback between exploitation and transformation. The activities of attempting to exploit knowledge contribute to and are part of understanding the transformation process. The various feedback processes are illustrated in the model below.

Transformation also can be described as: Learning a new frame of reference (without necessarily abandoning existing frames of reference) for looking at existing problems and capabilities. 
Slide 52

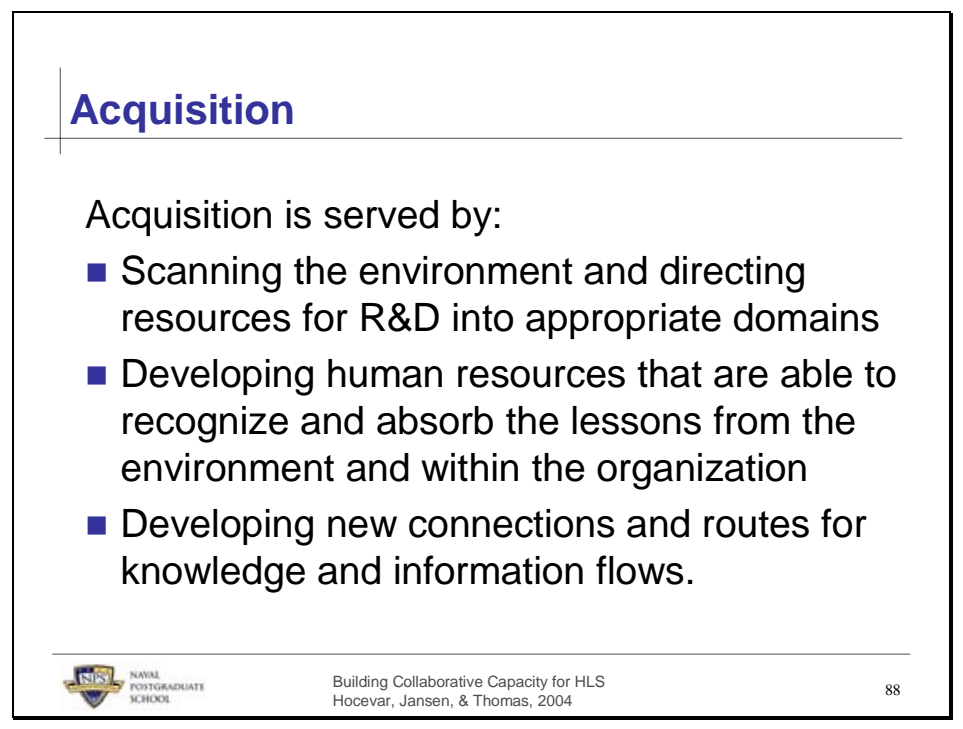

Each of these clearly are management implications of the theory. For example, the 9/11 commission hearings revealed the primary weaknesses and challenges reported by agencies involve bullet number two, along with the critical issue of retaining those human resources once they do develop their individual absorptive capacities and collaborative capacities. 
Slide 53

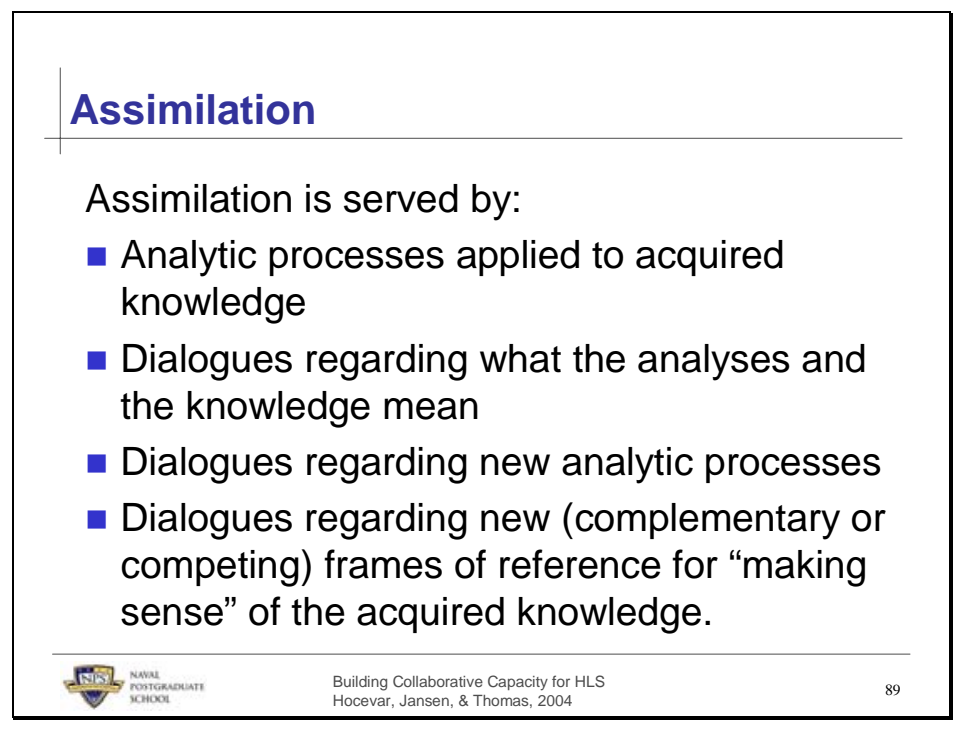

Each of these have management implications. 
Slide 54

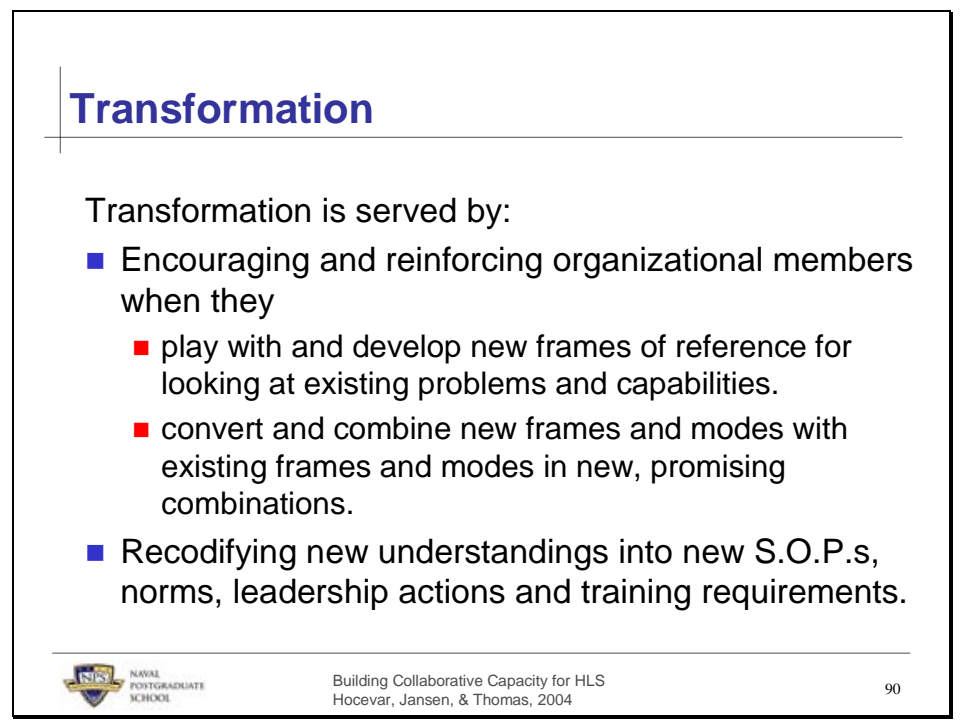

Each of these have management implications. 
Slide 55

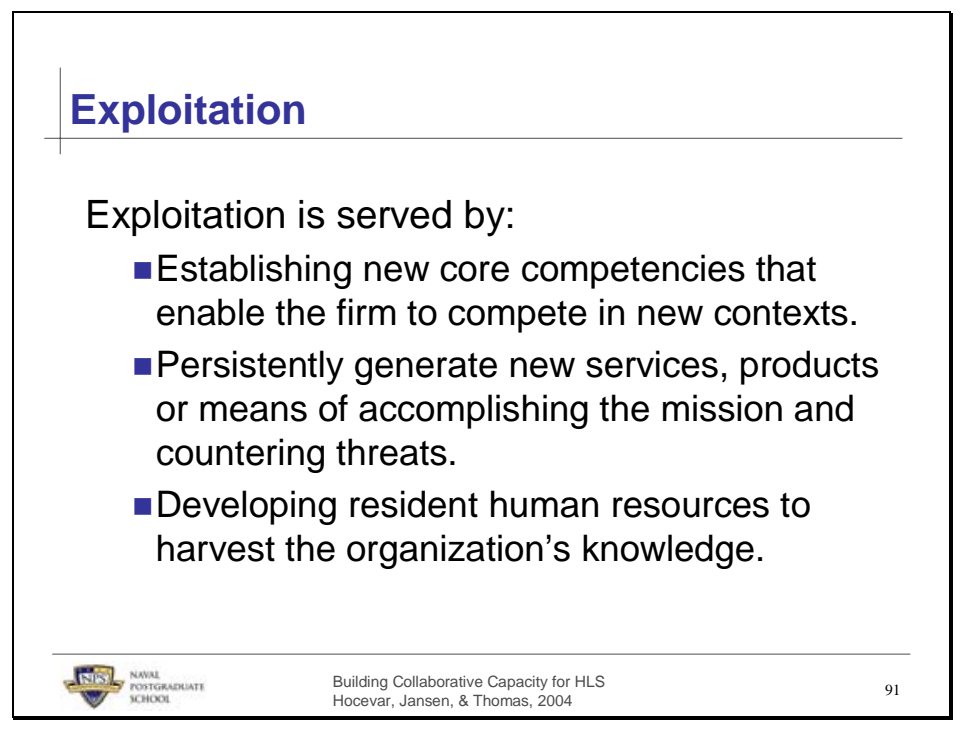

Each of these clearly are management implications of the theory. For example, the 9/11 commission hearings revealed the primary weaknesses and challenges reported by agencies involve bullet number two, along with the critical issue of retaining those human resources once they do develop their individual absorptive capacities and collaborative capacities. 
Slide 56

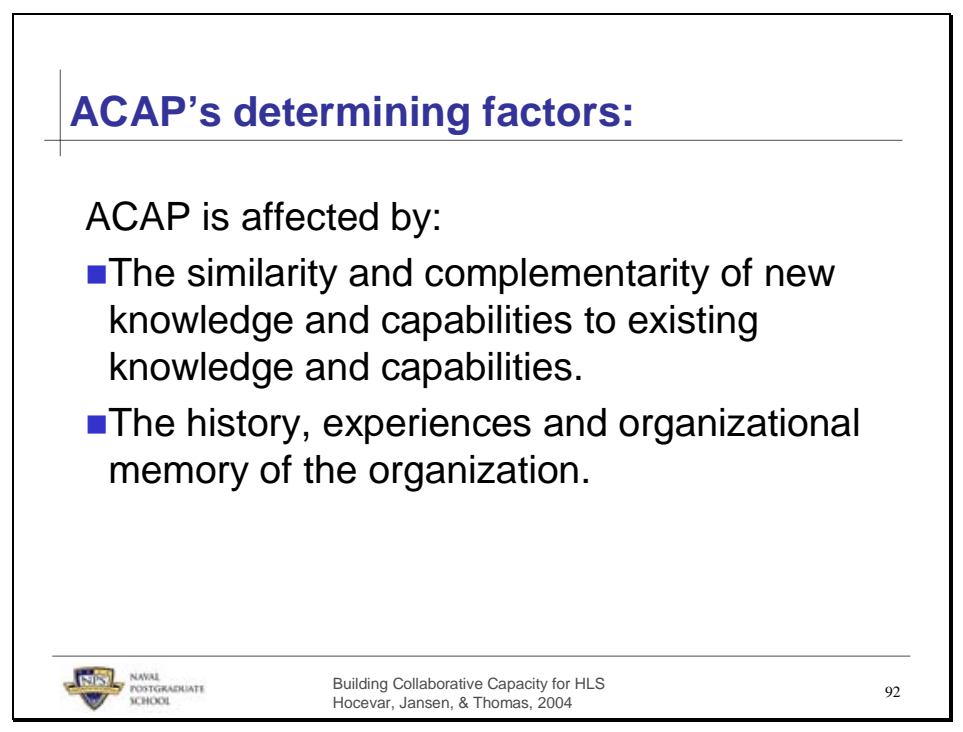

New knowledge must be incorporated on and developed based on existing knowledge (ACAP).

Research suggests that experience often matters more than asset investments. Pennings and Harianto (1992) 


\section{Slide 57}

\begin{tabular}{|l|}
\hline Absorptive Capacity (ACAP) \\
Looking within the organization, ACAP is enhanced by \\
Homogeneity of knowledge (i.e., overlapping \\
knowledge sets), which promote internal familiarity, \\
communication, and knowledge sharing. \\
Looking at the organization's external relationships, \\
ACAP is enhanced by \\
Diversity of knowledge, (i.e., non-overlapping \\
knowledge sets), which are able to recognize \\
relevance in external knowledge and work to acquire \\
that relevant knowledge. \\
The "ideal knowledge structure" of the organization thus \\
involves managing the tradeoffs between diversity and \\
commonality of knowledge, especially of units and \\
persons at critical organizational interfaces. (conen \& Levinthal, 1990) \\
\hline Building collaborative capacity for HLs \\
Hocevar, Jansen, \& Thomas, 2004
\end{tabular}


Slide 58

\section{Activation Triggers:}

Activation triggers (which include crises):

- "encourage or compel a firm to respond to specific internal or external stimuli"

- shape the intensity and scope of efforts to change (zanra a George, 2002)

- shape the locus of the search and the type of information and knowledge sought.

- Leadership has a critical role in creating a "felt need" by interpreting and emphasizing the importance of activation triggers. 
Slide 59

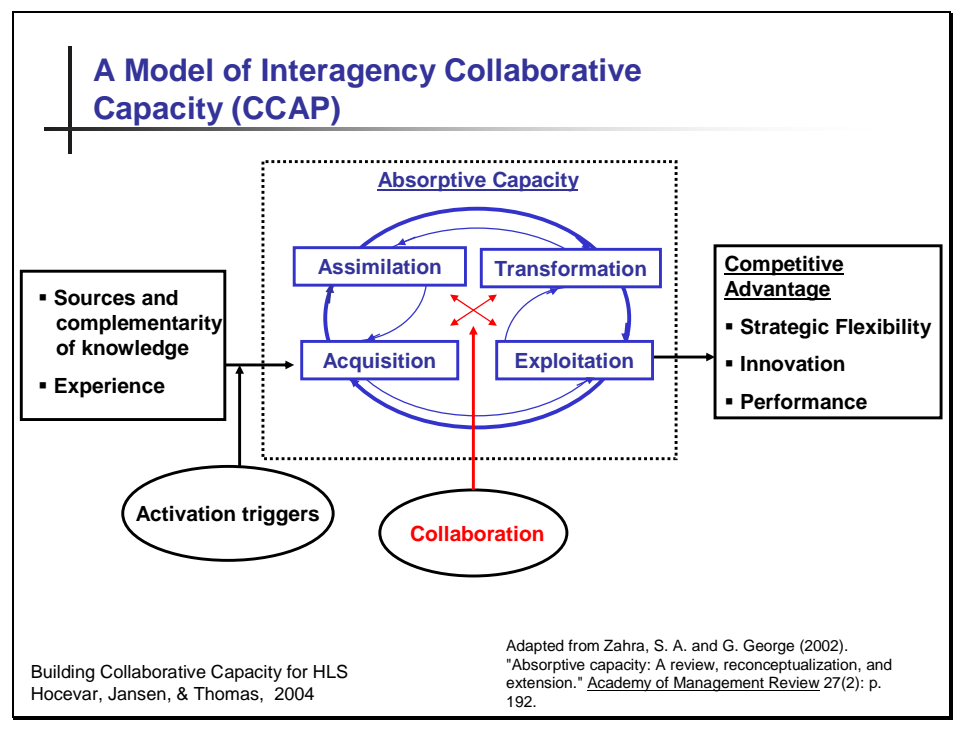

This model illustrates the four processes that contribute to absorptive capacity. It includes the additional factor of collaboration to represent the need to apply this concept in the context of homeland security. In this context, absorptive capacity should be evaluated in terms of the individual participating agencies as well as the interagency system. Thus, the concept of absorptive capacity can be applied to the domain of collaboration to generate a model for Interagency Collaborative Capacity. 
Slide 60

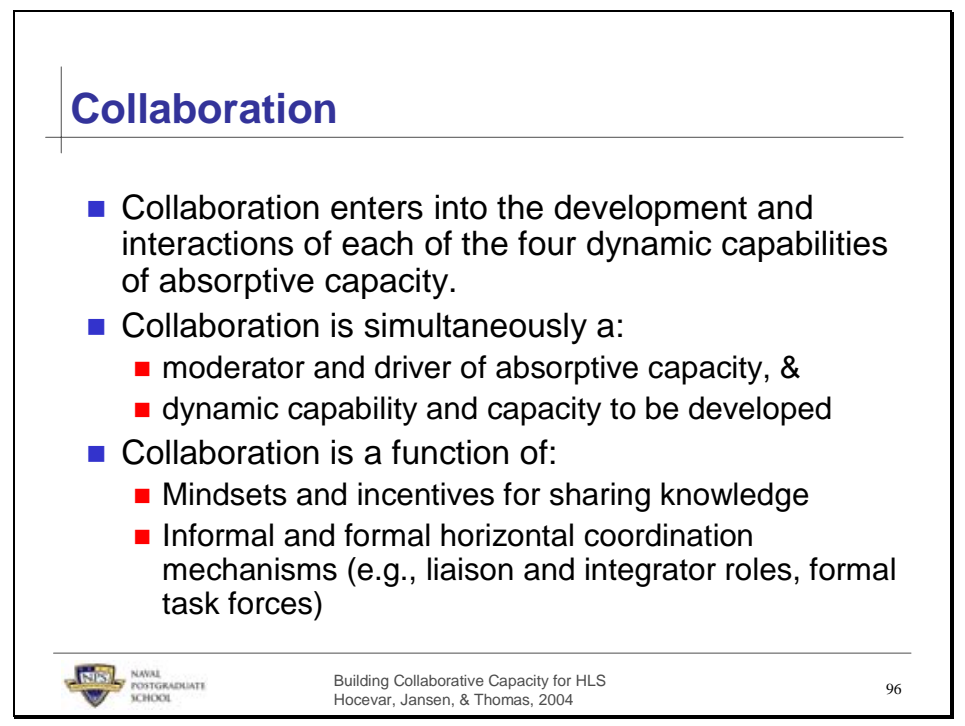

Zahra and George use the term "social integration" where we have used collaboration.

Social integration also can be conceptualized as a result of previous socialization experiences. 
Slide 61

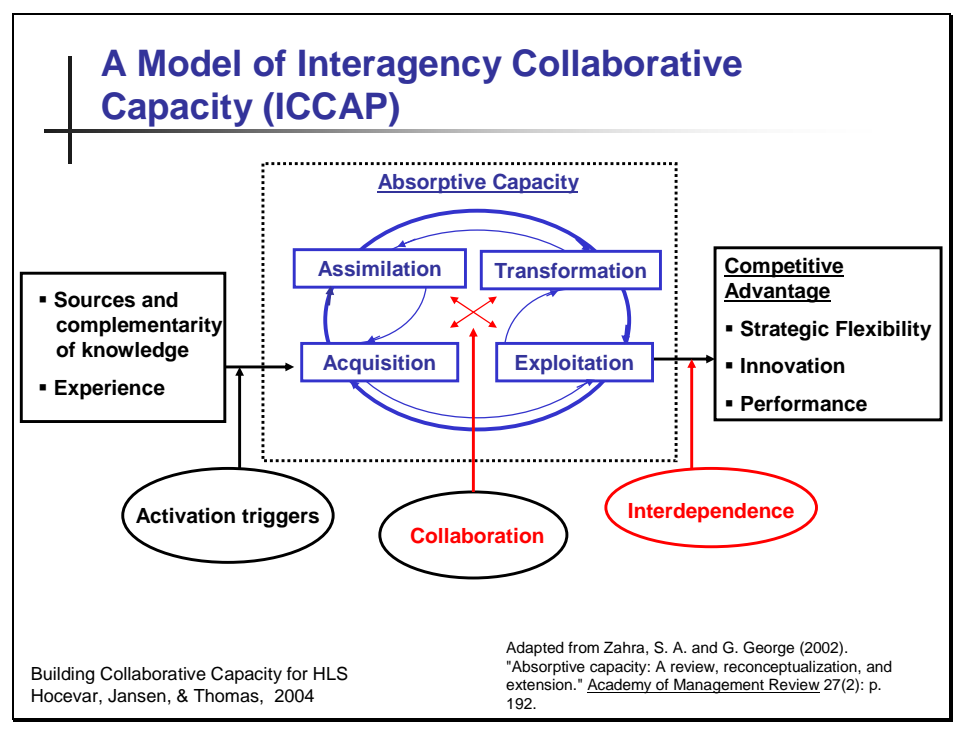

This slide incorporates the concept of interdependence as a mediating factor between Interagency Collaborative Capacity and the desired outcomes of collaboration. 
Slide 62

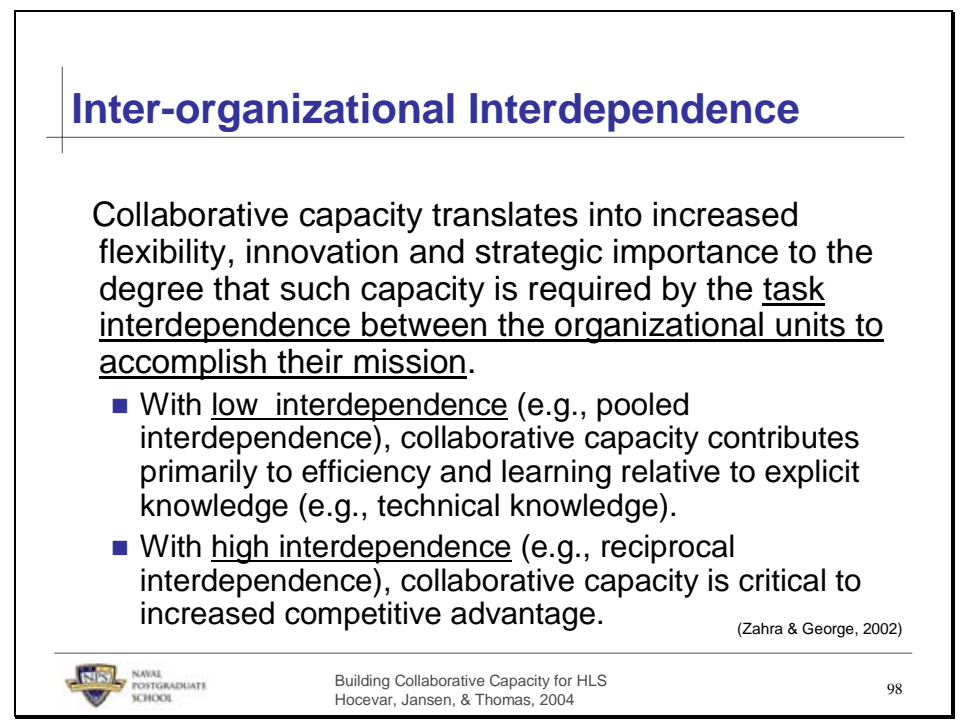


Slide 63

\section{Interagency Collaborative Capacity:}

CKSAs

- Interagency organizations must generate and develop Collaborative Knowledge, Skills and Abilities (CKSAs), including:

-Acquisition: valuing collaboration, trusting other agencies sufficiently to share information.

- Assimilation: understanding formal and informal frames of reference, and collaborative norms, styles and behaviors of other agencies.

\begin{tabular}{llr}
\hline Building Collaborative Capacity for HLS & (Zahra \& George, 2002) \\
\hline Hontowoum & Hocevar, Jansen, \& Thomas, 2004 & 99
\end{tabular}


Slide 64

Interagency Collaborative Capacity:

CKSAs

- Transformation: transforming and integrating CKSAs into negotiated situational understanding, shared frames of reference, collaborative norms, styles and behaviors (i.e., a collaborative culture) for the interagency organization.

- Exploitation: Integrated and coordinated actions that allow resource allocations to be reconfigured with changing conditions or even in response to crises.

\begin{tabular}{llr}
\hline Building Collaborative Capacity for HLS & (Zahra \& George, 2002) \\
Hocevar, Jansen, \& Thomas, 2004 & 100
\end{tabular}


Slide 65

Additional

Implications for Practice

- Absorptive capacity critically depends on boundary spanners: "individuals who stand at the interface of either the firm and the external environment or at the interface between subunits within the firm." Develop, select and capitalize on boundary spanners.

- Under conditions of rapid change (e.g., in technology), centralized, mechanistic interfaces are likely to be at a disadvantage compared to decentralized, organic interfaces, which result in more "receptors." Empower operators and boundary spanners. (Cohen \& Levinthal, 1990, p. 132)

\begin{tabular}{|c|c|}
\hline 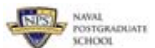 & $\begin{array}{l}\text { Building Collaborative Capacity for HLS } \\
\text { Hocevar, Jansen, \& Thomas, } 2004\end{array}$ \\
\hline
\end{tabular}

See also topical slides on "Boundary Spanners." 
Slide 66

\section{References}

- Bardach, E. (1998). Getting Agencies to Work Together: The Practice and Theory of Managerial Craftsmanship. Washington, D.C. : Brookings Institution Press.

- Cohen, W.M. \& Levinthal, D. A. (1990). Absorptive Capacity: A New Perspective on Learning and Innovation. Administrative Sciences Quarterly, 35(1): 128-152.

- Zahra, S.A. \& George, G. Absorptive Capacity: A Review, Reconceptualization, and Extension. Academy of Management Review, 27(2): 185-203. 
Slide 67

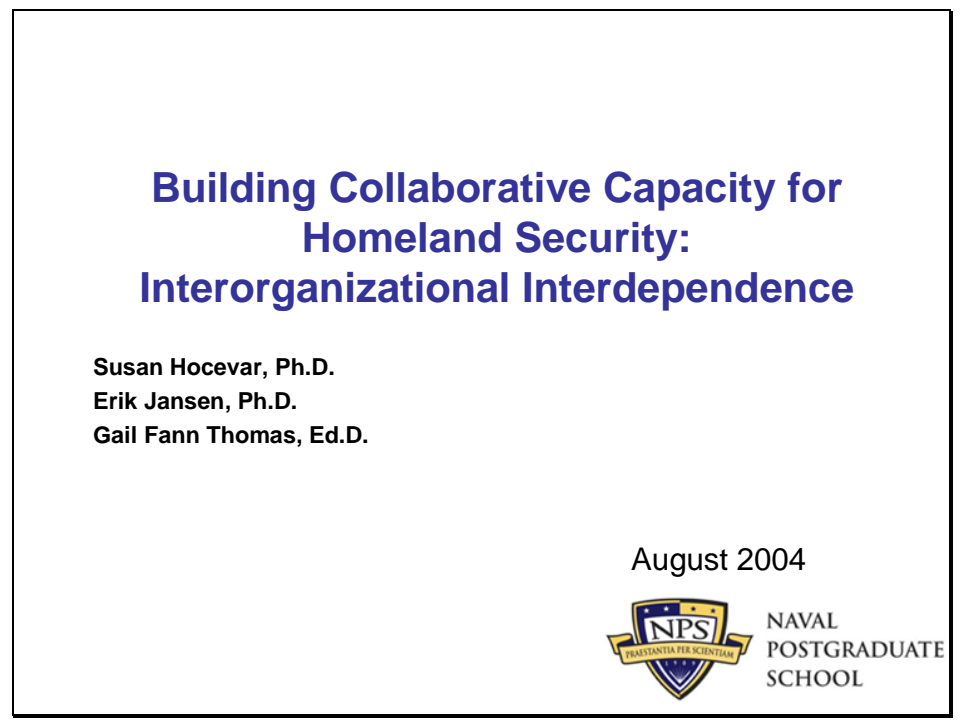


Slide 68

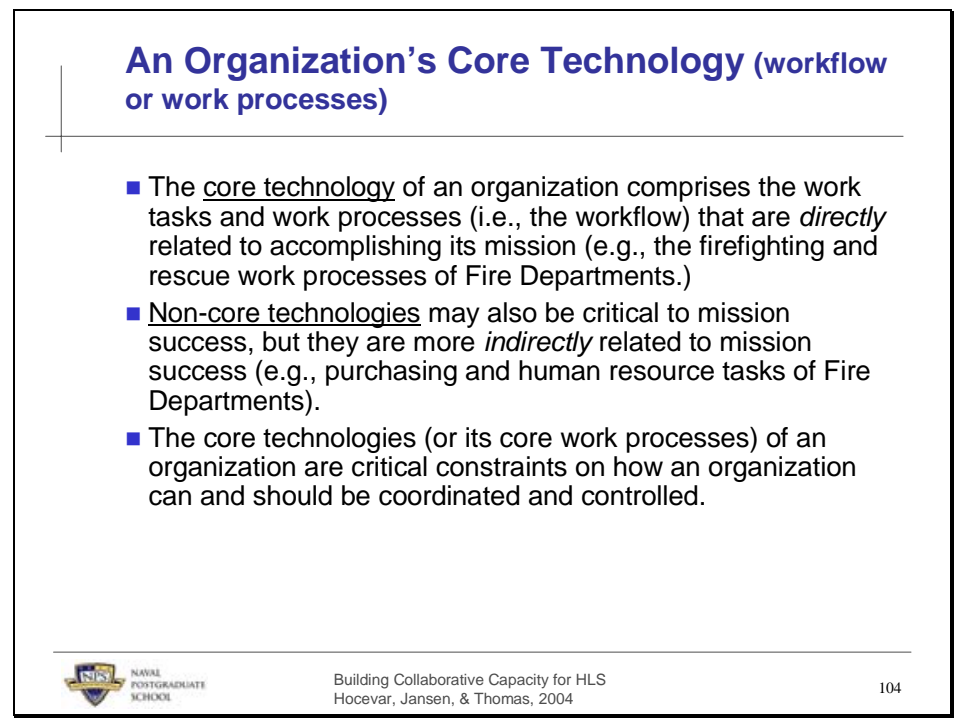

These are basic distinctions in organizational theory, particularly in socio-technical systems theory. They can be found in any basic, introductory text, in organizational theory, such as the ones by Daft or by Hodge, Anthony, \& Gale. 
Slide 69

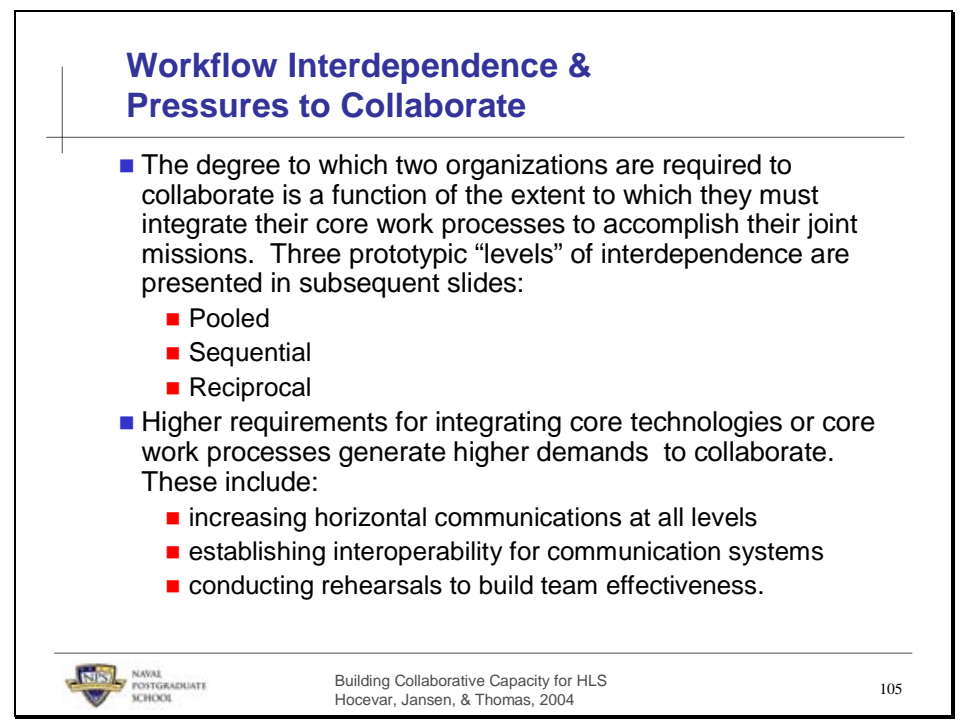

These statements are best classified as deductive generalizations of the theories of workflow interdependence posited by Thompson and the mechanisms of coordination described by Mintzberg. These theories are thus being extended from the organizational level to the interorganizational level. The important concept of rehearsal is in many literatures, but is most familiar to the author as it has been used by McRaven in the “Special Operations” literature. 
Slide 70

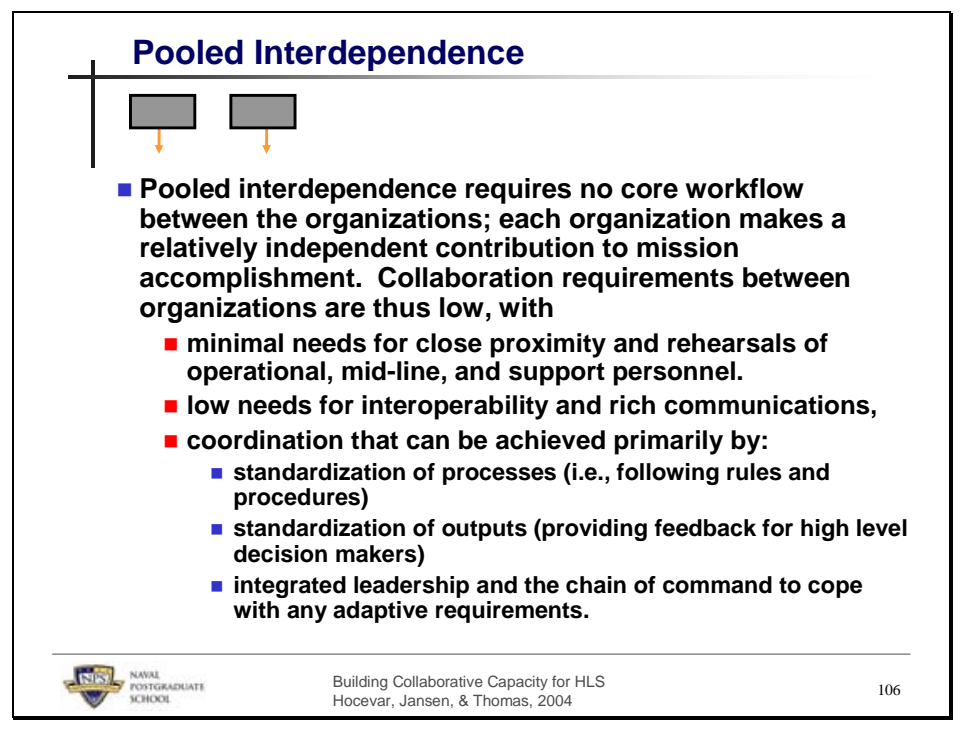

The foundational concepts of pooled, sequential and reciprocal interdependence are taken from Thompson. The basics of this theory can be found in Daft or Hodge, Anthony, \& Gale's text in "Organization Theory". The basic ideas are integrated with the theory of coordination processes (cf. Mintzberg) and expressed in terms of the "collaboration" construct. 
Slide 71

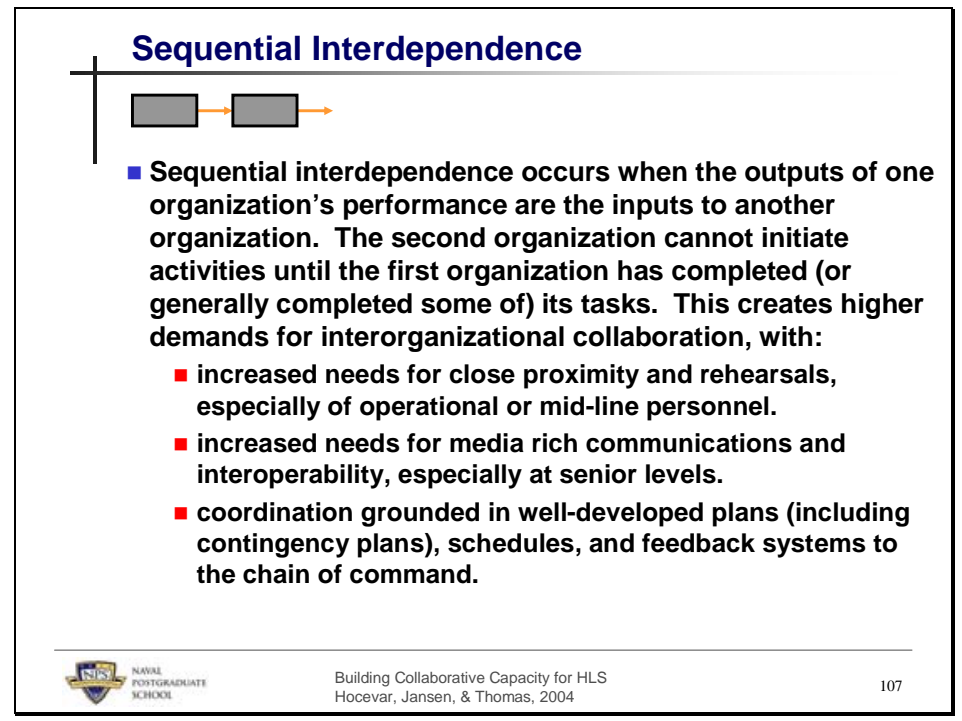


Slide 72

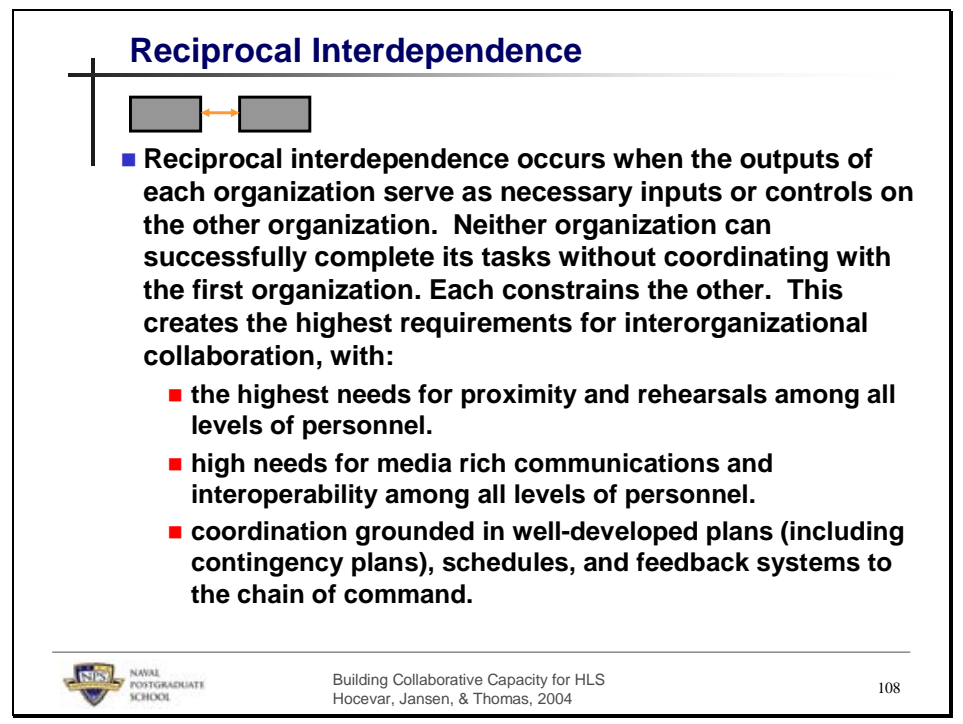


Slide 73

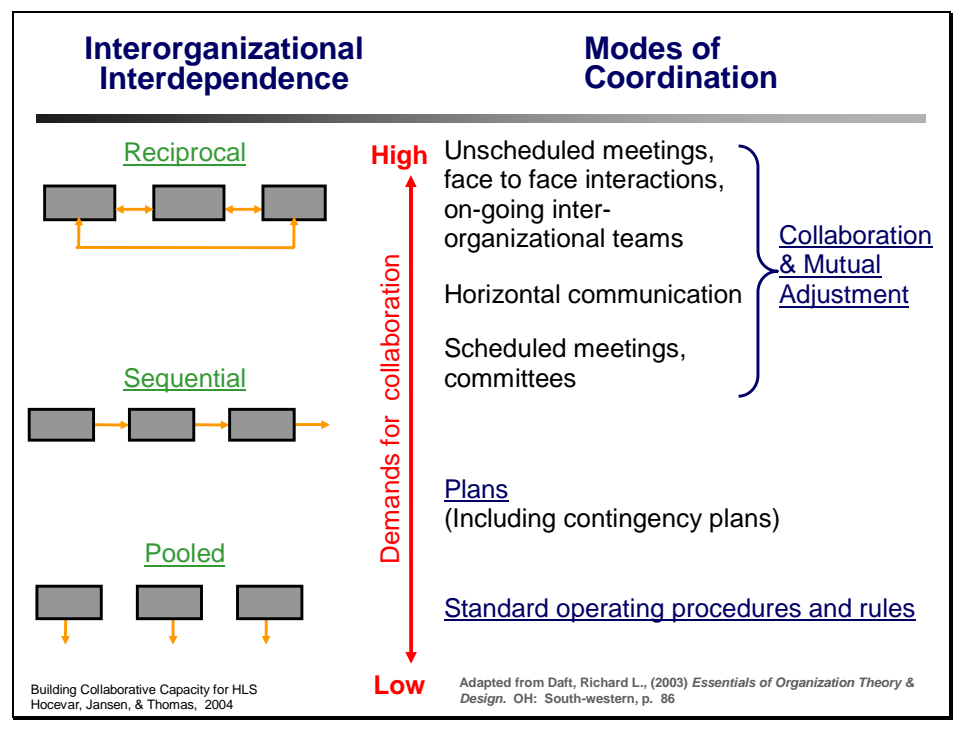

This figure is adapted from Daft's “Organization Theory” text, and he in turn adapted from an article by Van De Ven, Delbecq, \& Koenig (1976) in the American Sociological Review. The model was originally formulated for application at the organizational level, which the three boxes representing three departments. In the organizational case, they would all be under a hierarchy or common chain of command. Here, in the interagency problem, there is no hierarchy. Thus an option of "increasing vertical communications" or increased "vertical control" to coordinate the departments is not available.

We are thus generalizing the constructs from the organizational level to the interorganizational level. 
Slide 74

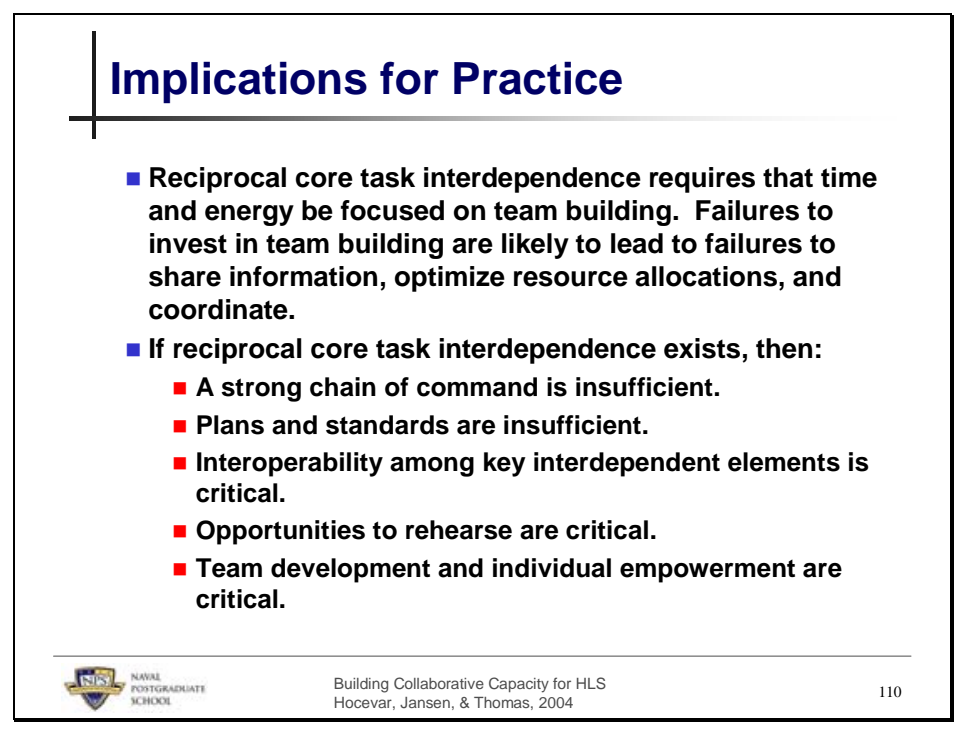

This slide synthesizes ideas from Thompson (the originator of the ideas of pooled, sequential, and reciprocal interdependence), and Mintzberg with theories of empowerment and team development (cf. Ed Lawler and Ken Thomas's work). The importance of interoperability and rehearsal comes from many fields, especially those that involve "command and control". 
Slide 75

\section{References}

- Daft, R.L. (2003). Essentials of Organization Theory \& Design. Mason, $\mathrm{OH}$ : South-Western.

- Hodge, B. J., Anthony, W. P., Gales, L. M. (1996). Organization Theory: A Strategic Approach. Englewood Cliffs, N.J.: PrenticeHall.

- Mintzberg, Henry. (1993). Structure in Fives: Designing Effective organizations. Englewood Cliffs, N.J.: Prentice-Hall.

- Thompson, J. (1967) Organizations in Action. N.Y.: McGraw Hill. 
Slide 76

\section{Building Collaborative Capacity for Homeland Security: Coordination and Collaboration}

Susan Hocevar, Ph.D.

Erik Jansen, Ph.D.

Gail Fann Thomas, Ed.D.

August 2004

NंPS NAVAL

POSTGRADUATE

SCHOOL 
Slide 77

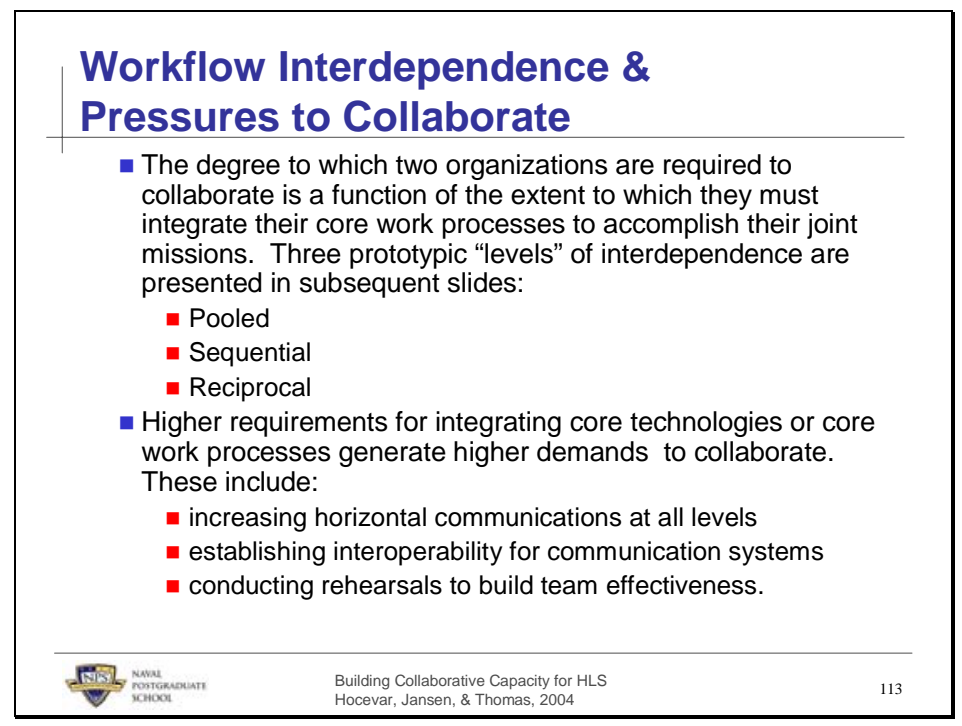

These statements are best classified as deductive generalizations of the theories of workflow interdependence posited by Thompson and the mechanisms of coordination described by Mintzberg. These theories are thus being extended from the organizational level to the interorganizational level. The important concept of rehearsal is in many literatures, but is most familiar to the author as it has been used by McRaven in the “Special Operations” literature. 
Slide 78

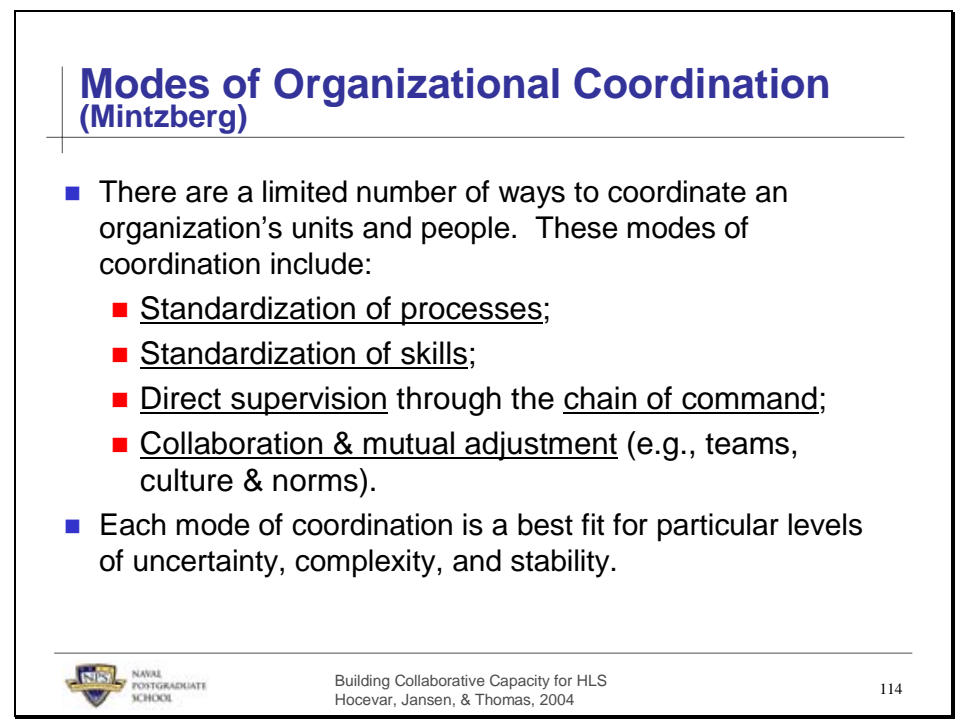

These coordination mechanisms apply within a given organization as well as to the interagency system or a given interagency unit. This is not, however, an exhaustive list. 
Slide 79

\section{Coordination through Standardization of Processes}

- Standardization of processes - the use of standard operating procedures and rule sets - is generally the most efficient mode of coordination.

- It works especially well in simple, stable contexts, and with simple, routine tasks and problems.

- It allows higher level managers to focus on exceptions that cannot be handled by the rules.

- When well designed, standard operating procedures generate reliable, dependable results.

\begin{tabular}{llr}
\hline B. & Building Collaborative Capacity for HLS & Cf. Mintzberg (1993, 1990) \\
Hocevar, Jansen, \& Thomas, 2004 & 115
\end{tabular}

Standardization of processes is given as "generally the most efficient mode of coordination." It is efficient because following the rules "no matter what" means nobody has to think very much; it thus relieves the need to keep referring decisions up the chain of command or to rely on teams or professionals to work through decisions. However, some situations arise that are beyond the domain of rules. While referring exceptions to leaders or complex decisions to more skilled operators may incur costs, it also increases the quality of decisions. Costs are thus higher, but so are benefits. Pure efficiency is sacrificed for effectiveness. 
Slide 80

\section{Coordination through Standardization of Skills}

- Standardization of skills -- standardizing the training, education \& professionalization of operational employees - is required when the organization's context and problem sets become complex.

- It substitutes competent human judgment for inappropriate reliance on standardized processes.

- It relieves higher level managers from dealing with exceptions by decentralizing complex judgments to skilled operators.

\begin{tabular}{llr}
\hline Cust. Mintzberg (1993, 1990) \\
116
\end{tabular}

Standardization of skills is accomplished by providing the time required for the operators in the operational core of the organization to get the training and earn the credentials to serve in various positions. This can range from weeks to years.

In addition, note that "professionals" are often trained not only to have high skill levels, but to make professional judgments that involve the application of values in assessing complex tradeoffs. 
Slide 81

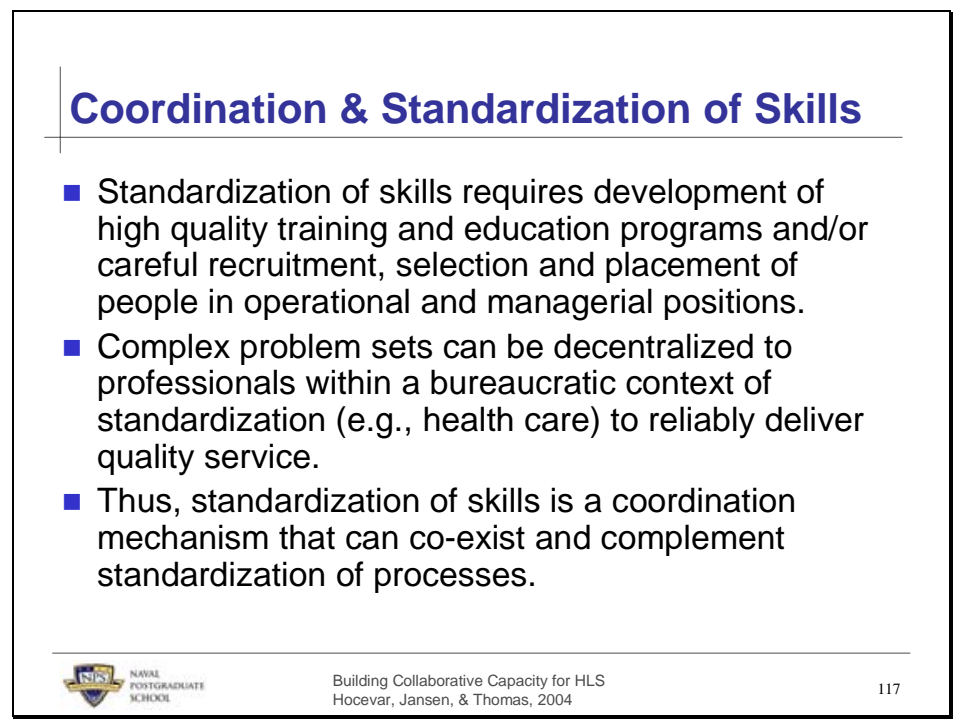

Weak standards, poor training and education, and inadequate experience cannot be a

foundation of operational effectiveness, especially in situations that have high variety and high complexity in the relevant problem sets faced by the people/organization. 
Slide 82

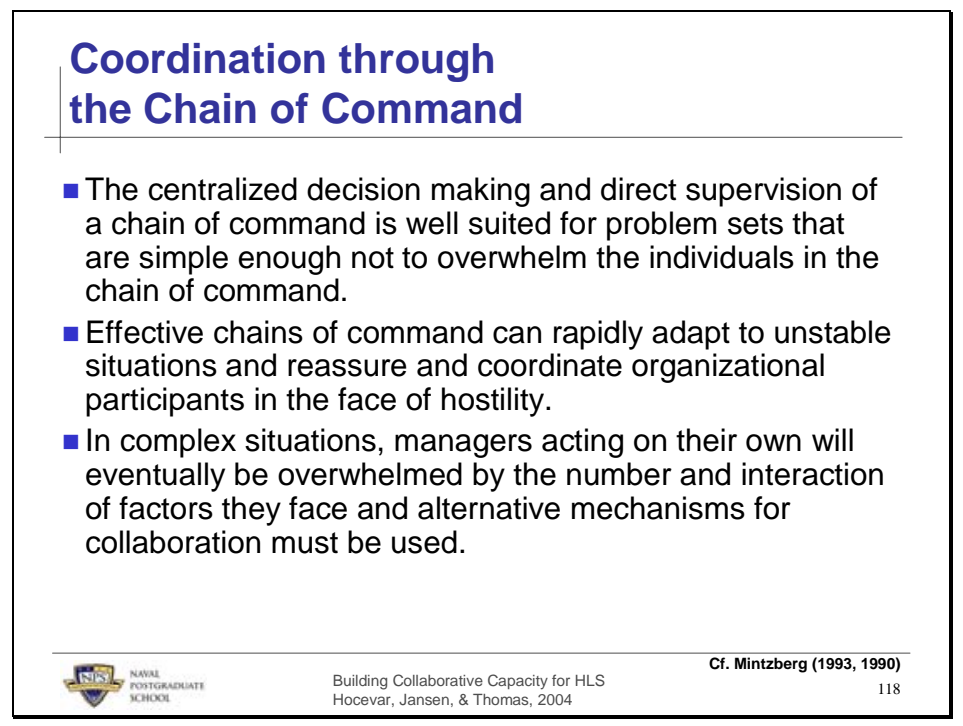

In complex situations, managers acting on their own will eventually be overwhelmed by the number and interaction of factors they face. In such cases, collaboration with other managers, staff, and/or operators becomes critical for dealing with complexity. 
Slide 83

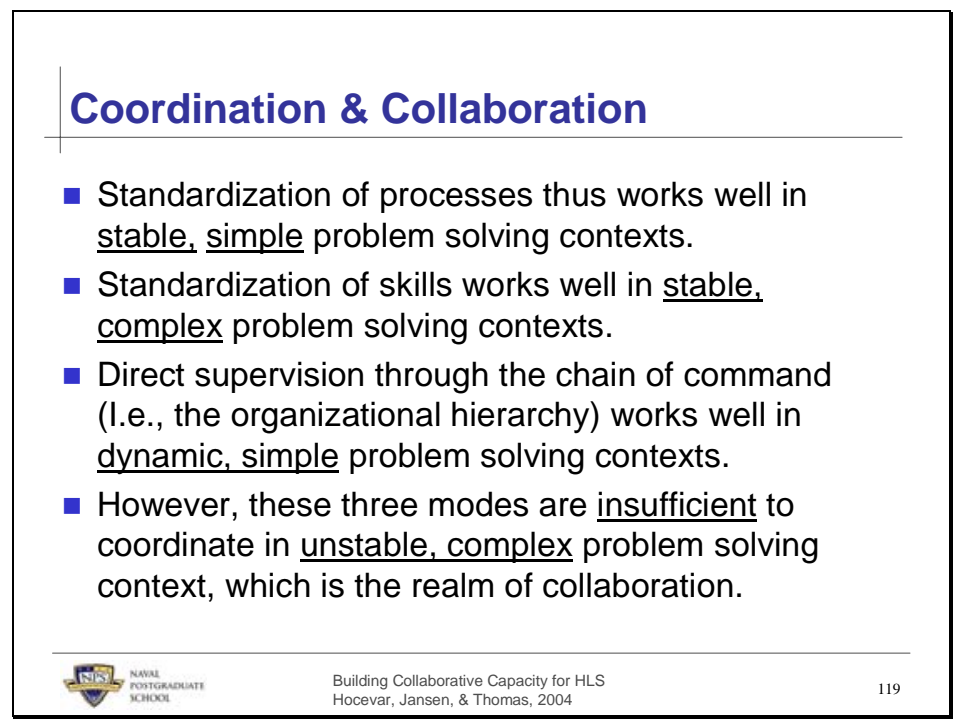

Note that the modes of standardization of processes, standardization of skills and the chain of command are insufficient for collaboration. That does not mean that they may not be necessary modes of coordination that are needed in addition to collaboration. (This depends partly on the degree to which the two organizations must integrate their core technologies: see the slides on interdependence.) 
Slide 84

\section{The Collaborative}

Problem Space

- Unstable,complex contexts and problems require that organizations rely on collaboration and mutual adjustment.

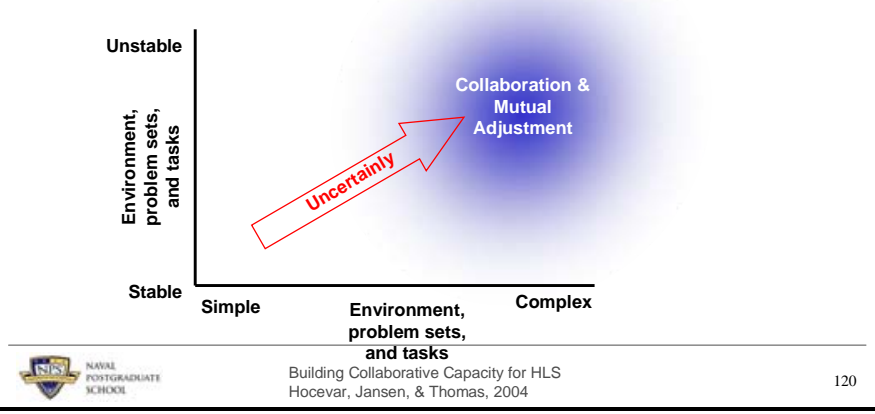


Slide 85

\section{The Collaborative Organizational Problem Space}

- Collaboration and mutual adjustment fit those complex contexts and problem sets that have many, interacting factors that require multiple points of view and considerable intellectual resources.

- Collaboration and mutual adjustment fit those unstable contexts and problem sets that are novel and innovative, such as getting new technologies, programs, organizations, and organizational partnerships up and running.

\begin{tabular}{|c|c|c|}
\hline 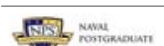 & Building Collaborative Capacity for $\mathrm{H}$ & Cf. Mintzberg $(\mathbf{1 9 9 3 ,}$ 1990) \\
\hline
\end{tabular}


Slide 86

\begin{tabular}{|c|}
\hline $\begin{array}{l}\text { Cooperation, Collaboration } \\
\text { \& Interorganizational Context }\end{array}$ \\
\hline $\begin{array}{l}\text {-Interagency collaboration - like organizational } \\
\text { collaboration - may require that organizations } \\
\text { also be able to coordinate at more basic levels } \\
\text { of } \\
\text {-Standardization of processes } \\
\text {-Standardization of skills } \\
\text {-The chain of command }\end{array}$ \\
\hline
\end{tabular}


Slide 87

\section{Interagency Coordination \& Standardization of Processes}

- Efficiency and reliability may require agencies to review and coordinate their organizations' standard operating procedures at critical points of interorganizational interdependence. Agencies aspiring for higher levels of collaboration risk coordination failures if their standardized processes are inconsistent and incompatible.

- New standard operating procedures are appropriate wherever the interagency organization discovers coordination problems that are routine, predictable, and relatively simple.

\begin{tabular}{|c|c|}
\hline ] & $\begin{array}{l}\text { Building Collaborative Capacity for HLS } \\
\text { Hocevar, Jansen, \& Thamas, } 2004\end{array}$ \\
\hline
\end{tabular}

Incompatible tactics, techniques and procedures, incompatible rules of engagement, incompatible formalization of behaviors, and inadequate communication systems for updating shifts in standards risk undermining collaborative capacity and mutual trust.

Leadership and staffs should analyze and identify critical points of interface among S.O.P.s to maximize collaborative capacity.

Some minimal levels of training are required for implementing even the simplest, most routine standardized processes. 
Slide 88

\section{Interagency Coordination \& Standardization of Skills}

- Complex interagency problems may require decentralizing some operations to credentialed, highly trained personnel. Such professionals may have standards and mindsets that have to be "integrated" or "de-conflicted" at critical points of interagency interdependence.

- Understanding, mutual respect, and trust may be critical for optimal collaboration by skilled operators in different agencies.

- Interagency organizations may need to establish joint education programs, conferences, and implement "rehearsals" to enhance mutual professional understanding and collaboration.

\begin{tabular}{ll}
\hline Building Collaborative Capacity for HLS \\
Hocevar, Jansen, \& Thomas, 2004
\end{tabular}

Weak standards, poor training and education, and inadequate experience cannot be a

foundation of operational effectiveness, especially in situations that have high variety and high complexity in the relevant problem sets faced by the people/organization. 
Slide 89

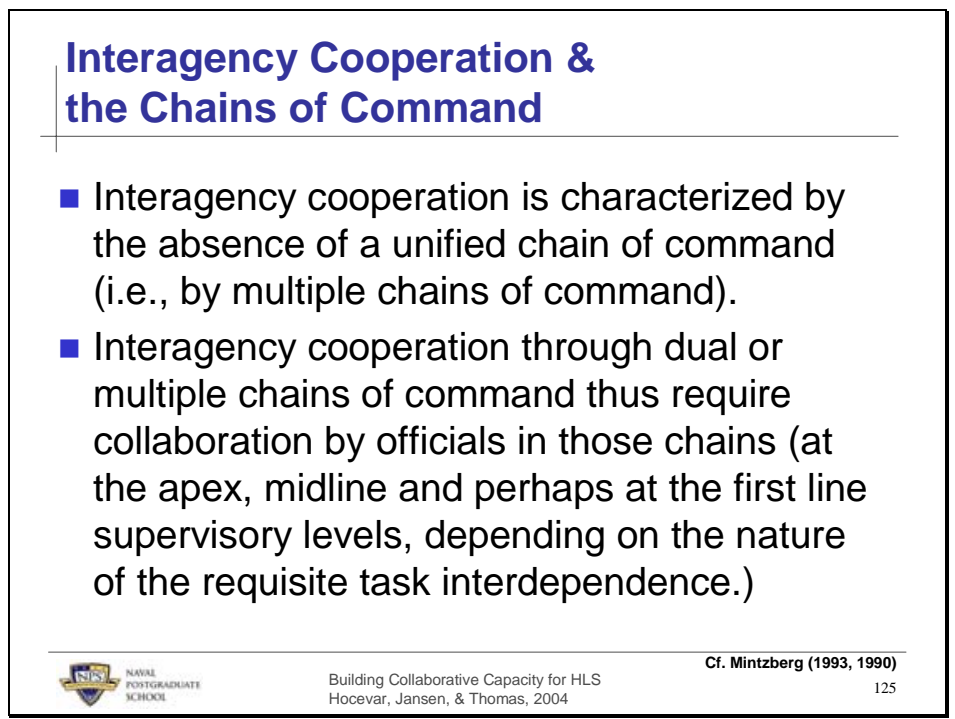

The requisite task interdependence is the extent to which the organizations are required to coordinate to accomplish their core tasks. (See the concepts of pooled, sequential and reciprocal task interdependence).

In some contexts (e.g., responding to an emergency), a unified chain of command (e.g., an incident command center) might function in an interagency context. Such a structure is generally not present in the planning and preparation phases, thus leading to the problem of being "underdesigned" and the requirements for collaborative mechanisms. 
Slide 90

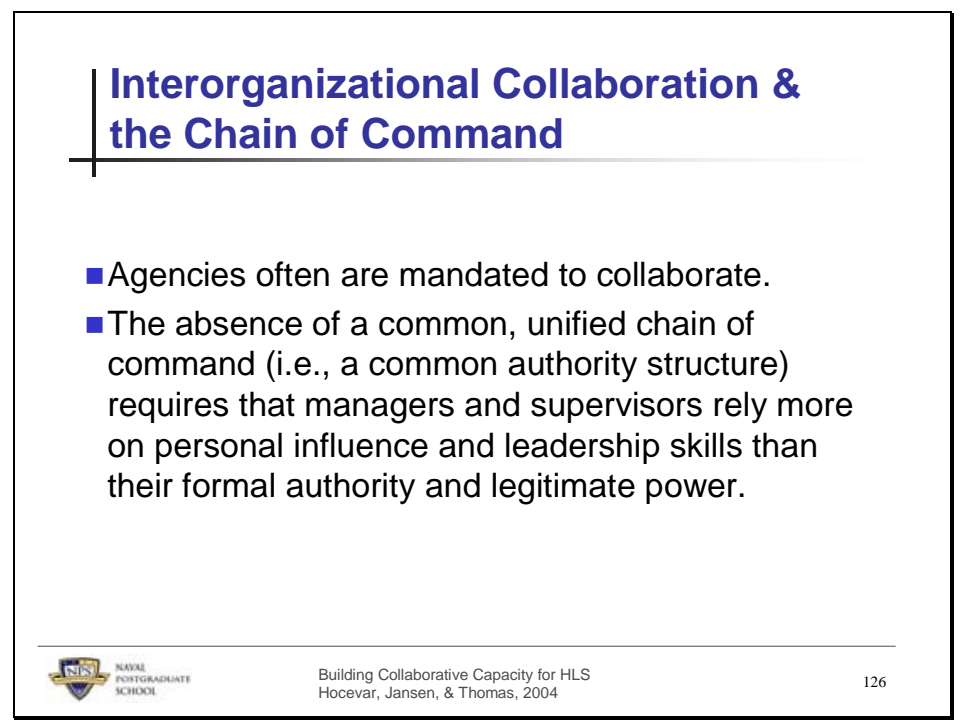

As other slide presentations also assert, interorganizational relationships are underdesigned. The lack of a unified chain of command is a major characteristic of these underdesigned systems. 
Slide 91

\section{Collaboration}

Collaboration provides increased:

- information processing capacity: more minds are enlisted to handle complex problems. Special coordinating roles (e.g., liaisons) as well as temporary and permanent teams provide intellectual resources and multiple points of view for generating, choosing and implementing action plans.

- Flexibility and innovation: standardization is replaced by a social network that harnesses human judgment and experience. There is no assumption that solutions programmed for yesterday meet the emerging problems of today or the actions needed for tomorrow.

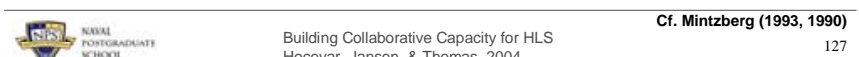


Slide 92

\section{Implications for Practice}

- Coordination mechanisms other than collaboration (e.g., standardization of processes and skills and the chain of command) may be critical and necessary for interagency collaboration. However, they may be insufficient for effective coordination -especially when problems are new, and characterized by complexity and instability.

\begin{tabular}{|c|c|c|}
\hline TN/, Nave & Building Collaborative Capacity for $\mathrm{H}$ & Cf. Mintzberg $(1993,1990)$ \\
\hline
\end{tabular}


Slide 93

\section{Implications for Practice}

- Important standards that affect multiple agencies require de-confliction and integration.

- Professionals and highly trained operators need to understand and build trust with other professionals/ operators they need to depend on.

- Management and operational personnel need to understand how its partner agencies coordinate their activities, especially at the critical interfaces of interagency cooperation and collaboration.

\begin{tabular}{llr}
\hline Cunstilding Collaborative Capacity for HLS & Cf. Mintzberg $(\mathbf{1 9 9 3 , 1 9 9 0 )}$ \\
Hocevar, Jansen, \& Thomas, 2004 & 129
\end{tabular}


Slide 94

\section{Implications for Practice}

- Collaboration goes beyond the cooperation achieved through direct supervision in a chain of command or standardization. Collaboration achieves cooperation through organic, adaptable processes.

Leaders are ultimately responsible for building collaborative capacity by investing time, energy and resources to developing their own and their personnel's:

- requisite skills and attitudes for collaboration.

- knowledge and understanding of the organizational structures, processes, and key actors of other agencies;

- ensuring that designated members of the an Interorganizational Collaborative Unit have the authority, credibility, and skills to represent their organization and/or its departments and to enter into the task of building collaborative capacity in their home organization. 
Slide 95

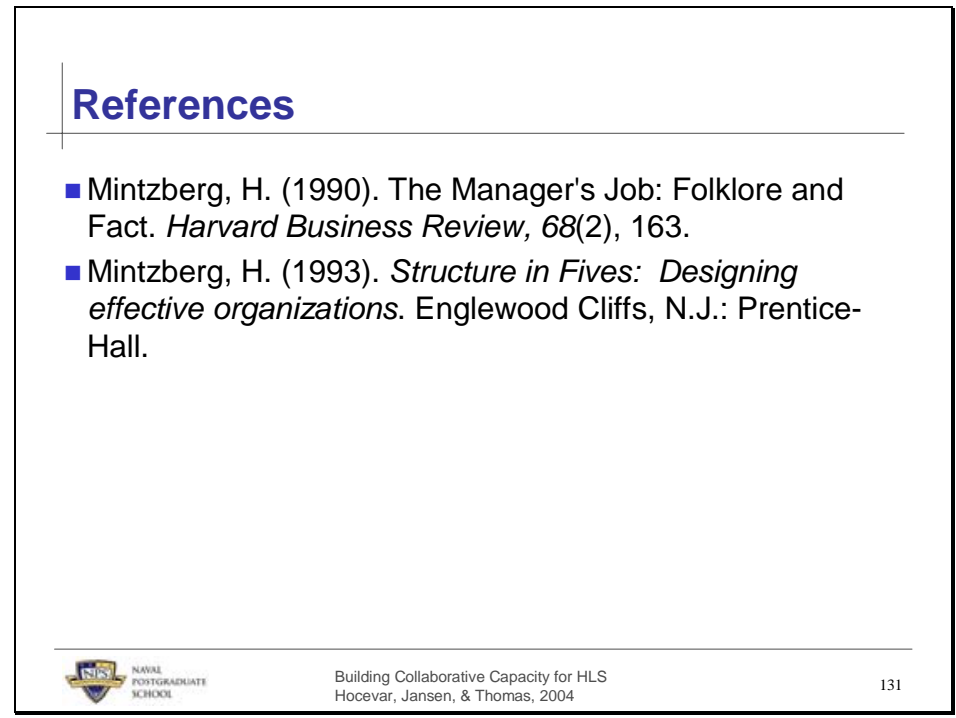


Slide 96

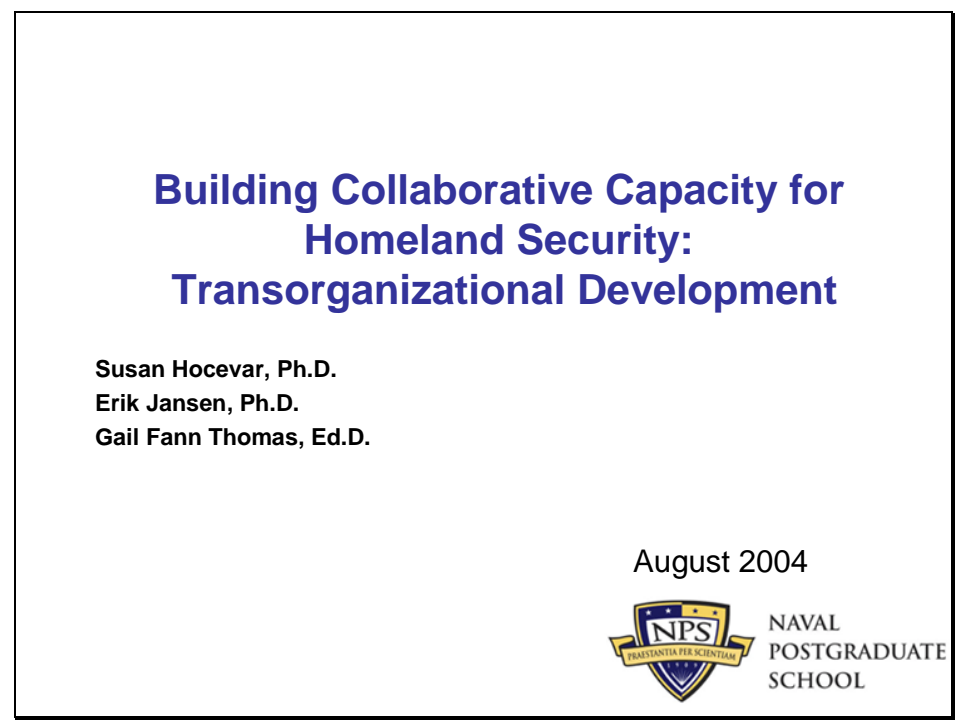


Slide 97

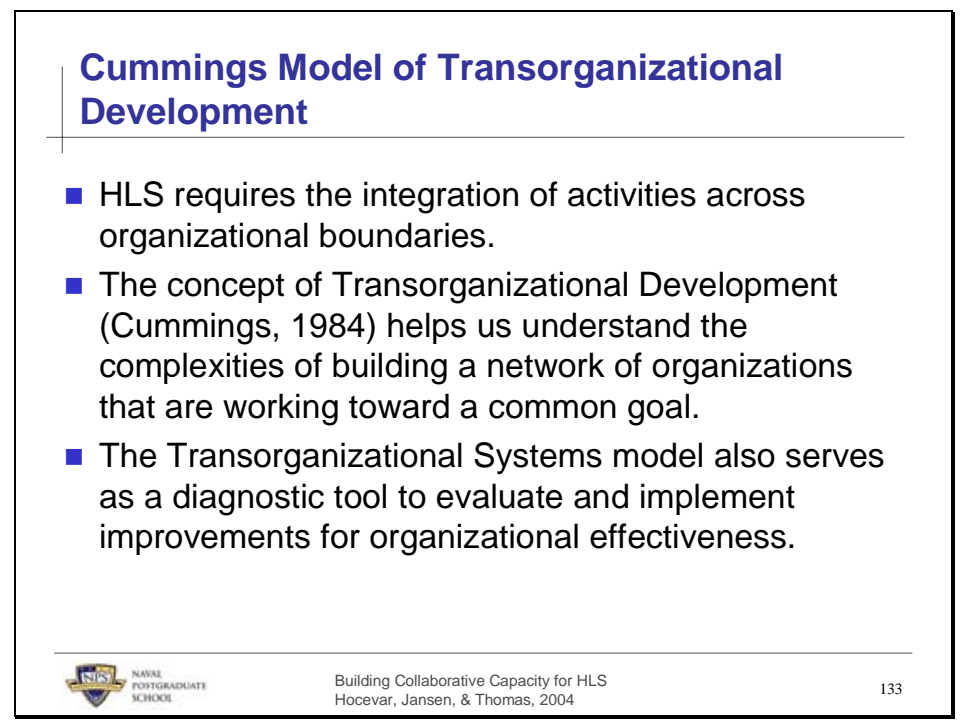

Homeland security requires the integration of activities across organizational boundaries. Cummings' (1984) concept of Transorganizational Development is relevant to understanding the complexities of developing such a network of organizations. His work predates much of the recent work on networks, but provides a comprehensive model applying the behavioral sciences to understanding how such systems are built and how they can be strengthened. The following slides first discuss what Cummings describes as "Transorganizational Systems" - a coalition of multiple organizations working together for some common or complementary purpose. The second major concept presented is "Transorganizational Development" which acknowledges that such multi-organization systems require a unique approach to evaluating and implementing improvements for organizational effectiveness. 
Slide 98

Transorganizational Systems (TS)

(Cummings, 1984)

- Transorganizational systems (TS) are "coalitional structures whose member organizations maintain their separate identities and

disparate goals, yet employ either some formal organization or informal collaboration for joint decision making." (Cummings, 1984, p. 368)

- TSs are generally underorganized systems and require a unique form of planned change distinctly different from what is typically outlined in traditional organization development (OD).

- TSs rely on two conceptual domains:

- interorganizational relations

- social problem solving 
Slide 99

Interorganizational Relations and Social Problem Solving

- Interorganizational Relations focus on power/dependence and autonomy:

- Organizations enter into relationships to obtain needed resources.

- Organizations also compete over essential resources while trying to minimize dependencies threatening organizational autonomy.

- Social Problem Solving focuses on collaboration:

- Helping organizations to cope with "metaproblems" by forming multi-organizational collectives. 
Slide 100

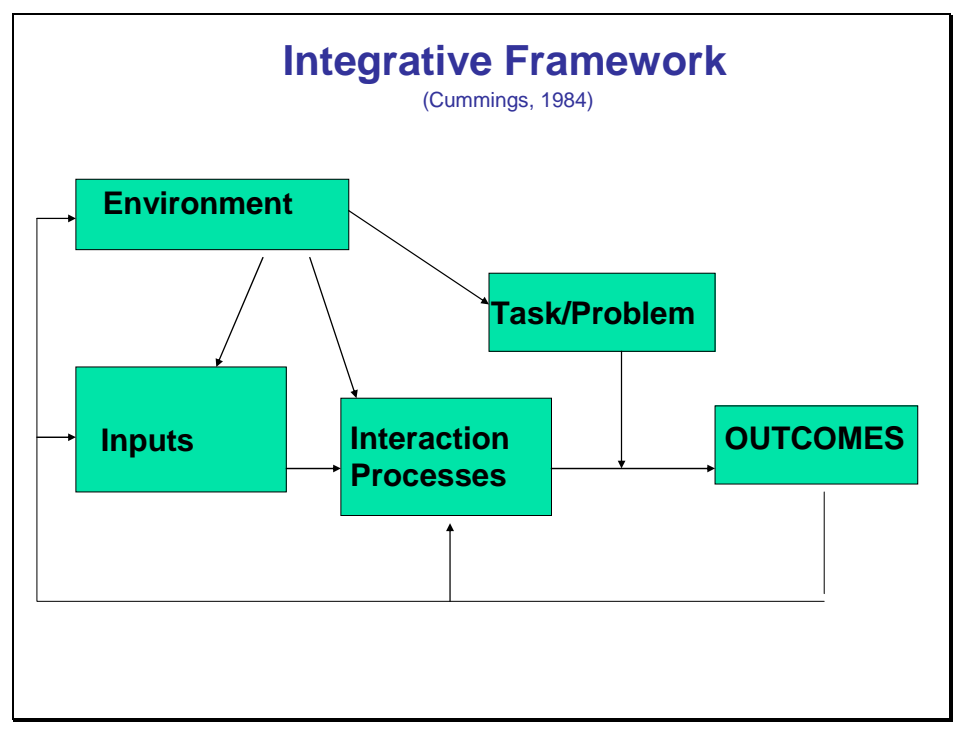

This graphic represents a typical open system model with Inputs $\rightarrow$ Interaction processes $\rightarrow$ Output in the context of the Environment. The "driver" for most transorganizational systems is a "task/problem" so this feature of the system is highlighted.

Typically, a transorganizational system begins with an assessment of a task/problem and a simultaneous assessment of which organizations have relevant "input" to the task/problem (e.g., motivation to interact, resource dependency, mandate).

As with all systems, the Environment impacts Inputs, Interaction processes and Task/problem characteristics.

The "Task/Problem" influences the extent to which interaction processes are salient for TS performance .

Outcomes generate feedback processes that affect the Inputs, Environment, and Interaction processes. 
Slide 101

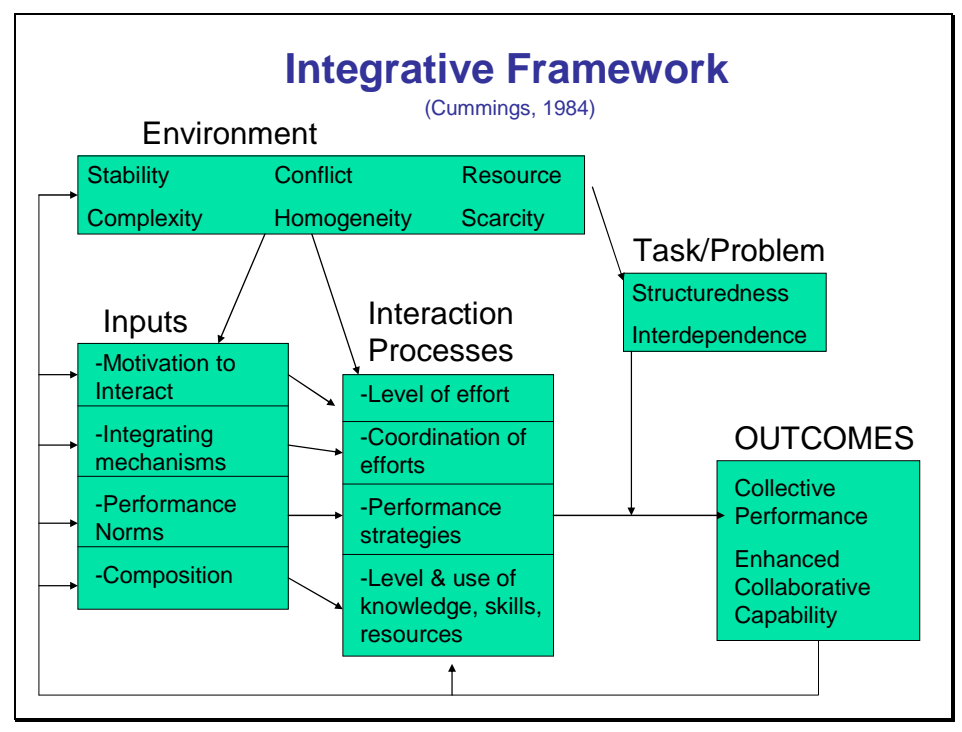

This more elaborated model details some of the critical characteristics of each of the elements in the model. These characteristics provide important guidance for design of the TS and for evaluating its effectiveness. For example, the "Input" element can be evaluated in terms of:

composition - are all relevant parties involved?

integrating mechanisms - are there necessary technical systems and cultural norms to support TS integration?

motivation to interact - does each participating organization see sufficient benefit to engaging in the TS to justify the "cost"? Are they participating due to mandate?

The interdependence assessment of the task/problem has implications to appropriate interaction processes. This is elaborated in another section of this report. 
Slide 102

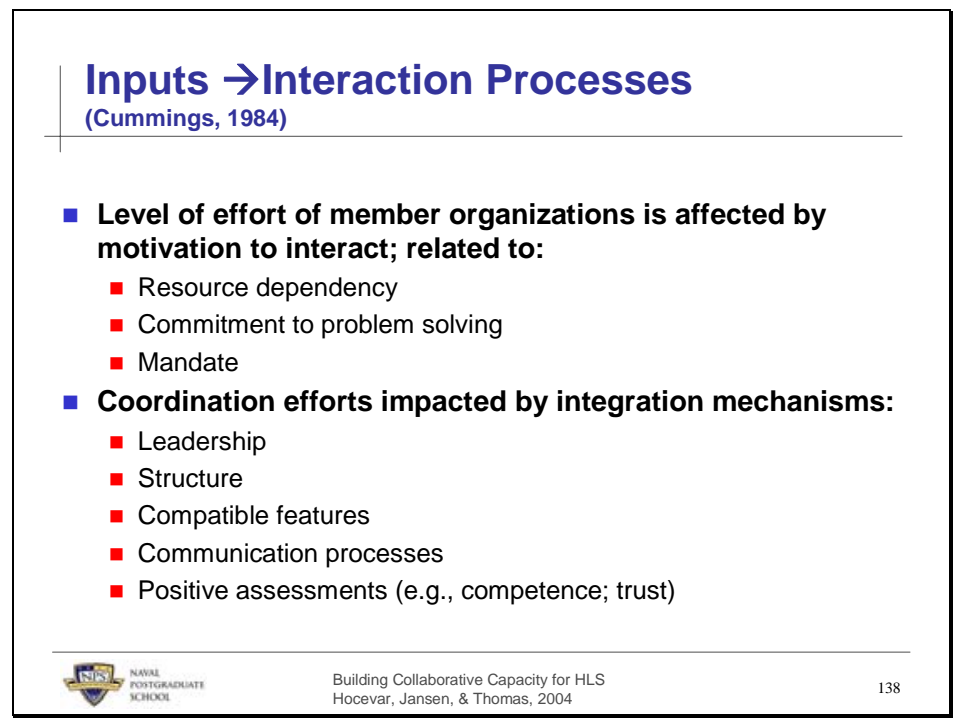

Specific characteristics of the "Input” element of the TS are related to specific elements in the "Interaction Processes."

\section{A. Motivation to Interact}

Resource dependency (influenced by):

Shared awareness of other's potential resources

Degree of consensus regarding respective domains

Assurance that autonomy will be retained

Moderate (vs. low or high) goal similarity

Commitment to problem solving influenced by:

Greater frequency of communication

Recognition of scale and complexity of shared problems and awareness of common interests and interdependence

Inducements and contributions

Existence of networks

\section{Coordination Efforts}

Leadership

Via coordinating agency; linking-pin organization

Integrating activities include: building exchange relationships; resolving interagency conflicts; managing interface among agencies Structure

Increased intensity of interactions $\rightarrow$ increased formalization \& centralization

Task driven requirements for coordination require functional analyses; leads to negotiated functional roles \& responsibilities and regulative processes for coordination.

Compatible features

Extent to which participating orgs' features, needs, values, technologies are compatible

Communication processes

Quality \& type of information sources; willingness to share information

Positive Assessments

Assessments of competence and trust are continually re-evaluated through interaction 
Slide 103

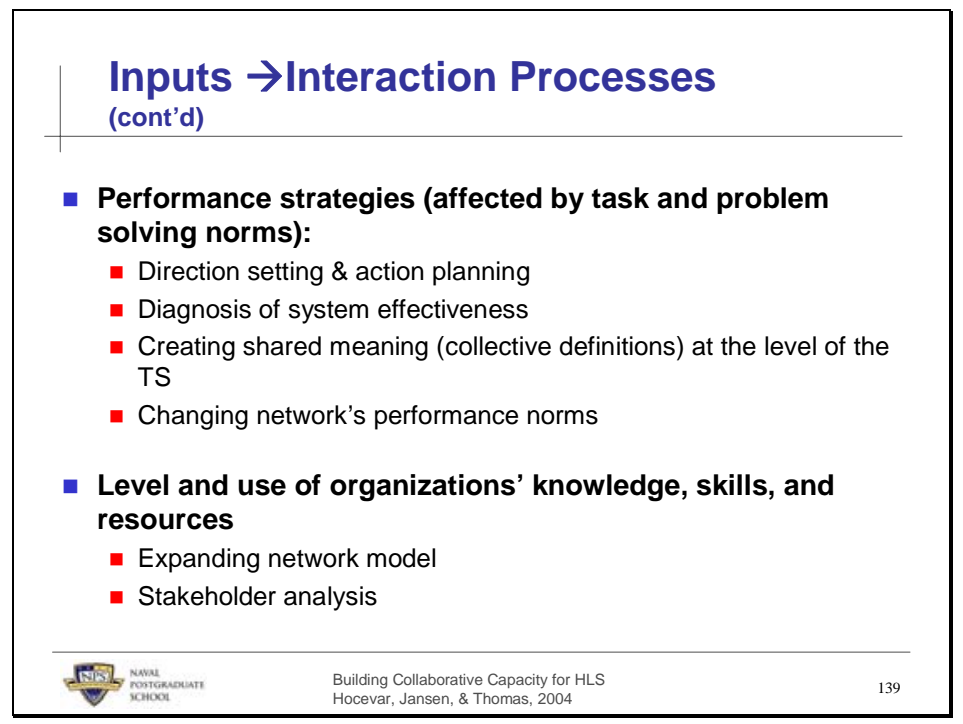

\section{Performance Strategies}

Direction setting \& action planning

Establish consensus on problem domain and desired ends

Devise action plans

Diagnosis

Focus on issues related to motivation to interact and coordination of efforts (outlined on previous slide and notes)

Create shared meaning at level of TS - may require frame breaking of existing organization-level collective definitions Changing networks performance norms

Assessment of degree of loose vs. tight coupling; implications to cohesion and performance strategies

\section{Level and use of org's knowledge, skills \& resources [affected by composition]}

Expand network model

Start TS with smaller core and expand with additional stakeholders as needed [depending on resource requirements; task analyses]

Stakeholder analysis

Based on resources, task requirements, problem interests, communication processes, and political assessments 
Slide 104

\section{Environment \& Context}

- TSs are most appropriate when:

- Environmental uncertainty is high;

- Environmental complexity is high;

- There is an enduring, shared problem.

- A federation of heterogeneous, specialist organizations who pool resources.

- Gaining flexibility, sacrificing efficiency.

- Heterogeneous organizations and unstable environments reduce the ability to standardize exchanges.

- Resource scarcity can reduce the motivation to interact. 
Slide 105

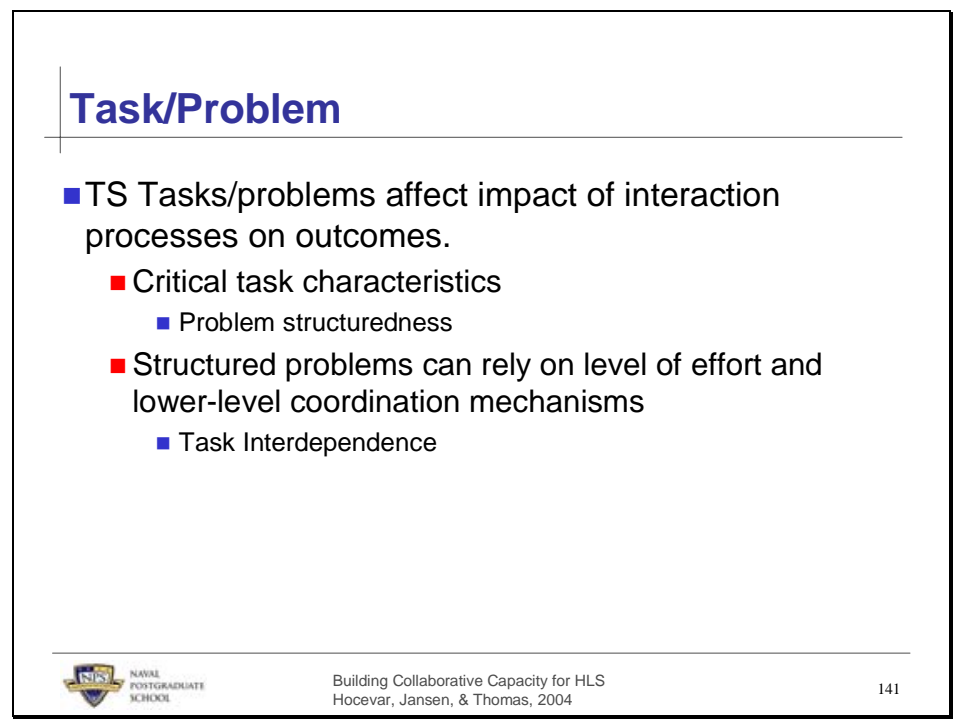

The properties of Task/Problem are explained in detail in two sections of this report. The dimension of Task Interdependence is discussed in topical slides entitled:

"HLS:Interorganizational Interdependence.” Problem structuredness is discussed in topical slides entitled: "Coordination and Collaboration." 
Slide 106

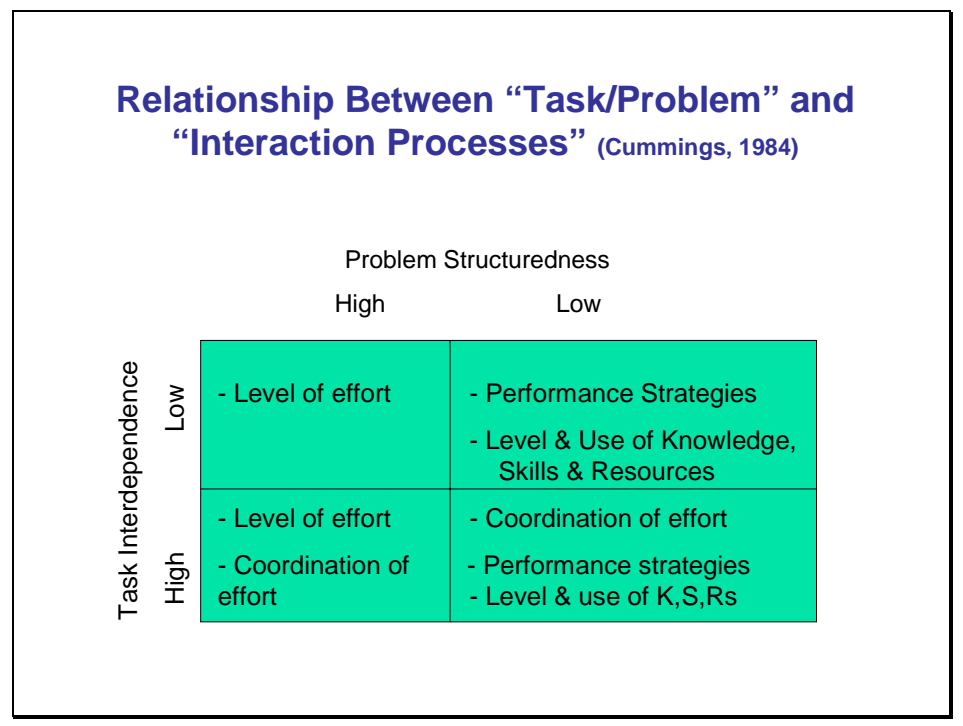

This figure refers back to the previous slide entitled "Integrative Framework." The proposition illustrated is that effectiveness of organizational outcomes reflect an interaction between "Task/Problem” and "Interaction Processes." The four categories of interaction processes presented in the "Integrative Framework" are therefore hierarchical. For example, when task interdependence is low and the problem is highly structured, the type of interaction process required is fairly "simple" and can rely on level of effort. As task interdependence increases, keeping problem structure stable, additional coordination strategies are required.

If problems are unstructured, it is never adequate to rely on standard level of effort. Even when task interdependence is low, the interaction process requirements demand specific performance strategies (e.g., diagnosis, developing shared meaning, direction setting, action planning) as well as an assessment of the needed knowledge, skills, and resources (i.e., stakeholder analysis). As task interdependence increases, unstructured problems require additional coordination mechanisms. 
Slide 107

\section{Transorganizational Development (TD)}

(Cummings, 1984)

- TSs are typically "underorganized" as a system, and require unique interventions:

- Aimed at increasing shared norms and values

- Designing structures, roles and technologies to create predictability, to regularize behavior, and evaluate intended effects.

- Phases of TD:

- Identification of relevant stakeholders

- Convening of members / motivation to interact

- Organizing appropriate structures and processes for joint task performance 
Slide 108

\begin{tabular}{|l}
\hline Phases of TD (Cummings, 1984) \\
Identification of relevant stakeholders \\
- Task analysis identifies levels and types of required knowledge, \\
skills, resources. \\
- Political analysis identifies organizations that control resource flows, \\
information, legitimacy. \\
It may be effective to decompose a larger network into more tightly \\
coupled subsets. \\
Convention of TS \\
- Who is convener? \\
- Who acts as representative(s) of participating organizations \\
(leadership, boundary spanner)? \\
If system is "underorganized," intervention will require focus on \\
developing motivations \& perceptions of task/problem, joint problem \\
solving, conflict mgt, organization design requirements, etc.
\end{tabular}


Slide 109

\section{Phases of TD (cont'd)}

\section{- Organization of TS}

- Determine outcomes desired from joint actions.

- These provide standards for assessment.

- Analyze task/problem and environment.

- Identify inputs affecting relevant interaction processes.

- Generate needed design factors such as roles, functions, coordination mechanisms, leadership, control mechanisms, communication processes, assessment mechanisms, etc.

- Determine extent to which design factors require change to existing organization structures, technologies, processes, norms (culture), personnel capabilities, etc.

- Implement necessary TD interventions for change. 
Slide 110

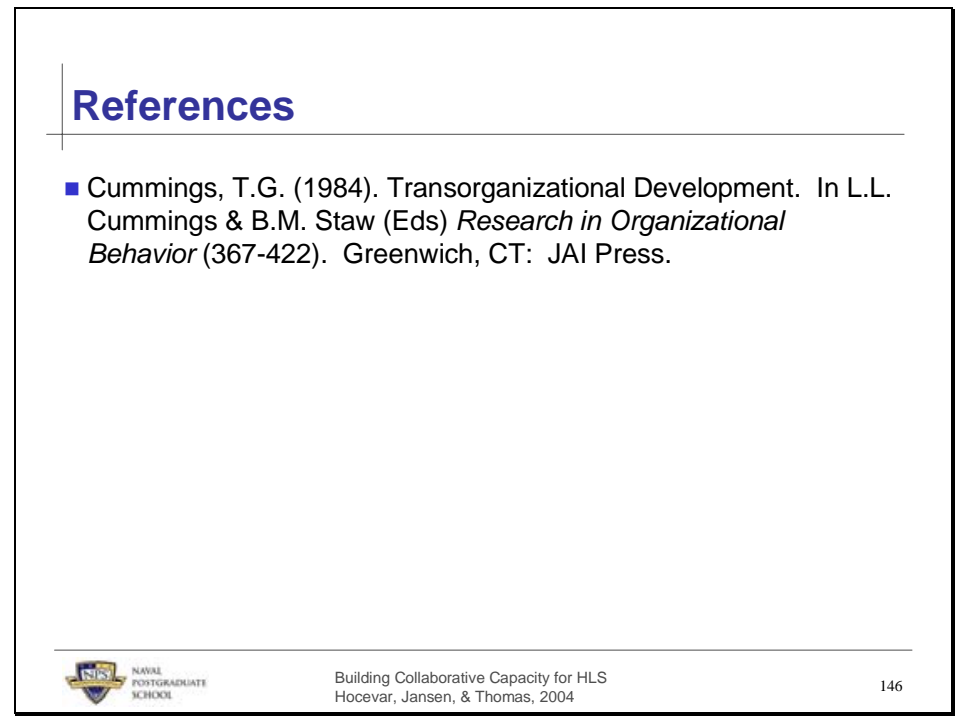


Slide 111

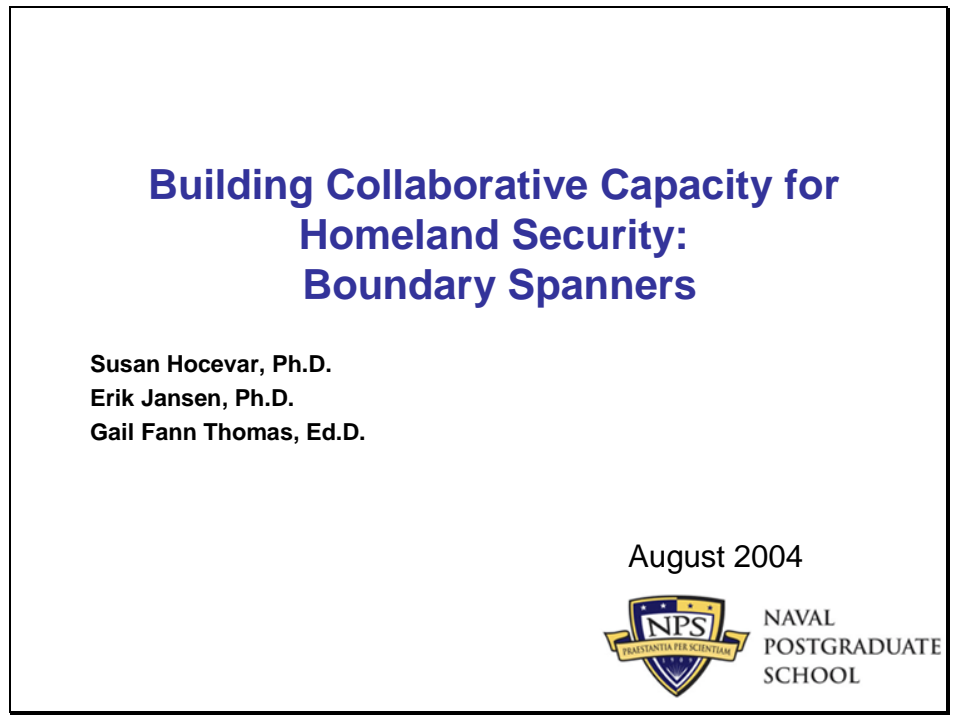


Slide 112

\begin{tabular}{|c|c|c|}
\hline \multicolumn{3}{|c|}{ Boundary Spanners } \\
\hline \multicolumn{3}{|c|}{ - Boundary spanners } \\
\hline \multicolumn{3}{|c|}{$\begin{array}{l}\text { Are defined by roles where there is reciprocal } \\
\text { interdependence between organizations } \\
\text { organizational units. }\end{array}$} \\
\hline \multicolumn{3}{|c|}{$\begin{array}{l}\text { Function at the margins/boundaries of the } \\
\text { organization. }\end{array}$} \\
\hline \multirow{2}{*}{\multicolumn{3}{|c|}{$\begin{array}{l}\text { - Are pivotal in managing inter-organizational } \\
\text { relations. } \\
\text { - Require unique individual characteristics to be } \\
\text { effective in this role. }\end{array}$}} \\
\hline & & \\
\hline F⿱ & $\begin{array}{l}\text { Building Collaborative Capacity for HLS } \\
\text { Hocevar, Jansen, \& Thomas, } 2004 \text {. }\end{array}$ & 148 \\
\hline
\end{tabular}


Slide 113

\section{Boundary Spanners}

- Boundary spanners are particularly important in the face of "wicked problems" (Williams, 2002):

- That cross organizational boundaries

- That have unclear causes

- Where there are competing/conflicting perspectives on problem definition

- That are intractable; requiring systemic change

- That are beyond the capability of a single organization.

- Such problems require mechanisms for coping with uncertainty \& complexity; network solutions, collaboration and innovation. 
Slide 114

\section{Boundary Spanning Roles}

(Williams, 2002)

- Trusted lynchpin between groups to provide predictability and risk taking in the face of uncertainty;

- Identify key stakeholders to be involved;

- Informational intermediary;

- Facilitate goal adjustment and shared expectations;

- Negotiate integrative strategies and joint problem solving;

- Arbiter in conflict resolution

- Offer innovation due to access to external partners, critical resources and information. 
Slide 115

Individual Competencies of Effective Boundary

Spanners (Williams, 2002)

1. Building Sustainable Relationships

- Aware of and appreciates perspective of others

- Interest in acquiring knowledge about others' roles, responsibilities, problems, values, etc.

- Communication skills (e.g., active listening; search for shared meaning)

- Effective conflict management

- Personal characteristics of openness, tolerance, respect, reliability, honesty

- Trust - reciprocal risk-taking 
Slide 116

Individual Competencies of Effective Boundary

Spanners (Williams, 2002)

2. Effective use of influence and negotiation

- Because power is dispersed and work is on the edges or outside the hierarchy, stronger reliance on informal sources of power and influence

- Social networking

- Consensus-building

3. Effective management of interdependencies

- Inter-organizational experience (empathy, perspective)

- Transdisciplinary knowledge (analytic ability \& legitimacy)

- Cognitive capability and ability to innovate 
Slide 117

\section{Organizational Factors and Boundary Spanner} Effectiveness

(Perrone et al., 2003)

- Role autonomy allows boundary spanners to be integrative, innovative and responsive when addressing the competing expectations of own and "other" organizations. This is instrumental in developing trust.

- Factors found to influence role autonomy and effective boundary spanning:

- Amount of functional interdependence within own organization constrains autonomy;

- Amount of tenure within own organization enables greater autonomy;

- Presence of an organizational culture that supports and encourages autonomy ("clan" culture). 
Slide 118

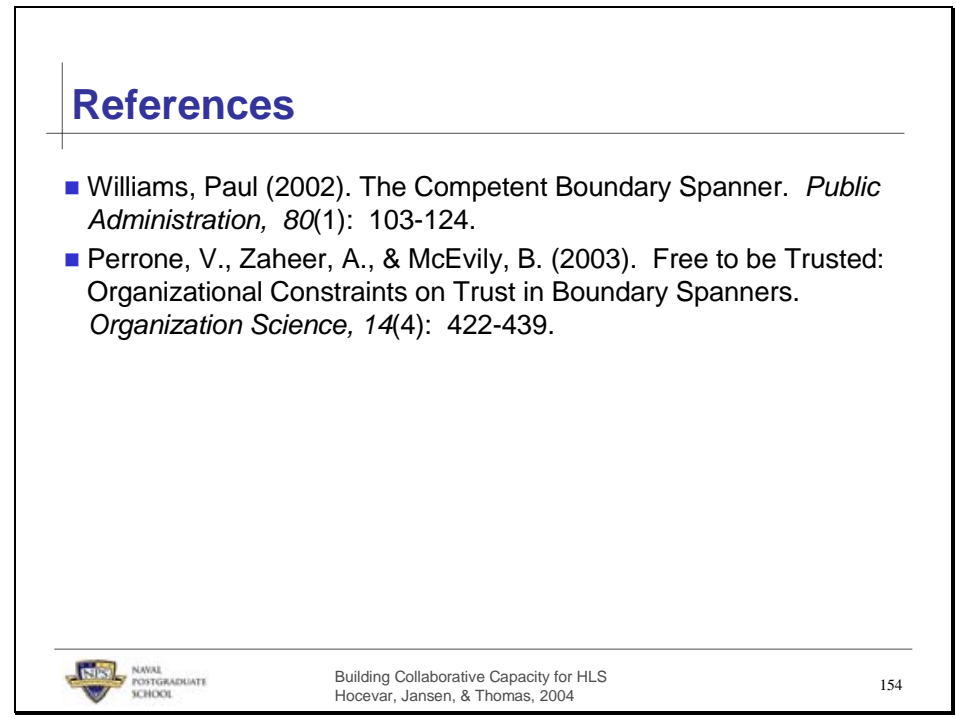


Slide 119

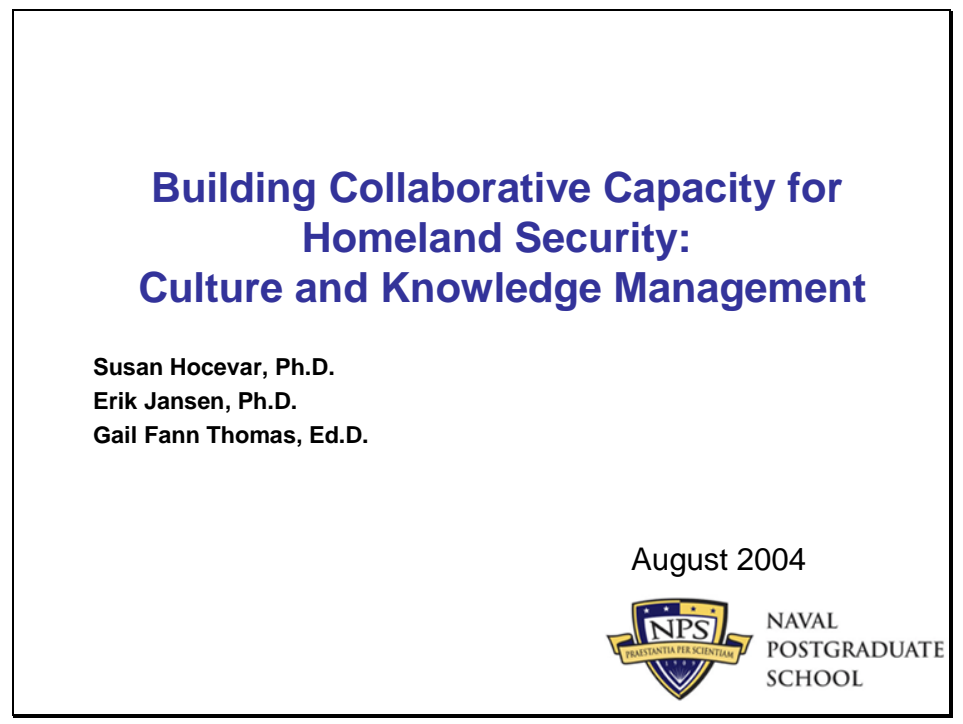


Slide 120

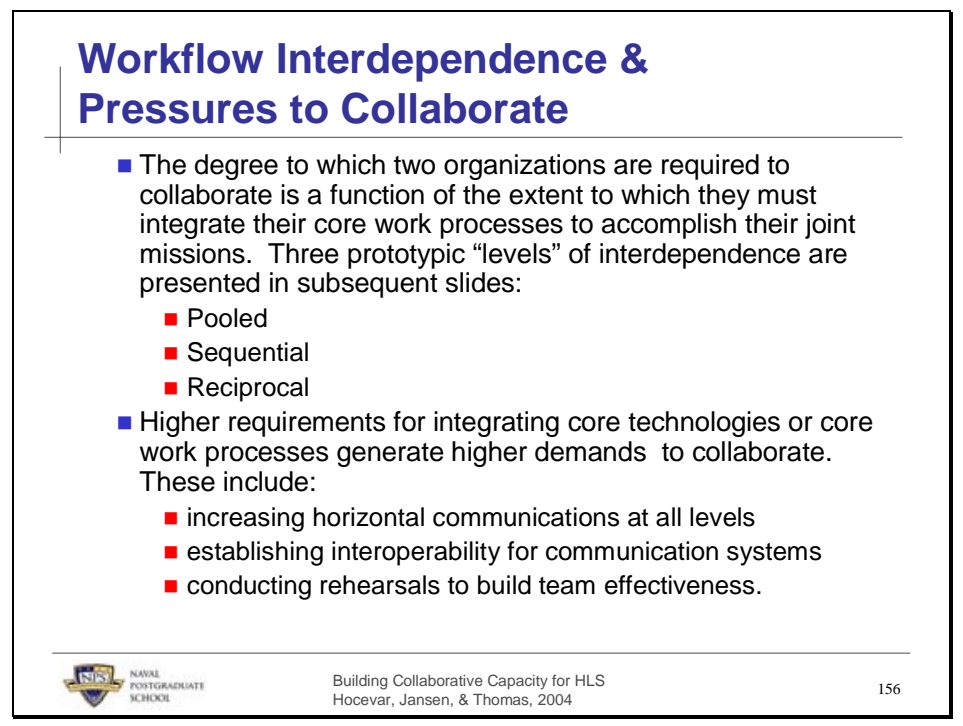

These statements are best classified as deductive generalizations of the theories of workflow interdependence posited by Thompson and the mechanisms of coordination described by Mintzberg. These theories are thus being extended from the organizational level to the interorganizational level. The important concept of rehearsal is in many literatures, but is most familiar to the author as it has been used by McRaven in the “Special Operations” literature. 
Slide 121

\section{Organizational Culture}

-A set of commonly shared values and beliefs which influences the behavior of people and is reflected in work practices how we do things here.

-Culture is a socially-derived control mechanism (norms and standards) that influences system performance. 
Slide 122

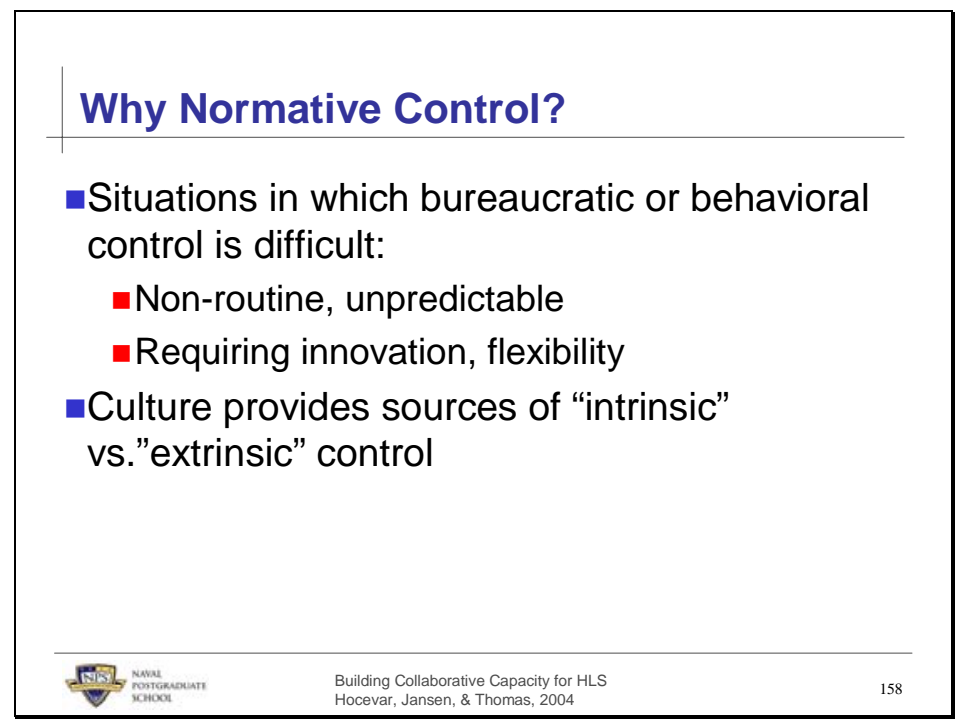


Slide 123

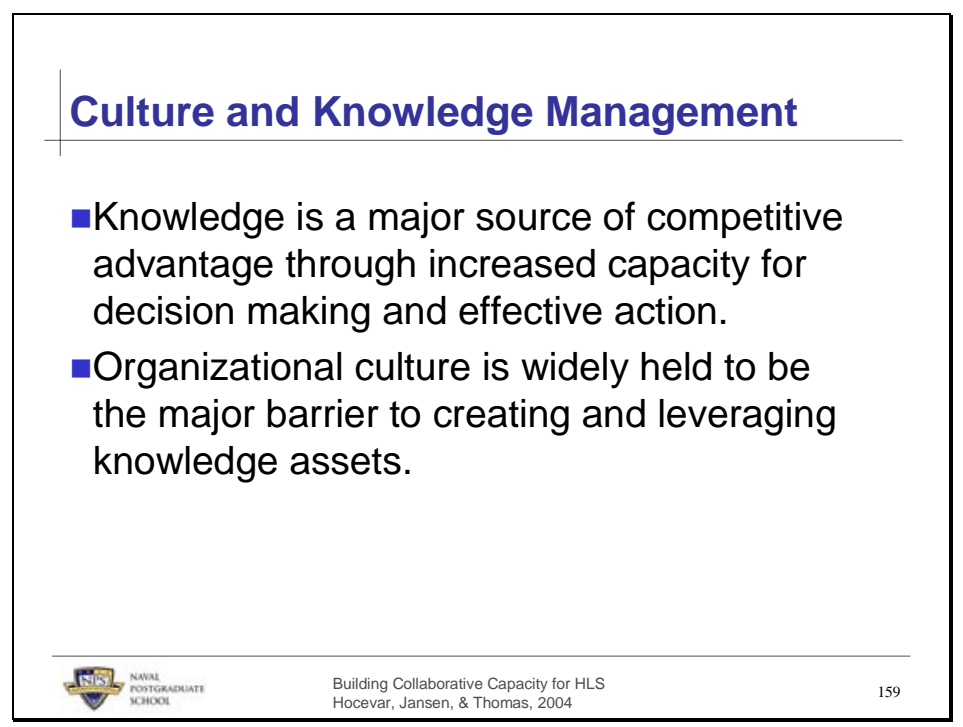


Slide 124

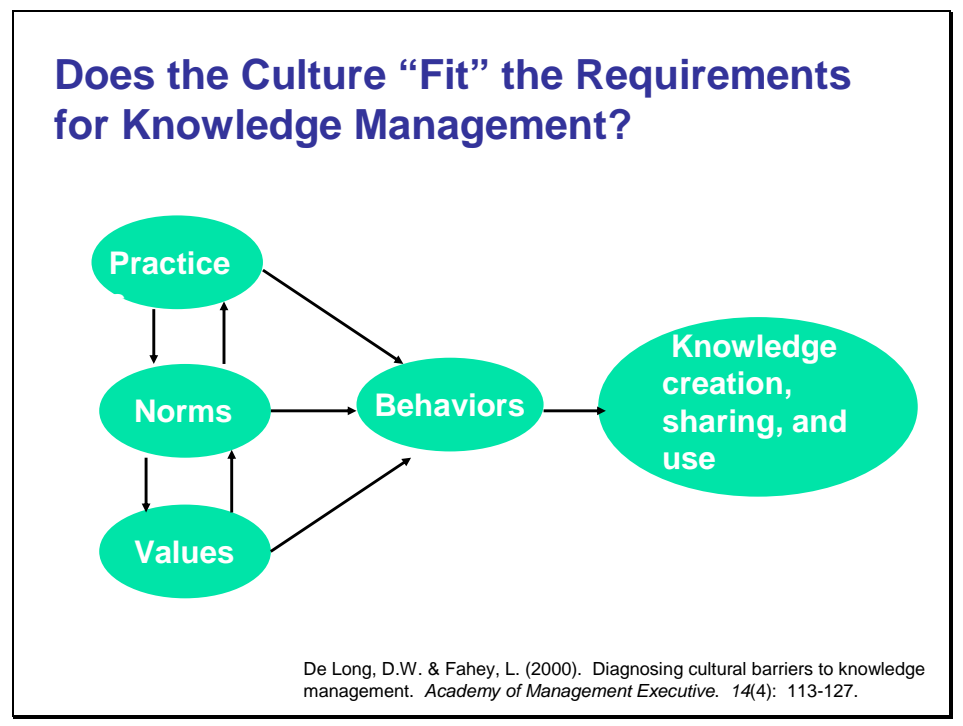


Slide 125

\section{Implications for Assessing the "Fit" of Culture with Requirements for KM}

1. Culture shapes assumptions about which knowledge is important and the value of $\mathrm{KM}$.

- ID behaviors that demonstrate that specific knowledge-building activities are essential to your organization.

- Are norms and practices presenting barriers to these knowledge-building activities/behaviors?

- Are key groups likely to define knowledge differently?

- Is there evidence of biases or blind spots of subcultures that lead to overlooking KM opportunities? Adapted from De Long, D.W. \& Fahey, L. (2000).

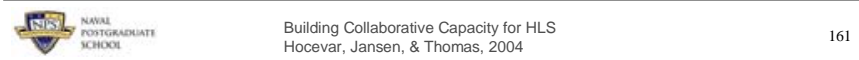


Slide 126

\section{Implications for Assessing the "Fit" of} Culture with Requirements for KM

2. Culture mediates the relationship between levels of knowledge (individual, group, organizational).

- What changes in attitudes about ownership of knowledge are needed to accomplish effective KM?

- How does the current culture facilitate or undermine redistribution of knowledge?

- What practices need to change to reinforce collaborative knowledge use?

Adapted from De Long, D.W. \& Fahey, L. (2000).

\begin{tabular}{lll}
\hline Building Collaborative Capacity for HLS \\
Hocevar, Jansen, \& Thomas, 2004
\end{tabular}


Slide 127

\section{Implications for Assessing the "Fit" of Culture with Requirements for KM}

3. Culture creates a context for social interaction.

- ID norms and practices that are barriers to discussing sensitive topics.

- What are practices by senior management that encourage accessibility and approachability?

- What norms and practices in the organization encourage:

- High frequency of interaction

- Expectation of collaborative problem solving

- Seeking out existing expertise and knowledge instead of

"reinventing the wheel"

- Identifying and learning from mistakes

Adapted from De Long, D.W. \& Fahey, L. (2000) 
Slide 128

Implications for Assessing the "Fit" of Culture with Requirements for KM

4. Culture shapes creation and adoption of new knowledge.

- Is there evidence that new knowledge was ignored, discounted, or undiscovered by your organization? What norms and practices created barriers to adopting, creating, or applying this new knowledge.

- Is there evidence that new knowledge was adopted or created by your organization that led to improved effectiveness? What practices or norms allowed this to happen?

- Are there norms and practices that support constructive confrontation? $\quad$ Adapted from De Long, D.W. \& Fahey, L. (2000) 
Slide 129

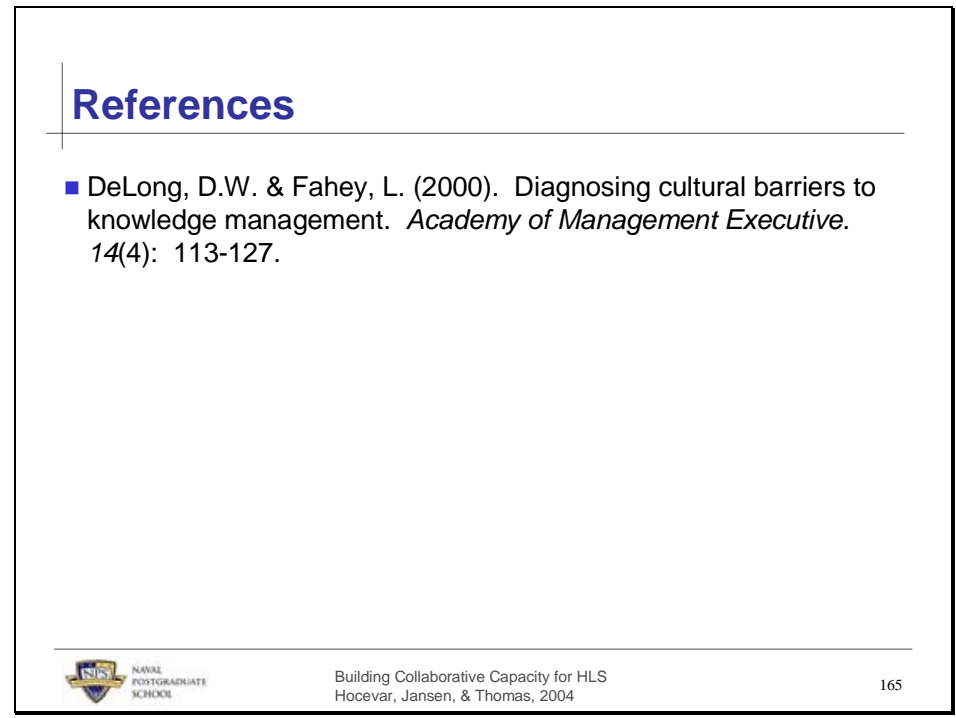


Slide 130

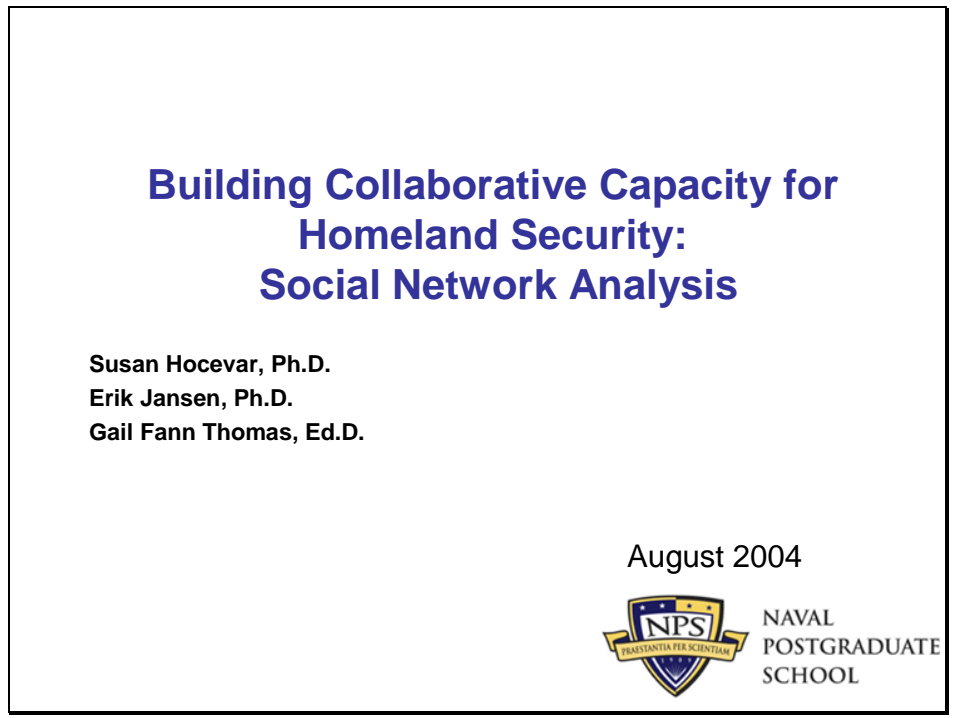


Slide 131

\section{Social Networks}

- Networks are patterns of interactions among organizational members.

- Agencies within the Department of Homeland Security can be considered a network of organizations.

- Interactions among the various actors in the network create opportunities for exchange of information, ideas, practices, and values. 
Slide 132

\section{Social Networking}

Analysis and Innovation

- Informal networks are important to organizational innovation and adaptation.

-Who you know often has a great deal to do with what you come to know.(Cross \& Parker, 2004) 
Slide 133

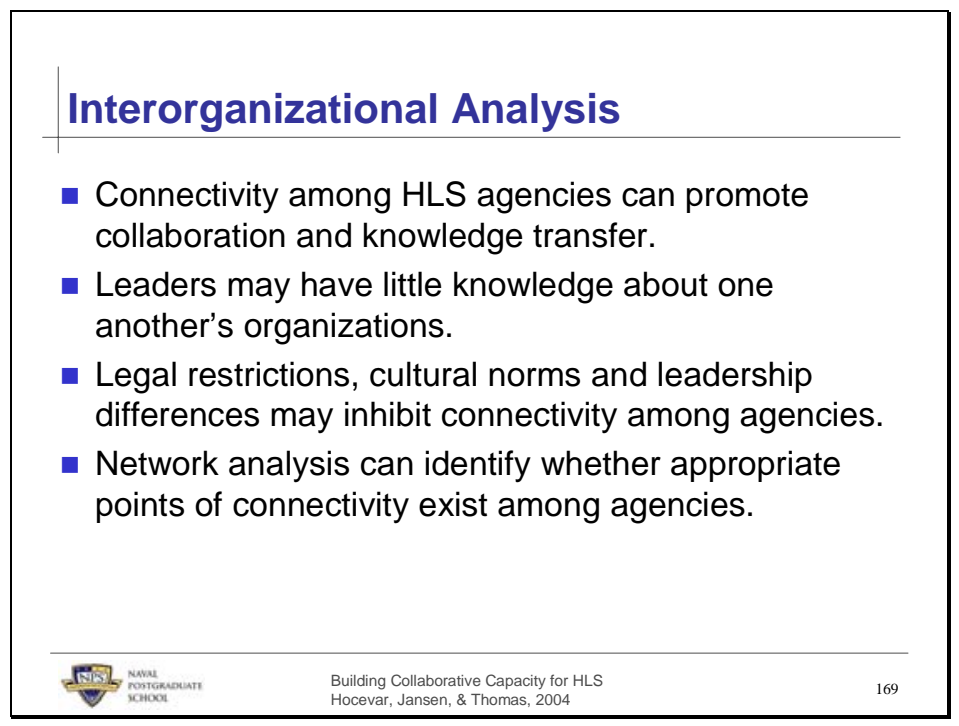


Slide 134

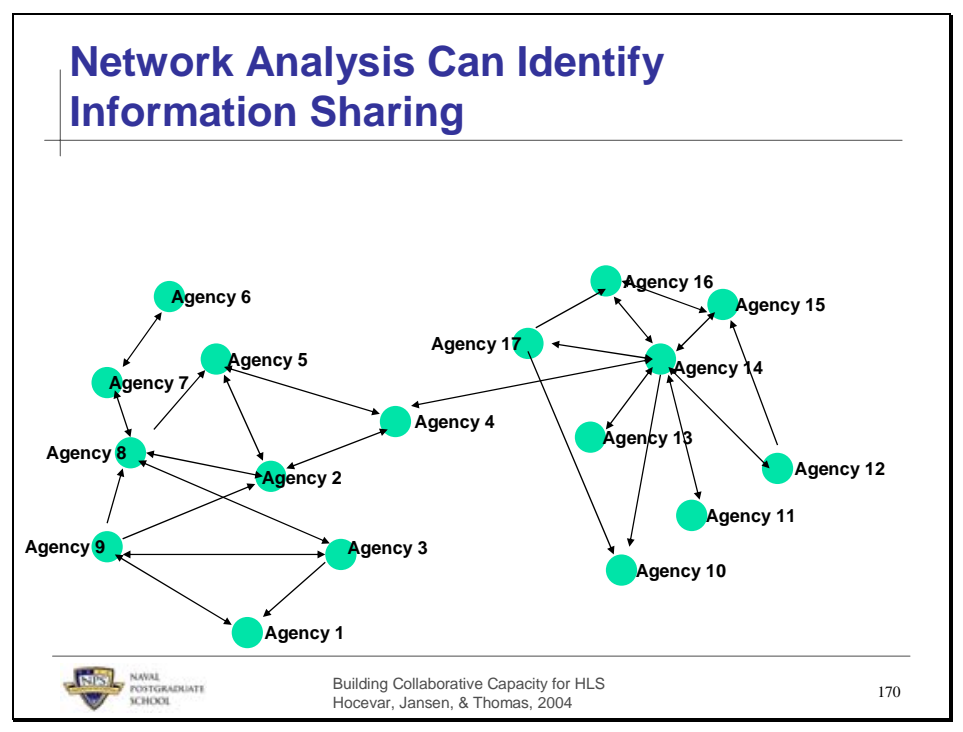

Network analysis can assess information-sharing networks, identifying who is connected to whom.

Arrows show directionality—is information sharing one-way or two-way?

Network analysis can identify central connectors, boundary spanners, information brokers, and peripheral specialists.

This analysis shows how various agencies are sharing information with one another. An assessment would identify which agencies are sharing information. Follow-on discussions could identify who should be sharing information with whom and then strategies can be determined to encourage sharing, if sharing information is deemed appropriate. Discussion can also surface as to why agencies are not sharing information with one another. Networks can be monitored over time to assess the success of interventions designed to increase information sharing. 
Slide 135

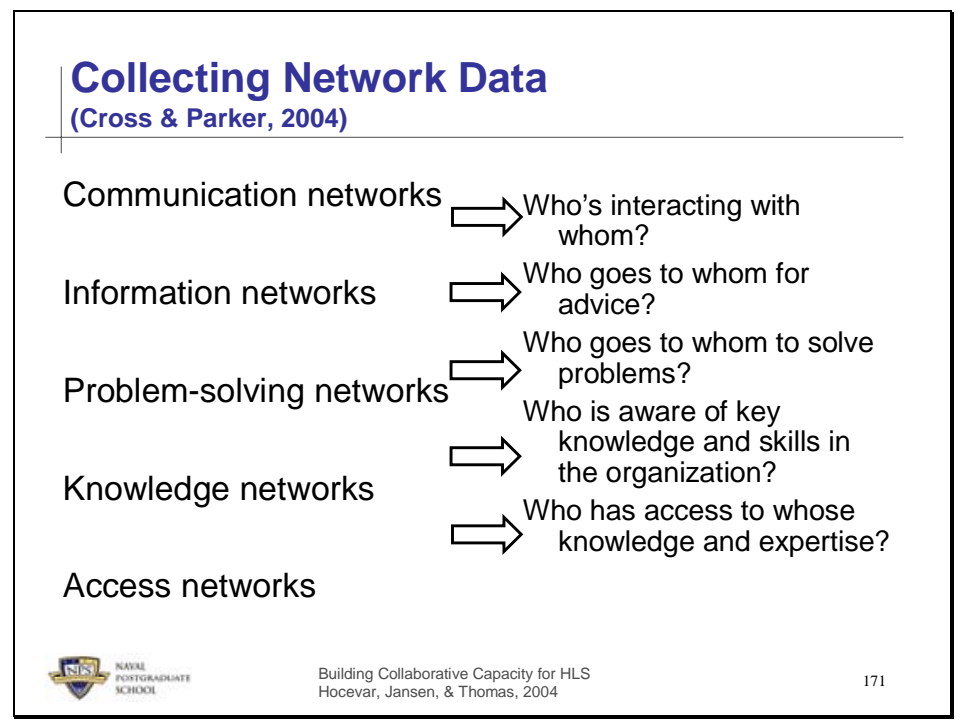

Network analysis can be used to identify different types of networks. 
Slide 136

\section{Value of Social Network Analysis}

- Data can be generated from 10-15 minute survey - Survey assesses information sharing, knowledge flow or collaboration among members of a group (intraorg) or members of different groups (inter-org)

- Various networks can be assessed (trust, leadership, strategic initiatives)

- Gaps in critical information sharing can be identified - Interventions can be designed to remedy the gaps 
Slide 137

\section{References}

- Cross, R. \& Parker, A. (2004). The Hidden Power of Social Networks: Understanding How Work Really Gets Done in Organizations. Boston, MA: Harvard Business School Press

- Monge, P.R. \& Contractor, N.S. (2001). "Emergence of Communication Networks," in The New Handbook of Organizational Communication, edited by F.M. Jablin \& L.L. Putnam, Thousand Oaks, CA: Sage Publications. 
Defense Technical Information Center

8725 John J. Kingman Rd., STE 0944

Ft Belvoir, VA 22060-6218

Dudley Knox Library, Code 013

Naval Postgraduate School

Monterey, CA 93943

Ted Lewis

Code OHS/04

Naval Postgraduate School

Monterey, CA 93943

Gail Thomas

Code GB/Fa

Naval Postgraduate School

Monterey, CA 93943

Susan Hocevar

Code GB/Hc

Naval Postgraduate School

Monterey, CA 93943

Eric Jansen

Code IS/Ek

Naval Postgraduate School

Monterey, Ca 93943

Christopher Bellavita

Code NS

Naval Postgraduate School

Monterey, CA 93943

Douglas A. Brook, Dean

Code GB/Kb

Naval Postgraduate School

Monterey, CA 93943 